\title{
Sheet, stream, and shelf flow as progressive ice-bed uncoupling: Byrd Glacier, Antarctica and Jakobshavn Isbrae, Greenland
}

\author{
T. Hughes ${ }^{1}$, A. Sargent ${ }^{2}$, J. Fastook ${ }^{3}$, K. Purdon ${ }^{4}$, J. Li $^{4}$, J.-B. Yan ${ }^{4}$, and S. Gogineni ${ }^{4}$ \\ ${ }^{1}$ School of Earth and Climate Sciences, Climate Change Institute, University of Maine, Orono, ME, USA \\ ${ }^{2}$ School of Science and Humanities, Husson University, Bangor, ME, USA \\ ${ }^{3}$ Computer Sciences Department, Climate Change Institute University of Maine, Orono, ME, USA \\ ${ }^{4}$ Center for Remote Sensing of Ice Sheets, School of Engineering, University of Kansas, Lawrence, KS, USA \\ Correspondence to: T. Hughes (terry.hughes@maine.edu)
}

Received: 12 March 2015 - Published in The Cryosphere Discuss.: 17 August 2015

Revised: 16 November 2015 - Accepted: 27 November 2015 - Published: 21 January 2016

\begin{abstract}
The first-order control of ice thickness and height above sea level is linked to the decreasing strength of icebed coupling along flowlines from an interior ice divide to the calving front of an ice shelf. Uncoupling progresses as a frozen bed progressively thaws for sheet flow, as a thawed bed is progressively drowned for stream flow, and as lateral and/or local grounding vanish for shelf flow. This can reduce ice thicknesses by $90 \%$ and ice elevations by $99 \%$ along flowlines. Original work presented here includes (1) replacing flow and sliding laws for sheet flow with upper and lower yield stresses for creep in cold overlying ice and basal ice sliding over deforming till, respectively, (2) replacing integrating the Navier-Stokes equations for stream flow with geometrical solutions to the force balance, and (3) including resistance to shelf flow caused by lateral confinement in a fjord and local grounding at ice rumples and ice rises. A comparison is made between our approach and two approaches based on continuum mechanics. Applications are made to Byrd Glacier in Antarctica and Jakobshavn Isbrae in Greenland.
\end{abstract}

\section{Introduction}

A holistic approach to ice-sheet modeling requires smooth transitions from sheet flow to stream flow to shelf flow. We accomplish this by treating these transitions as progressive reductions in ice-bed coupling, beginning with the strongest coupling at interior ice divides where ice is frozen to the bed and complete uncoupling at the calving front of an ice shelf.
To simplify our approach, we examine one-dimensional flow along either flowlines or flowbands, a flowband lying being two flowlines. Uncoupling begins when a frozen bed thaws for sheet flow, continues when basal water is deep enough to drown parts of the bed for stream flow, and is complete when grounding alongside confining embayments and at local basal pinning points vanishes for shelf flow. For sheet flow, uncoupling is quantified using a thawed fraction $f$ of the bed, with separate yield stresses for creep of cold ice above frozen patches, and for sliding of overlying ice and/or deformation of underlying till for thawed patches. For stream flow, uncoupling is quantified using a floating fraction $\phi$ of ice above the bed. For shelf flow, uncoupling is quantified using an unbuttressed ice fraction $\phi_{O}$ at the grounding line to represent loss of side confinement and local pinning. These three fractions all have a physical basis, and all vary from 0 to 1 .

Our treatment avoids integrating the partial differential equations in continuum mechanics, but we compare our approach with two approaches that do use continuum mechanics, one by Schoof and Hindmarsh (2010) and one by Pattyn (2003). Modeling using continuum mechanics range from the simple shallow ice and shelfy stream approximations such as IcEIS, UMISM, SICOPOLIS, PISM, and PenState3D (Saito and Abe-Ouchi, 2005; Fastook and Prentice, 1994; Greve, 1997; Bueler and Brown, 2009; Pollard and DeConto, 2012) to higher-order Blatter-Pattyn treatments such as ISSM and CISM 2.0 (Blatter, 1995; Pattyn, 2003; Larour et al., 2012; Bougamont et al., 2011), and on to the computationally intensive Full-Stokes solutions where no stresses are 
neglected in the equilibrium equations, see Sargent and Fastook (2010) and results for Elmer/ICE (Seddik et al., 2012). All these holistic conditions are treated by ISSM. Continuum mechanics allow solving the force, mass, and energy equations in three dimensions over time. Our approach is limited to solving the force and mass balance in one dimension under steady-state conditions. We have no energy balance that uses the surface temperature and mass balance to calculate internal ice temperatures, whether the bed is frozen or thawed for a given (and often unknown) geothermal heat flux, the amount, distribution, and hydrology of water on a thawed bed, and how water mobilizes any subglacial till by dilatation using poorly known till rheology. Minor changes in surface conditions can cause major changes in basal conditions that determine the strength of ice-bed coupling indirectly. We determine ice-bed coupling directly from the thickness and elevation of overlying ice.

In our approach, the thickness and height of ice is primarily controlled by $f, \phi$, and $\phi_{O}$. For example, consider a marine ice sheet $4000 \mathrm{~m}$ thick and $3000 \mathrm{~m}$ above sea level at the center, where ice is frozen to the bed. Ice spreads as sheet flow from this center so frictional heat gradually thaws the bed, with thawing occurring along tributaries that eventually converge on ice streams. Flowline profiles are generally convex for sheet flow and thawing the bed reduces ice thickness by about $20 \%, 800 \mathrm{~m}$ in this case, leaving ice $3200 \mathrm{~m}$ thick and $2200 \mathrm{~m}$ high (Hughes, 1981). Flowline profiles become generally concave along ice streams as basal water drowns more of the bed, lowering ice elevations to about $100 \mathrm{~m}$ when ice becomes afloat (Hughes, 1992, 1998, chapter 6). Flowline profiles are nearly flat for shelf flow, but thin to about $300 \mathrm{~m}$ thick, $30 \mathrm{~m}$ above sea level, at the calving front, where all grounding vanishes (Kenneally and Hughes, 2006; Benn et al., 2009). Ice-bed uncoupling alone reduces ice thickness by over $90 \%$ and ice elevations by $99 \%$. These three flow regimes are shown in Fig. 1 for the Antarctic Ice Sheet (Rignot et al., 2011).

\section{Ice-bed uncoupling for sheet flow}

Figure 1 requires a way to treat basal thermal conditions for sheet flow that departs somewhat from the treatment provided by Wilch and Hughes (2000). They used ice surface slopes and heights above the bed to divide the bed into basal frozen, thawed, melting, and freezing zones. Melting zones connected a frozen bed to a thawed bed by having thawed patches grow and coalesce downslope until the whole bed was thawed. Freezing zones connected a thawed bed to a frozen bed by having frozen patches grow and coalesce downslope until the whole bed was frozen. A flow "law" was used for ice creeping over frozen parts of the bed $(f=0)$ and a sliding "law" was used for ice sliding over thawed parts of the bed $(f=1)$. Now we know sheet flow consists of faster tributaries separating slower ice in a pattern that resembles a

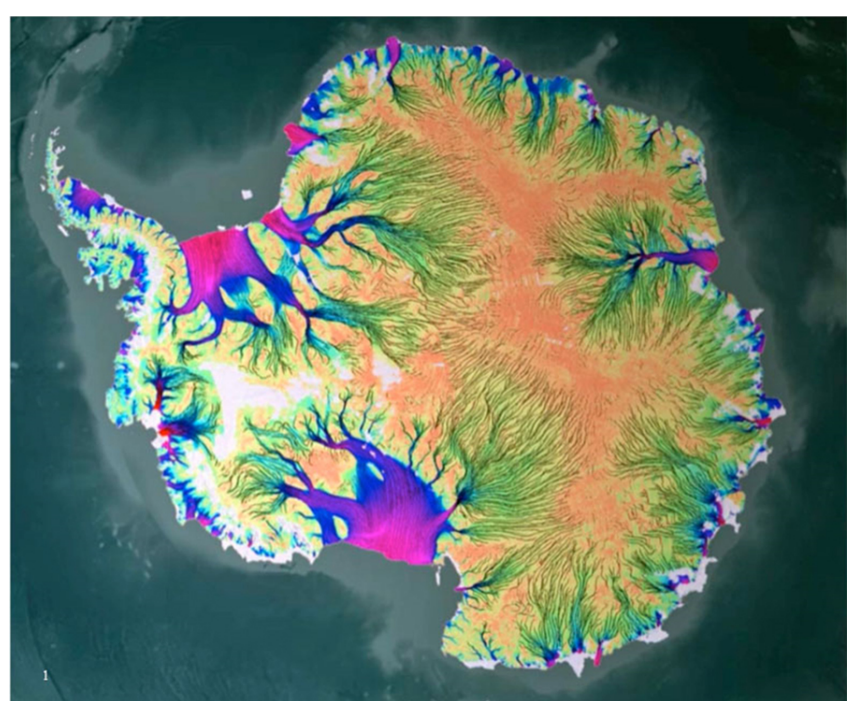

Figure 1. A full map of Antarctic ice flow showing tributaries supplying major ice streams. This map was compiled by NASA-funded research at the Jet Propulsion Laboratory of the California Institute of Technology and the University of California at Irvine, using data from Earth-orbiting satellites provided by the Japanese, European, and Canadian Space Agencies. Ice velocities increase from orange near interior ice divides to green in ice tributaries to blue in ice streams to red on ice shelves. A video showing motion of the tributaries is available on the NASA News website. From Rignot and others (2011).

fluvial river system, with the tributaries converging on large ice streams that discharge most of the ice. In the new treatment provided here, the mosaic of frozen and thawed patches is replaced with tributaries on a thawed bed converging in ice streams as seen in Fig. 1. We also replace problematic flow and sliding "laws" with more reliable yielding criteria, with a lower yield stress applied to tributaries and a higher yield stress applied between tributaries.

In producing Fig. 1, Rignot et al. (2011) took velocities over $50 \mathrm{~m} \mathrm{a}^{-1}$ as distinguishing faster tributaries imbedded in slower sheet flow. We use thawed fraction $f$ of the bed to quantify ice-bed uncoupling for sheet flow along ice flowlines, with $f \geq 0.6$ for tributaries and $f \leq 0.4$ between tributaries, assuming thawed parts of the bed are connected along flow when $f>0.5$ and disconnected for $f<0.5$ to account for the $50 \mathrm{~m} \mathrm{a}^{-1}$ difference. We treated sheet flow along ice flowlines in the downslope direction normal to ice elevation contour lines, with flow in the negative $x$ direction for $x$ positive upslope. In the simplest treatment, the force balance along a flowline balances gravitational force $1 / 2 P_{\mathrm{I}} h_{\mathrm{I}}$ against basal drag force $\tau_{O} x$ at horizontal distance $x$ from the ice-sheet margin for basal shear stress $\tau_{O}$, where $1 / 2 P_{\mathrm{I}}=1 / 2 \rho_{\mathrm{I}} g h_{\mathrm{I}}=\bar{P}_{\mathrm{I}}$ is the average ice pressure in ice of height $h_{\mathrm{I}}$ above the bed for gravity acceleration $g$ and ice density $\rho_{\mathrm{I}}$. Balancing forces gives a parabolic surface profile above a horizontal bed for constant $\tau_{O}$ as a first-order 
approximation (Nye, 1952a):

$x=1 / 2\left(\rho_{\mathrm{I}} g / \tau_{O}\right) h_{\mathrm{I}}^{2}$.

Actually, $\tau_{O}$ and bed topography vary along $x$. These variations are included by differentiating Eq. (1) for constant $\tau_{O}$ only over distance $\mathrm{d} x$ and solving for surface slope $\alpha$ $=d h / d x=\tau_{O} / \rho_{\mathrm{I}} g h_{I}$ when ice elevation $h$ above sea level differs from ice elevation $h_{\mathrm{I}}$ above the bed. Replacing $d h / d x$ with change $\Delta h$ in constant incremental length $\Delta x$ between steps $i$ and $i+1$,

$h_{i+1}=h_{i}+\left[\left(\tau_{O} / h_{\mathrm{I}}\right)_{i} / \rho_{\mathrm{I}} g\right] \Delta x=\left[\tau_{O} /\left(h-h_{\mathrm{B}}\right)\right]_{i} \Delta x / \rho_{\mathrm{I}} g$,

where $\tau_{O}$ and $h_{\mathrm{I}}$ are specified at each $\Delta x$ step for integers $i$. Eq. (2) allows variable $\tau_{O}$ and bed topography $h_{\mathrm{B}}=h-h_{\mathrm{I}}$ above (+) and below (-) sea level along the flowline, which we measured by radar sounding for Byrd Glacier and Jakobshavn Isbrae. The bed is approximated by an up-down staircase, with $\alpha=\left(h_{i+1}-h_{i}\right) / \Delta x=\Delta h / \Delta x=\Delta h_{\mathrm{I}} / \Delta x$ on steps and changes $\pm h_{\mathrm{B}}$ put between steps (Hughes, 2009; 2012, chapter 8). Similarly, $\tau_{O}$ is constant on steps and changes between steps. When terrestrial ice margins are on broad, rather flat plains, Eq. (1) can be used to obtain height $h_{O}$ at distance $x$ from the ice margin, where $i=0$ in Eq. (2).

Equation (2) is an initial-value, finite-difference recursive formula. Initial ice elevation $h_{O}$ above the bed must be specified at $i=0$ in order to start the iterative process of calculating $h_{\mathrm{I}}=h-h_{\mathrm{B}}$ along the flowline at each $i$ step. Presentday values of $h_{\mathrm{B}}$ can be adjusted to account for isostatic depression and rebound of the bed during a glaciation cycle (Hughes, 1998, chapter 5, 2007; Hughes, 2012, chapter 22). This adjustment is not necessary in our study using only present-day conditions.

\subsection{Quantifying ice-bed uncoupling}

Owing to reduced ice-bed coupling when the bed thaws, ice shearing over a frozen bed has basal shear stress $\tau_{F}$ that is higher than basal shear stress $\tau_{T}$ for ice sliding over a thawed bed or for shearing water-saturated till between basal ice and bedrock. Thawing lowers the ice surface. Thawed fraction $f$ then gives the following:

$\tau_{O}=f \tau_{\mathrm{T}}+(1-f) \tau_{\mathrm{F}}=\rho_{\mathrm{I}} g h_{\mathrm{I}} \alpha$.

Expressions for $\tau_{F}$ and $\tau_{T}$ can be provided by respective flow laws and sliding laws for ice (Denton and Hughes, 1981, chapter 5; Hughes, 1998, chapters 3 and 5; Hughes, 2012, chapter 17). For sheet flow in the Antarctic Ice Sheet, $0.25 \leq f \leq 0.75$ is widespread, with $f=0$ common under ice domes over subglacial highlands and $f=1$ common under ice domes over subglacial basins and at the heads of ice streams entering deep fjords (Hughes, 1998, chapter 3; Hughes, 2012, chapter 24; Wilch and Hughes, 2000).

Flow and sliding laws give vertically averaged ice velocities and basal sliding velocities, respectively, with the basal sliding velocity only slightly less than the ice surface velocity owing to reduced basal drag on a thawed bed. In our earlier work, cited above, we used these velocities in a massbalance equation to calculate ice elevations above the bed along flowlines using Eq. (2) and evaluating $\tau_{O}$ for thawed fraction $f$ in Eq. (3). That approach has defects we now wish to avoid. In original theories of basal sliding, sliding velocity depends on melting and freezing rates of ice on the stoss and lee sides of bedrock bumps, and on high-stress creep rates around bumps (Weertman, 1957a), and also on an "effective" basal water pressure (Lliboutry, 1968; Iken, 1981). Till deformation under West Antarctic ice streams appears to be nearly viscous, based on field measurements (Anandakrishnan and Alley, 1997), or nearly plastic, based on laboratory experiments (Kamb, 2001), conducted on the same till. Given ambiguities in deformation studies for glacial sliding over bedrock and till shearing between basal ice and bedrock, we propose a different approach in this study based on using separate yield stresses for creep in ice and for basal sliding with till deformation. These ambiguities arise from the extreme variability of ice and till near the bed of West Antarctic ice streams, as documented in detail for Kamb Ice Stream (formerly ice steam C) by Engelhardt and Kamb (2013).

Quantifying links between subglacial hydrology and deforming till dilated by water is a daunting task (Clark, 1992; Jenson et al., 1995, 1996, Carslon et al., 2000). Till can deform near both the viscous and plastic ends of the viscoplastic creep spectrum, and presumably anywhere in between, depending on the applied shear stress, and variable mineral compositions, lithological textures, and water content (Rathbun et al., 2008; Sane et al., 2008). Pending establishing these links, we allow separate yield stresses for creep of cold ice and for creep in a composite of temperate basal ice, possibly charged with basal debris, and deforming till, with sliding possible at the ice-till interface. We measured $h_{\mathrm{I}}$ and $\alpha$ directly using radar sounding, so values of $f$ in Eq. (3) can be calculated using specified values of $\tau_{\mathrm{T}}$ and $\tau_{\mathrm{F}}$ for given values of $n$ in Fig. 2, which shows the viscoplastic creep spectrum for crystalline and composite materials. These values of $n$ appear in Eq. (4), a version of the flow law of ice that links creep rates to yield stresses:

$\dot{\varepsilon}=\dot{\varepsilon}_{O}\left(\sigma / \sigma_{O}\right)^{n}$,

where $\dot{\varepsilon}$ is the strain rate caused by applied stress $\sigma$, the plastic yield stress is $\sigma_{O}$, the viscoplastic creep exponent is $n$, and $\dot{\varepsilon}_{O}$ is the strain rate when $\sigma=\sigma_{O}$ for all values of $n$ over the range $1 \leq n \leq \infty$. For viscous flow when $n=1$, the viscosity is $\eta=\sigma / \dot{\varepsilon}$ and yield stress $\sigma_{O}=0$. For plastic flow when $n=\infty$, viscosity $\eta=\infty$ when $\sigma<\sigma_{O}$ and $\eta=0$ when $\sigma=\sigma_{O}$. In between, a viscoplastic yield stress $\sigma_{\mathrm{V}}$ and a viscoplastic viscosity $\eta_{\mathrm{V}}=d \sigma / d \dot{\varepsilon}$ must be specified. For glacier ice, $n=3$ is typical.

Gravitational spreading during sheet flow is resisted primarily by basal drag, so the dominant resisting stress $\sigma_{x z}$ produces strain rate $\dot{\varepsilon}_{x z}=\partial u_{x} / \partial z$ for ice velocity $u_{x}$ when $x$ 
Table 1. Solutions of Eq. (6) for two surface velocities in Figs. 1 and 3.

\begin{tabular}{llll}
\hline & $u_{x}=75 \mathrm{ma}^{-1}$ & & $u_{x}=25 \mathrm{ma}^{-1}$ \\
\hline$n=1:$ & $A=6.8 \times 10^{13} \mathrm{~kg} \mathrm{~m}^{-1} \mathrm{~s}^{-1}$ & $n=1:$ & $A=2.0 \times 10^{14} \mathrm{~kg} \mathrm{~m}^{-1} \mathrm{~s}^{-1}$ \\
$n=3:$ & $A=4.6 \times 10^{7} \mathrm{~kg} \mathrm{~m}^{-1} \mathrm{~s}^{-2+1 / 3}$ & $n=3:$ & $A=6.7 \times 10^{7} \mathrm{~kg} \mathrm{~m}^{-1} \mathrm{~s}^{-2+1 / 3}$ \\
$n=50:$ & $A=7.7 \times 10^{4} \mathrm{~kg} \mathrm{~m}^{-1} \mathrm{~s}^{-2+1 / 50}$ & $n=50:$ & $A=7.9 \times 10^{4} \mathrm{~kg} \mathrm{~m}^{-1} \mathrm{~s}^{-2+1 / 50}$ \\
\hline
\end{tabular}

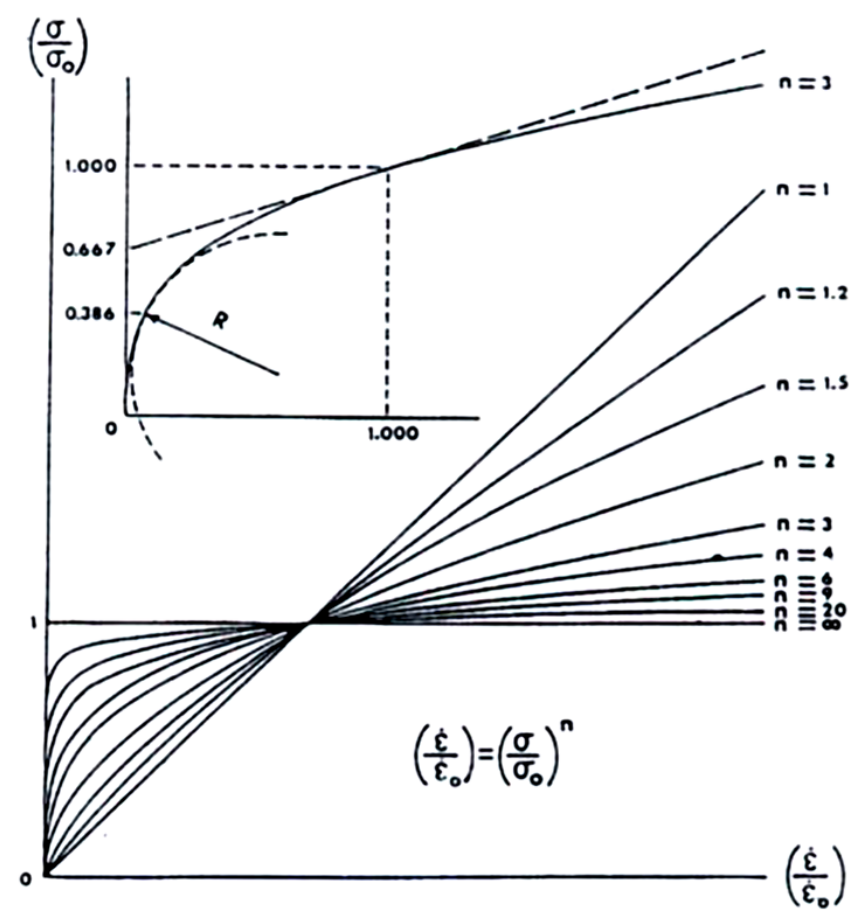

Figure 2. The viscoplastic creep spectrum for steady-state creep in crystalline materials. Applied stress $\sigma$ causes strain rate $\dot{\varepsilon}$ in the expression $\dot{\varepsilon}=\dot{\varepsilon}_{O}\left(\sigma / \sigma_{O}\right)^{n}$ where viscoplastic exponent $n$ varies from unity to infinity, $\sigma_{O}$ is the plastic yield stress, and $\dot{\varepsilon}_{O}$ is the strain rate at $\sigma_{O}$ for all values of $n$. The inset shows two criteria to obtain a viscoplastic yield stress $\sigma_{\mathrm{V}}$ for ice, taking $n=3$. The tangent to the curve at $\dot{\varepsilon}_{O}$ gives $\sigma_{\mathrm{V}}=0.667 \sigma_{O}$ as the critical strain rate yield criterion, and the critical shear stress yield criterion gives $\sigma_{\mathrm{V}}=0.386 \sigma_{O}$ where radius of curvature $R$ is a minimum. Critical shear stress $\sigma_{\mathrm{V}}=0.683 \sigma_{O}$ occurs when $n=8$. Hughes (1983, Fig. 5; 1998, Fig. 8.3) derives both expressions for yielding at all values of $n$.

is horizontal distance in the downslope direction of ice flow and $z$ is vertical distance above the bed. The flow law of ice for this case is the following (Glen, 1958):

$\dot{\varepsilon}_{x z}=\dot{\varepsilon}_{O}\left(\sigma_{x z} / \sigma_{O}\right)^{n}=\left(\sigma_{x z} / A\right)^{n}$,

where $\sigma_{x z}=\tau_{O}=\rho_{\mathrm{I}} g h_{\mathrm{I}} \alpha$ and $A=\sigma_{O} / \dot{\varepsilon}_{O}^{1 / n}$ is an ice hardness parameter that depends on the fabric of polycrystalline ice and ice temperature. Basal drag produces an easy-glide ice fabric in ice near the bed in which the optic axes of ice crystals tend to be normal to the bed, and produces frictional heat that makes ice warmer toward the bed.
Following Hughes (2012, Appendix O), for constant $A$ the vertical profile of horizontal ice velocity is obtained by integrating Eq. (5):

$u_{x}=2\left(\rho_{\mathrm{I}} g \alpha / A\right)^{n}\left[h_{\mathrm{I}}^{n+1}-\left(h_{\mathrm{I}}-z\right)^{n+1}\right] /(n+1)$,

for which the vertically averaged horizontal ice velocity is the following:

$\bar{u}_{x}=\left[2 h_{\mathrm{I}} /(n+2)\right]\left(\rho_{\mathrm{I}} g h_{\mathrm{I}} \alpha / A\right)^{n}=\left[2 h_{\mathrm{I}} /(n+2)\right]\left(\tau_{O} / A\right)^{n}$.

Then the ratio of $\bar{u}_{x}$ to $u_{x}$ at $z=h_{\mathrm{I}}$ is $(n+1) /(n+2)$, which is $2 / 3$ for $n=1,4 / 5$ for $n=3$, and $51 / 52$ for $n=50$. Figure 3 shows velocity profiles from Eq. (6) for $n=1, n=3$, and $n=50$, all for constant $A$ determined by Reeh (1982, 1984 ) and Paterson (1994) for ice accumulation rate $a$, with ice thinning rate $r$ added by Hughes (2012, Appendix O), both averaged along $x$ :

$A=\left[4 \tau_{O}^{n+1} /(n+2) \rho_{\mathrm{I}} g(a-r)\right]^{1 / n}$.

The dependence of $A$ on $(a-r)$ quickly becomes insignificant as $n$ increases, and vanishes when $A$ becomes $\tau_{O}$ at $n=\infty$. Since Rignot et al. (2011) took a surface velocity change of $50 \mathrm{~m} \mathrm{a}^{-1}$ in and between tributaries, we take $u_{x}=75 \mathrm{~m} \mathrm{a}^{-1}$ in tributaries and $u_{x}=25 \mathrm{~m} \mathrm{a}^{-1}$ between tributaries for sheet flow as typical. Table 1 gives values of $A$ in Eq. (6) for the values of $n$ in Fig. 3 when surface velocities are $75 \mathrm{~m} \mathrm{a}^{-1}$ and $25 \mathrm{~m} \mathrm{a}^{-1}$ in Fig. 1.

\subsection{The physical basis for ice-bed uncoupling}

We do not include an energy balance that would allow us to calculate temperatures with depth, and we do not know the correct rheology when complex ice fabrics develop in debrischarged ice near the bed (Gow et al., 1997), all of which determine how $A$ varies with depth. So we keep $A$ constant and allow $n$ to accommodate these changes. As a first approximation, $n=3$ might provide a reasonable velocity profile for cold ice over a frozen bed and $n=50$ might provide a reasonable velocity profile when temperate basal ice slides over deforming till (Kamb, 2001). The lowest part of this velocity profile is almost linear, which would be the case if $n=1$ in the till (Anandakrishnan and Alley, 1997). For $n>50$, ice velocity becomes virtually constant through $h_{\mathrm{I}}$ as $n$ increases, with velocity increases confined to ice sliding over wet deforming till. Scofield et al. (1991) showed how $n$ could be 


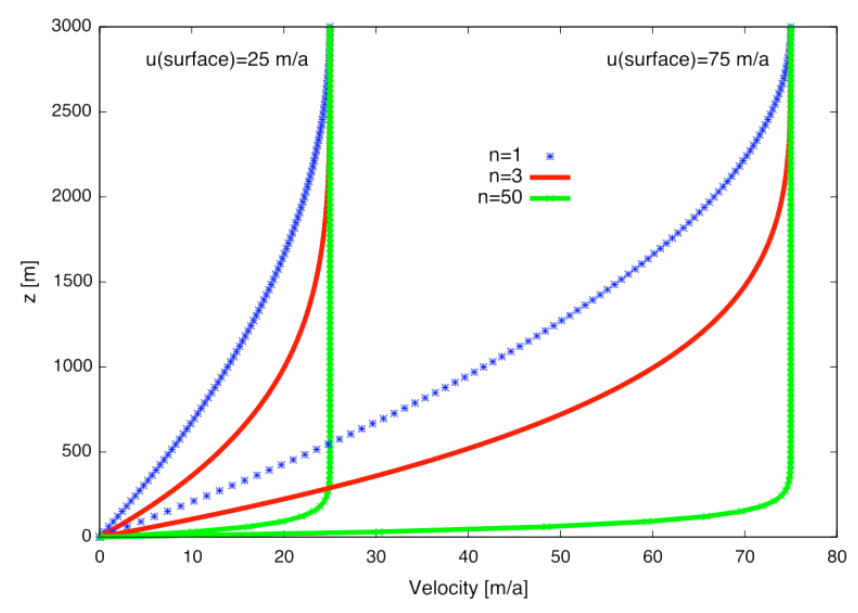

Figure 3. Vertical profiles of horizontal ice velocity for sheet flow in ice $3 \mathrm{~km}$ high. Profiles are for $n=1$ for viscous flow, $n=3$ for ice flow, and $n=50$ for plastic flow in Eq. (6) when the surface velocity is $75 \mathrm{~m} \mathrm{a}^{-1}$ in ice tributaries and $25 \mathrm{~m}$ between ice tributaries in Fig. 1. Warmer ice having an easy-glide ice fabric near the bed causes $n$ to increase if $A$ is artificially kept constant. Velocity profiles will be between those for $n=3$ and $n>50$, with $n$ in tributaries being higher than $n$ between tributaries. In tributaries, the rapid increase in velocity just above bedrock at $z=0$ is caused by ice sliding over deforming wet till. This uncertainty makes combining the force, mass, and energy balance problematic.

varied to obtain velocity profiles comparable to those satisfying mass-balance equilibrium for Byrd Glacier. This approach shows how the velocity profile changes when a frozen bed thaws, but it has no physical basis.

We provide a physical basis by introducing separate viscoplastic yielding criteria for cold ice above the bed and for temperate ice with any associated wet till at the bed. The viscoplastic yield stress $\sigma_{\mathrm{V}}$ is higher for cold ice than for temperate ice over wet till because cold ice is stiffer. Take $\sigma_{\mathrm{V}}=\tau_{F}$ for cold ice above a frozen bed and $\sigma_{\mathrm{V}}=\tau_{T}$ for temperate ice and wet till when the bed is thawed in Eq. (3), with $\tau_{F}>\tau_{T}$. These two yield stresses are shown in the inset of Fig. 3 where $n=3$, noting that $n=3 \pm 1$ is commonly observed for a wide variety of composite and crystalline materials (Cook et al., 2014; Gerbi et al., 2015), such as debrisfilled glacier ice (Engelhardt and Kamb, 2013). In the critical strain rate yield criterion, values at $\dot{\varepsilon}_{O}$ are $\eta_{\mathrm{V}}$ as the slope of the line tangent to the curve and $\sigma_{\mathrm{V}}$ is the stress-intercept of the tangent line. In the critical shear stress yield criterion, $\sigma_{\mathrm{V}}$ is the point on the curve where stress curvature $\mathrm{d}^{2} \sigma_{x z} / \mathrm{d} \dot{\varepsilon}_{x z}^{2}$ is greatest, and $\eta_{\mathrm{V}}$ is the slope of the line tangent to this point on the curve. These two yielding criteria were originally proposed for nucleation and propagation, respectively, of cracks leading to crevasse formation and calving of icebergs (Hughes, 1983, 1998, chapter 8). We assume $\tau_{\mathrm{F}}$ for cold ice over a frozen bed and $\tau_{\mathrm{T}}$ for temperate ice sliding over a thawed bed that includes deforming till after the ice fraction in till melts.

For ice to slide over bedrock or for wet till to be mobilized, sensible and latent heat must be provided to warm and melt ice that contacts bedrock or ice that cements basal till. Basal heat is provided by geothermal heat and frictional heat produced by deforming ice. Per unit volume of ice, frictional heat is the product of the shear stress and the shear strain rate (Paterson, 1994), $\sigma_{\mathrm{V}}$ is defined by $\dot{\varepsilon}_{O}$ at all values of $n$ just before melting takes place, with $\sigma_{\mathrm{V}}=0.667 \sigma_{O}$ for $n=3$. After basal ice in contact with bedrock or in ice-cemented till melts, basal sliding and till deformation become possible and are concentrated at the ice-bed interface where $u_{O}$ is the ice velocity. Then the creep rate does not depend on $\dot{\varepsilon}_{O}$ and prevails because heat generated by deforming unit area of basal ice is the product of $u_{O}$ and $\sigma_{\mathrm{V}}$, with $\sigma_{\mathrm{V}}=0.386 \sigma_{O}$ for $n=3$. The energy needed to provide latent heat of melting is not required, so a lower stress and strain rate are allowed, compared to frozen-bed conditions. This, of course, is an assumption of convenience to avoid dealing with complex basal deformation processes described by Iken and Bindschadler (1986), and possibly linked to unknown values of $n$. It should be abandoned when these processes are fully quantified and linked to known values of $n$.

As an approximation for ice, $\sigma_{O}=100 \mathrm{kPa}$ is commonly taken (Paterson, 1994). Then in Eq. (3), $\tau_{F}=\sigma_{\mathrm{V}}=66.7 \mathrm{kPa}$ for ice creeping above a frozen bed and $\tau_{T}=\sigma_{V}=38.6 \mathrm{kPa}$ for ice sliding above a thawed bed that can include mobilized till. The value $\tau_{\mathrm{F}}=66.7 \mathrm{kPa}$ for $n=3$ is close to $\sigma_{\mathrm{V}}=$ $68.3 \mathrm{kPa}$ using the critical shear stress yield criterion when $n=8$ (Hughes, 1983). The gravitational driving stress for sheet flow in the Antarctic Ice Sheet, where Eq. (3) applies, is commonly $45-55 \mathrm{kPa}$ (e.g., Budd et al., 1971; Drewry, 1983). These values lie between the 38.6 and $66.7 \mathrm{kPa}$ limits for viscoplastic yield stress $\sigma_{\mathrm{V}}$ in Fig. 2 postulated here for temperate ice moving over a thawed bed or wet till and for generally colder ice moving over a frozen bed or till, respectively applied to ice in tributaries and to ice between tributaries. For typical flowlines $1500 \mathrm{~km}$ long on the East Antarctic Ice Sheet, take $\rho_{\mathrm{I}}=917 \mathrm{~kg} \mathrm{~m}^{-3}, g=9.8 \mathrm{~m} \mathrm{~s}^{-2}$, $h_{\mathrm{I}}=3 \mathrm{~km}, \alpha=0.002$, and $(a-r)=0.1 \mathrm{ma}^{-1}$. Then $\tau_{O}=$ $\rho_{\mathrm{I}} g h_{I} \alpha=54 \times 10^{3} \mathrm{~kg} \mathrm{~m}^{-1} \mathrm{~s}^{-2}=54 \mathrm{kPa}$, which lies between $\tau_{F}=66.7 \mathrm{kPa}$ and $\tau_{T}=38.6 \mathrm{kPa}$ in Eq. (3). All this provides a physical basis for our two viscoplastic yield stresses that accompany ice-bed uncoupling.

Following Hughes (1998, chapter 9), if thawing of a frozen bed begins in hollows between hills, so the bed becomes a mosaic of frozen and thawed patches, thawed patches will increasingly include hills until the whole bed is thawed. Conversely, if a thawed bed becomes frozen first on hills, frozen patches will increasingly include hollows until the whole bed is frozen. This rolling bed topography typically developed before glaciation when fluvial processes produced a dendritic pattern of small streams supplying large rivers. Therefore, the thawed patches should lengthen in the direc- 
tion of ice flow and become tributaries that supply major ice streams, as shown dramatically by Rignot et al. (2011) for the Antarctic Ice Sheet, see Fig. 1. Their results are consistent with this way of linking thawed areas to bed topography and even subglacial lakes in applying Eq. (3), see Wilch and Hughes (2000), Siegert (2001), and Smith et al. (2009). Bed topography provides locations for converting slow sheet flow into fast stream flow. We let increasing $f$ in Eq. (3) reflect the convergence of tributaries as they crowd together to become ice streams. Figure 1 then becomes a map of places where $f=1$ (tributaries) and $f=0$ (between tributaries), which may be approximately the case, but isolated thawed patches can exist between tributaries.

\section{Ice-bed uncoupling for stream flow}

Ice streams develop from their tributaries when basal meltwater progressively drowns bedrock bumps that penetrate basal ice and supersaturates till, thereby dilating till in directions of ice flow. This occurs when $f=1$, so additional melting must deepen the basal water layer, rather than increase its areal extent, and must supersaturate subglacial till. Then floating fraction $\phi$ replaces thawed fraction $f$ along flowlines.

\subsection{Quantifying ice-bed uncoupling}

A geometrical force balance combines with a simple mass balance to calculate $h_{\mathrm{I}}$ based on the formula (Hughes et al., 2011; Hughes, 2012, chapter 10):

$\phi=h_{\mathrm{F}} / h_{\mathrm{I}}$,

where $h_{\mathrm{F}}$ is the height (thickness) of ice that floats in basal water. It is related to basal ice area $A_{\mathrm{F}}$ that floats in given basal area $A_{O}$ so that $\phi=A_{\mathrm{F}} / A_{O}$ because $h_{\mathrm{F}}$ is adjusted until $h_{\mathrm{F}} A_{O}=h_{\mathrm{I}} A_{\mathrm{F}}$ are volumes of ice that exert the same vertical gravitational force on the bed. At a point having zero basal area, height $h_{\mathrm{F}}$ is still determined by $A_{\mathrm{F}} / A_{O}$ in the immediately surrounding basal area, see Fig. 4. This flotation condition exists under West Antarctic ice streams (Kamb, 2001; Fricker and Scambos, 2009; Engelhardt and Kamb, 2013).

A holistic ice-sheet model must provide smooth transitions from sheet flow to stream flow to shelf flow for the longitudinal force balance in the direction of gravitational flow of ice, a task now accomplished by continuum models (e.g., Pattyn, 2003; Sargent, 2009; Sargent and Fastook, 2010; Blatter et al., 2011). In continuum mechanics, divergence of the stress tensor reduces to extending (or compressive) flow in flowlines or flowbands of constant width, a simplification we employ here.

Our force balance is done for flowbands having the width of an ice stream, assumed to be constant, so the six resisting stresses in the equilibrium equations reduce to four, a longi-

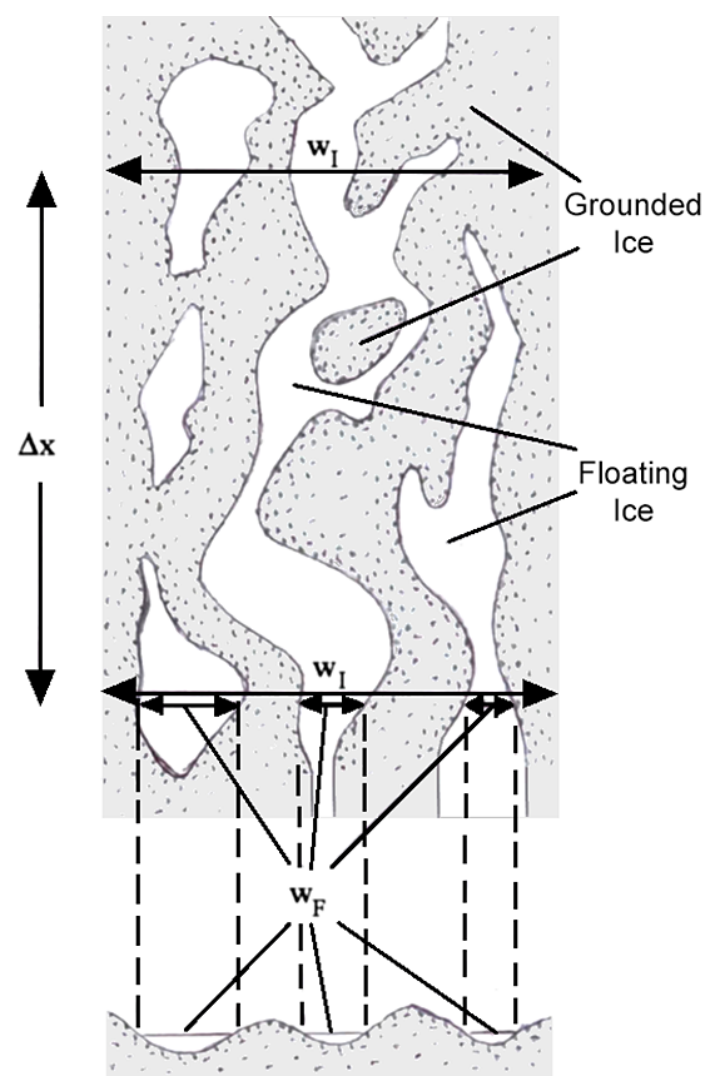

Figure 4. A cartoon of the bed under an ice stream. Ice flow is along incremental length $\Delta x$ in plan view (top) and at $x$ in transverse cross-section (bottom). Ice is either floating above bedrock or supersaturated sediments and till (undotted areas) or grounded on bedrock or unsaturated sediments and till (dotted areas) for respective floating flowband widths $w_{\mathrm{F}}$ and grounded flowband widths $w_{\mathrm{I}}$ $-w_{\mathrm{F}}$. Floating fraction $\phi$ of ice over area $w_{\mathrm{I}} \Delta x$ becomes $\phi=w_{\mathrm{F}}$ $/ w_{\text {I }}$ at $x$ when $\Delta x \rightarrow 0$.

tudinal tension stress $\sigma_{\mathrm{T}}$ that pulls upslope ice, a longitudinal compression stress $\sigma_{\mathrm{C}}$ that pushes downslope ice, a basal shear stress $\tau_{O}$ due to basal drag, and a side shear stress $\tau_{S}$ due to side drag. Transverse stresses caused by converging and diverging flow that changes the flowband width can then be ignored in the essentially one-dimensional solutions presented here. This allows a force balance based on simple geometry in the longitudinal direction of ice flow, along which all of these stresses vary with changing floating fraction $\phi$ of ice in the flowband. This is a visual approach, with forces represented by geometrical areas. Partial differential equations such as the equilibrium equations are avoided. For sheet flow, $\phi=0$ when the bed is dry (frozen) and $\phi$ approaches zero when the bed is wet (thawed). For stream flow, $0<\phi<1$ with $\phi$ often increasing downstream. For shelf flow, $\phi=1$ for a freely floating ice shelf and $\phi$ approaches one when a confined and locally pinned ice shelf buttresses the ice stream. 
Figure 4 is a cartoon showing places where $\phi=0$ for ice grounded on a wet bed under an ice stream, and $\phi=1$ for places where ice floats in water under the ice stream. Hughes (2012, chapter 10) assumed these places generally correspond to hills and hollows in bedrock topography, or to soft sediments or till that are unsaturated and supersaturated with water, respectively. Bedrock hills and unsaturated till resist gravitational motion. Taking Cartesian coordinates with $x$ horizontal and positive against ice flow, $y$ horizontal and transverse to ice flow, and $z$ vertical and positive above sea level, at distance $x$ from the ice-shelf grounding line, a flowband of width $w_{\text {I }}$ has floating segments that add up to width $w_{\mathrm{F}}<w_{\mathrm{I}}$ in the ice stream. Floating fraction $\phi$ defined by Eq. (9) is linked to the horizontal longitudinal force-andmass balance at $x$ using this elaboration:

$\phi=\frac{w_{\mathrm{F}}}{w_{\mathrm{I}}}=\frac{h_{\mathrm{F}}}{h_{\mathrm{I}}}=\frac{\left(\rho_{\mathrm{W}} / \rho_{\mathrm{I}}\right) h_{\mathrm{W}}}{h_{\mathrm{I}}}=\frac{\rho_{\mathrm{W}} g h_{\mathrm{W}}}{\rho_{\mathrm{I}} g h_{\mathrm{I}}}=\frac{P_{\mathrm{W}}^{*}}{P_{\mathrm{I}}}$,

where $h_{\mathrm{F}}=h_{\mathrm{I}}\left(w_{\mathrm{F}} / w_{\mathrm{I}}\right)=h_{\mathrm{I}} \phi$ is the part of ice thickness $h_{\mathrm{I}}$ supported by basal water, $\rho_{W}$ is water density, $\rho_{\mathrm{I}}$ is ice density, $h_{\mathrm{W}}$ is an effective water depth that would float thickness $h_{\mathrm{F}}$ of ice, $P_{\mathrm{W}}^{*}$ is a reduction of basal water pressure $P_{\mathrm{W}}$ that is caused by $h_{\mathrm{W}}$ and increases as basal drag resisting ice flow decreases, $P_{\mathrm{I}}$ is the ice overburden pressure, and $g$ is gravity acceleration. In a vertical force balance, apply Newton's second and third laws of motion to the base of columns having basal area $A_{O}=w_{\mathrm{I}} \Delta x$. Gravity forces $\rho_{\mathrm{I}} g h_{\mathrm{I}} A_{O}$ and $\rho_{W} g h_{\mathrm{W}} A_{O}$ are balanced by pressure forces $P_{\mathrm{I}} A_{O}$ and $P_{\mathrm{W}}^{*} A_{O}$, respectively, giving $P_{\mathrm{W}}^{*}=\rho_{W} g h_{\mathrm{W}}$ as the actual basal water pressure and $P_{\mathrm{I}}=\rho_{\mathrm{I}} g h_{\mathrm{I}}$ as the basal ice pressure. For ice shelves, $P_{\mathrm{W}}^{*}=P_{\mathrm{W}}=P_{\mathrm{I}}$ everywhere. For ice streams $P_{\mathrm{W}}^{*}<P_{\mathrm{W}} \approx P_{\mathrm{I}}$ because basal water flowing from sources to sinks causes variations in $P_{\mathrm{W}}$ that do not coincide everywhere with $P_{\mathrm{I}}$. Taking $\sigma_{\mathrm{W}} h_{\mathrm{I}}=\bar{P}_{\mathrm{W}}^{*} h_{\mathrm{W}}$ in a longitudinal force balance introduces back-stress $\sigma_{\mathrm{W}}$ in ice due to $\bar{P}_{\mathrm{W}}^{*}=1 / 2 P_{\mathrm{W}}^{*}$ that resists ice motion, where $P_{\mathrm{W}}^{*}<P_{\mathrm{W}}$ at $x>0$ under an ice stream and $P_{\mathrm{W}}^{*}=P_{\mathrm{W}}$ at $x=0$ under an ice shelf (see Fig. 5). At the calving front water is in direct contact with a vertical ice cliff and $\sigma_{\mathrm{W}}=1 / 2 P_{\mathrm{W}}\left(h_{\mathrm{W}} / h_{\mathrm{I}}\right)$ in the longitudinal force balance.

\subsection{Stresses resisting stream flow}

Figure 5 shows an exaggerated vertical longitudinal crosssection of a flowband from the ice divide to an ice stream and ending at the calving front of a confined and pinned ice shelf. Flow is from right to left. The top panel shows in shading the part of the flowband that rests on the bed. Solid, broken, and dashed lines show respective heights $h_{\mathrm{I}}, h_{\mathrm{F}}$, and $h_{\mathrm{W}}$ above basal ice. The ice shelf lies in a confining embayment grounded along side lengths $L_{\mathrm{S}}$, at an ice rise of circumference $C_{\mathrm{R}}$, and at ice rumples of area $A_{\mathrm{R}}$, so it buttresses the ice stream. Stresses resisting gravitational flow are $\sigma_{\mathrm{T}}, \sigma_{\mathrm{C}}$, $\tau_{O}$, and $\tau_{S}$ shown at distance $x$ from the ice-shelf grounding line for longitudinal tension, longitudinal compression, basal

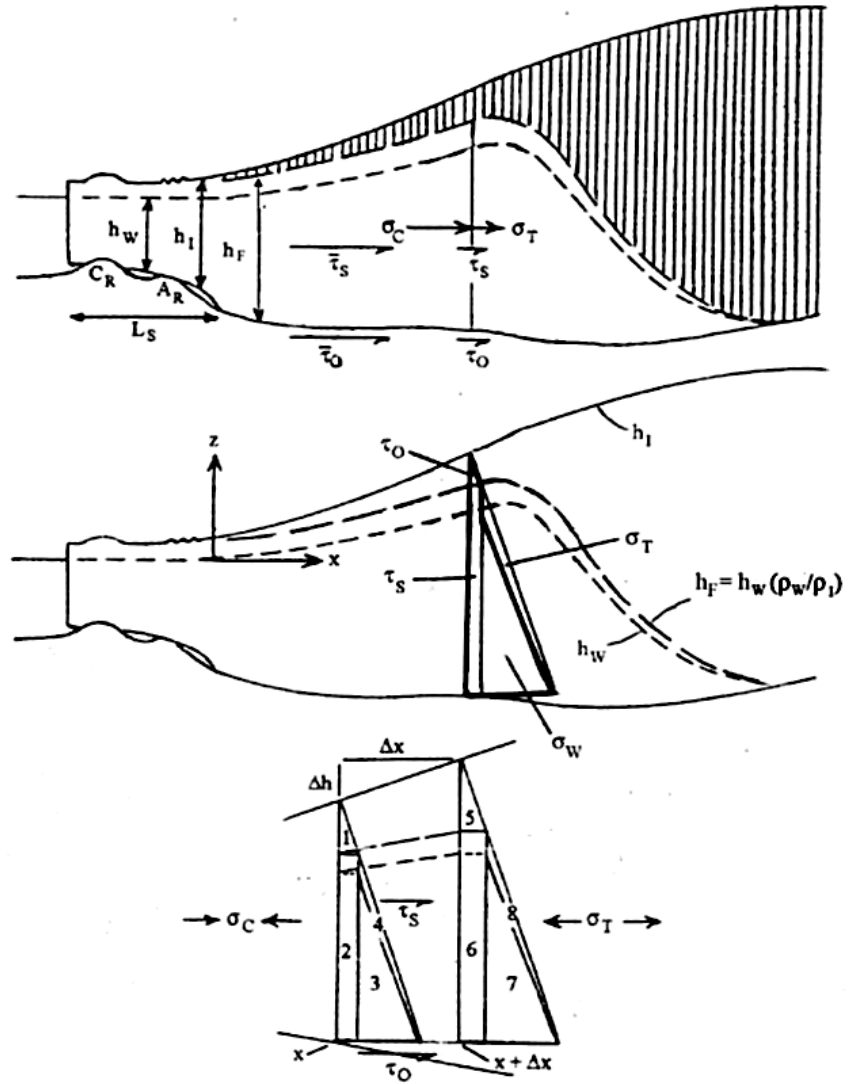

Figure 5. The geometrical force balance on an ice stream ending as a confined ice shelf. Top: resisting stresses that resist gravitational flow. The bed supports ice in the shaded area. Ice in the unshaded area is supported by basal water pressure. Middle: gravitational forces at $x$ represented as triangles and a rectangle are linked to specific resisting stresses. The area inside the thick border is linked to $\sigma_{\mathrm{C}}$. Heights $h_{\mathrm{I}}, h_{\mathrm{W}}$, and $h_{\mathrm{F}}$ are measured from the bed for $x>0$. Bottom: resisting stresses and gravitational forces along $\Delta x$. Resisting and gravitational forces are balanced along $x$ and $\Delta x$.

drag, and side drag, respectively, with $\bar{\tau}_{O}$ and $\bar{\tau}_{\mathrm{S}}$ averaged over the distance from 0 to $x$. In the middle and bottom panels, the areas of large triangles are longitudinal gravitational driving forces for stream flow, with the areas of smaller triangles and rectangles within these large triangles being longitudinal forces that resist gravitational flow. Before our discussion of Fig. 5, readers not familiar with the geometric treatment of the longitudinal force balance should go to Appendix $\mathrm{A}$ and see the simplest applications, using the area of triangles to represent longitudinal gravitational forces for linear sheet flow on a horizontal bed and linear shelf flow at the calving front. In the middle panel of Fig. 5, the area of the largest triangle is the gravitational driving force at $x$. It is reduced at the calving front of the ice shelf, with only interior areas linked to $\sigma_{\mathrm{T}}$ and $\sigma_{\mathrm{W}}$ remaining, where $\sigma_{\mathrm{T}}$ is a tensile stress and $\sigma_{\mathrm{W}}$ is a water buttressing stress in the longitudinal force balance $\sigma_{\mathrm{W}} h_{\mathrm{I}}=\bar{P}_{\mathrm{W}} h_{\mathrm{W}}$, see Appendix A. In the 
lower panel of Fig. 5, the difference in the areas of the large triangles at $x$ and $x+\Delta x$ is the gravitational driving force. When inner triangular areas 1 and 5 grow to equal the size of the respective large triangles as $x$ increases, their difference in area is linked to basal shear stress $\tau_{O}$ for sheet flow, see Appendix A.

The middle panel shows a large triangular area equal to gravitational driving force $1 / 2 P_{\mathrm{I}} h_{\mathrm{I}}$. Within that triangle are areas linked to resisting forces, with the area inside the bold border linked to compressive force $\sigma_{\mathrm{C}} h_{\mathrm{I}}$ that pushes downstream ice, and the remaining small triangular area linked to tensile force $\sigma_{T} h_{\mathrm{I}}$.that pulls upstream ice. Because ice height $h_{\mathrm{I}}$ is common to all three forces, this force balance gives (Thomas, 2004):

$$
1 / 2 P_{\mathrm{I}}=\bar{P}_{\mathrm{I}}=\sigma_{\mathrm{C}}+\sigma_{\mathrm{T}}
$$

Note that $\sigma_{\mathrm{C}} \gg \sigma_{\mathrm{T}}$ because area $1+2+3$ enclosed by the bold border at $x$ greatly exceeds triangle area 4 see the bottom panel, so a minor downslope decrease in resistance to ice flow causes a small decrease in $\sigma_{\mathrm{C}}$ but a large increase in $\sigma_{\mathrm{T}}$ because $P_{\mathrm{I}}$ is initially unchanged until $h_{\mathrm{I}}$ lowers. This shows how $\sigma_{\mathrm{T}}$ can pull more ice out of ice sheets for only a small decrease in downslope resistance to ice flow (Hughes, 1992). At the calving front of an ice shelf, Appendix A shows how Eq. (11) becomes the Weertman (1957b) analytical solution of the Navier-Stokes equations because here $\sigma_{\mathrm{C}}=\bar{P}_{\mathrm{W}}\left(h_{\mathrm{W}} / h_{\mathrm{I}}\right)=\bar{P}_{\mathrm{I}}\left(\rho_{\mathrm{I}} / \rho_{\mathrm{W}}\right)$.

The bottom panel equates areas 1,2 , and 3 with compressive force $\sigma_{\mathrm{C}} h_{\mathrm{I}}$, triangular area 4 to tensile force $\sigma_{\mathrm{T}} h_{\mathrm{I}}$, triangular area 3 to water-buttressing force $\sigma_{\mathrm{W}} h_{\mathrm{I}}$, area $3+4$ to flotation force $\sigma_{\mathrm{F}} h_{\mathrm{I}}$, the difference between triangular areas 5 and 1 to basal drag force $\tau_{O} \Delta x$, and the difference between rectangular areas 6 and 2 to side drag force $2 \tau_{\mathrm{S}} \Delta x$ for two sides. Balancing these longitudinal forces as $\Delta x \rightarrow 0$ gives (Hughes, 2009, 2012, Appendix G):

$$
\begin{aligned}
& \sigma_{\mathrm{T}}=1 / 2 \rho_{\mathrm{I}} g h_{\mathrm{I}}\left(1-\rho_{\mathrm{I}} / \rho_{\mathrm{W}}\right) \phi^{2}=\bar{P}_{\mathrm{I}}\left(1-\rho_{\mathrm{I}} / \rho_{\mathrm{W}}\right) \phi^{2} \\
& \sigma_{\mathrm{C}}=1 / 2 \rho_{\mathrm{I}} g h_{\mathrm{I}}\left[1-\left(1-\rho_{\mathrm{I}} / \rho_{\mathrm{W}}\right) \phi^{2}\right]= \\
& \bar{P}_{\mathrm{I}}\left[1-\left(1-\rho_{\mathrm{I}} / \rho_{\mathrm{W}}\right) \phi^{2}\right] \\
& \sigma_{\mathrm{W}}=1 / 2 \rho_{\mathrm{I}} g h_{\mathrm{I}}\left(\rho_{\mathrm{I}} / \rho_{\mathrm{W}}\right) \phi^{2}=\bar{P}_{\mathrm{I}}\left(\rho_{\mathrm{I}} / \rho_{\mathrm{W}}\right) \phi^{2} \\
& \sigma_{\mathrm{F}}=\sigma_{\mathrm{T}}+\sigma_{\mathrm{W}}=\bar{P}_{\mathrm{I}} \phi^{2} \\
& \tau_{O}=\rho_{\mathrm{I}} g h_{\mathrm{I}}(1-\phi)\left[\alpha_{\mathrm{I}}-\partial\left(h_{\mathrm{I}} \phi\right) / \partial x\right] \rightarrow P_{\mathrm{I}}(1-\phi)^{2} \alpha \\
& \tau_{\mathrm{S}}=1 / 2 \rho_{\mathrm{I}} g h_{\mathrm{I}}\left(w_{\mathrm{I}} / h_{\mathrm{I}}\right)\left[\phi \alpha_{\mathrm{I}}+(1-2 \phi) \partial\left(h_{\mathrm{I}} \phi\right) / \partial x\right] \\
& \rightarrow P_{\mathrm{I}}\left(w_{\mathrm{I}} / h_{\mathrm{I}}\right) \phi(1-\phi) \alpha .
\end{aligned}
$$

The arrow in Eqs. (16) and (17) means "approaches" when $\partial \phi / \partial x$ variations are placed between $\Delta x$ steps. Figure 6 plots variations with $\phi$ for the resisting stresses given by Eqs. (12) through (17), normalized with respect to gravitational driving stresses $P_{\mathrm{I}} \alpha$ or $\bar{P}_{\mathrm{I}}$.

Side shear strain rate $\dot{\varepsilon}_{x y}$ increases and becomes more narrowly confined to lateral shear zones downstream for both

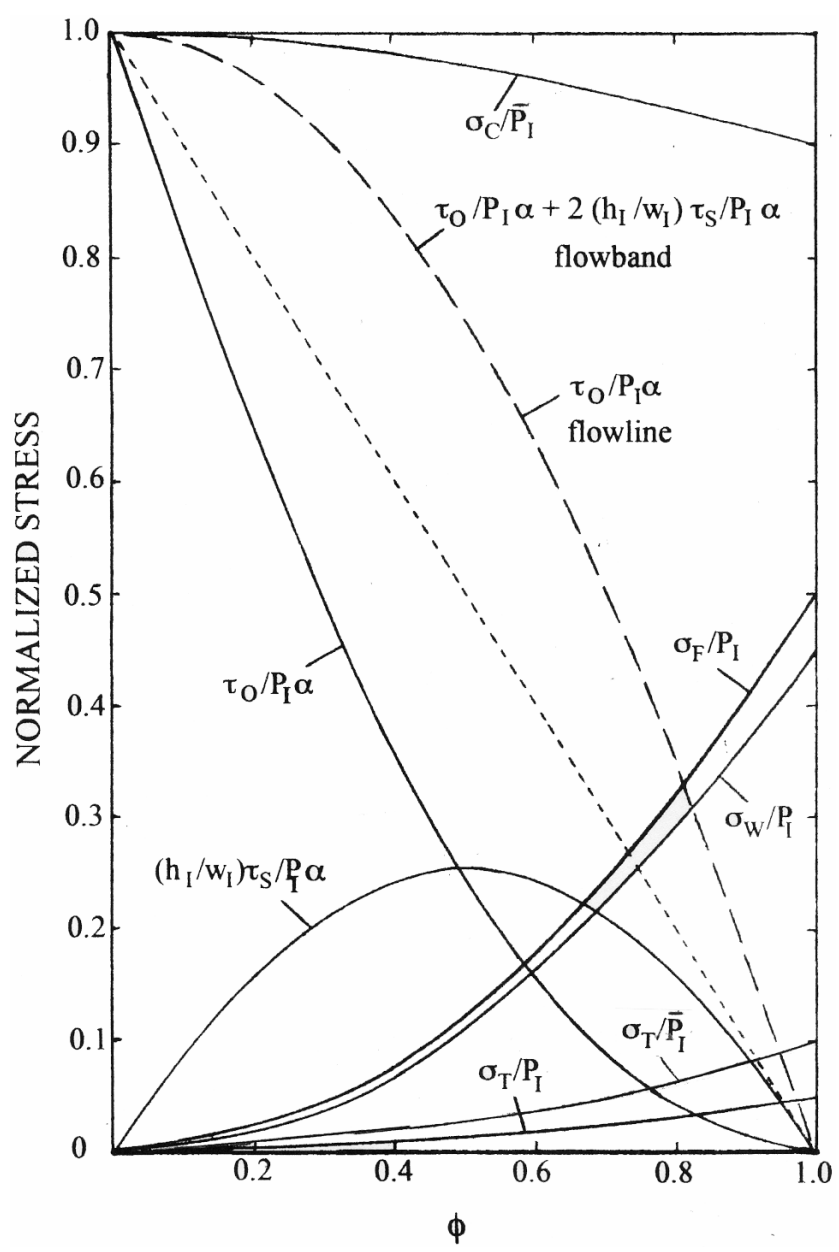

Figure 6. Variations of normalized stresses in Eqs. (12) through (17) with floating fraction $\phi$ of ice. Solid curves are for flowbands. Broken curve $\tau_{O} / P_{\mathrm{I}} \alpha$ for a flowline is identical to $\tau_{O} / P_{\mathrm{I}} \alpha+$ $2\left(h_{\mathrm{I}} / h_{\mathrm{W}}\right) \tau_{\mathrm{S}} / P_{\mathrm{I}} \alpha$ for a flowband, when side drag in the flowband is added to basal drag in its central flowline, see Hughes (2009, 2012, chapter 12 and appendices $\mathrm{G}$ through $\mathrm{N}$ ). The linear dashed line is the average of $\tau_{O} / P_{\mathrm{I}} \alpha$ and $\tau_{O} / P_{\mathrm{I}} \alpha+\left(h_{\mathrm{I}} / h_{\mathrm{W}}\right) \tau_{\mathrm{S}} / P_{\mathrm{I}} \alpha$ for flowbands.

Byrd Glacier (Whillans et al., 1989; Van der Veen et al., 2014) and Jakobshavn Isbrae (Fastook et al., 1995), even though side shear stress $\tau_{\mathrm{S}}=\sigma_{x y}$ in Fig. 6 rises to a maximum and then decreases to zero. This is because $\tau_{\mathrm{S}}$ varies with the product $\phi(1-\phi)$ in Eq. (17), as required to balance the net gravitational force in Fig. 5 represented by the difference in areas between rectangles 6 and 2 with resisting force $\tau_{\mathrm{S}} \Delta x$. Physically, the decrease of $\tau_{\mathrm{S}}$ can be ascribed to increased downstream frictional heating and development of an easy-glide ice fabric in the two lateral shear zones which combine to reduce side coupling with slower ice on either side of these ice streams. This in itself would allow side shear strain rate $\dot{\varepsilon}_{x y}$ to increase. A decrease of $\tau_{\mathrm{S}}$ as $\phi$ increases from 0.5 to 1.0 will occur if shear rupture (Schulson and Duval, 2009) fractures the whole ice thickness, with 


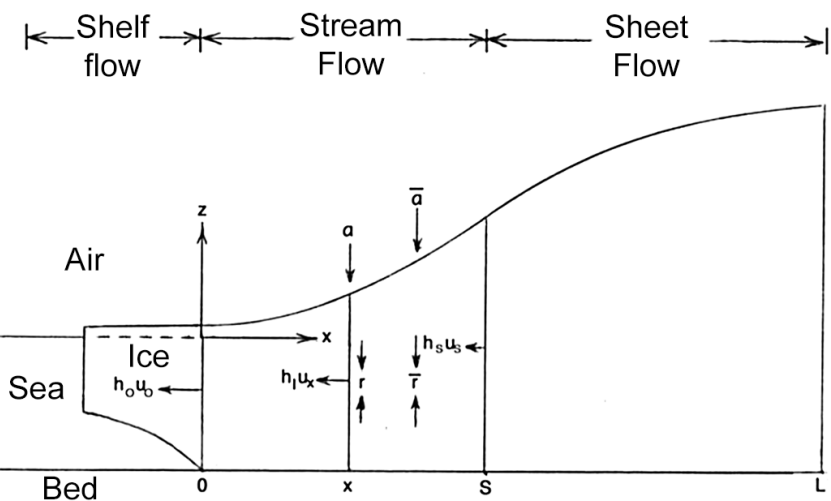

Figure 7. A longitudinal profile of an ice-sheet flowband of constant width on a horizontal bed showing components of the mass balance for sheet, stream, and shelf flow from right to left. Ice thickness $h_{\mathrm{I}}$ and mean ice velocity $u_{x}$ are shown at the ungrounding line $(x=0)$, along an ice stream $(x)$, at the beginning of stream flow $(x=S)$, and at the beginning of sheet flow $(x=L)$ for mean accumulation rate $\bar{a}$ and ice thinning rate $\bar{r}$ averaged along $x$, and rates $a$ and $r$ at $x$. These same components exist for variable bed topography.

top crevasses extending downward toward sea level (Van der Veen, 1998a) and bottom crevasses extending upward toward sea level (Van der Veen, 1998b). This is seen by the lateral rifts that open alongside Byrd Glacier when it leaves the lateral confinement of the fjord walls in Barne Inlet (Hughes, 1977), and the longitudinal rifts called "The Zipper" that open in Jakobshavn Isbrae when floating ice spills over the south wall of Jakobshavn Isfjord to form a broad ice lobe ending on land (Prescott et al., 2003). This allows extending strain rates $\dot{\varepsilon}_{y y}$ across shear zones.

Longitudinal strain rate $\dot{\varepsilon}_{x x}$ beyond the ungrounding line is initially compressive for Byrd Glacier, due to the great inertia of the Ross Ice Shelf (Van der Veen et al., 2014), and is almost zero for Jakobshavn Isbrae, primarily due to buttressing from ice rumples near the calving front that probably contributes to the lateral spreading (Prescott et al., 2003). Ice-shelf buttressing is an important part of our study.

The longitudinal force gradient has dimensions of stress and is (Hughes, 2012, chapter 12):

$$
\begin{aligned}
& \partial\left(\sigma_{\mathrm{F}} h_{\mathrm{I}}\right) / \partial x=\partial\left(\sigma_{\mathrm{T}} h_{\mathrm{I}}\right) / \partial x+\partial\left(\sigma_{\mathrm{W}} h_{\mathrm{I}}\right) / \partial x \\
& =P_{\mathrm{I}}\left(\rho_{\mathrm{W}} / \rho_{\mathrm{I}}\right) \phi \alpha_{\mathrm{W}} \rightarrow P_{\mathrm{I}} \phi^{2} \alpha_{\mathrm{I}},
\end{aligned}
$$

where $\Delta h / \Delta x \rightarrow \alpha$ is the ice surface slope, $\Delta h_{\mathrm{I}} / \Delta x \rightarrow \alpha_{I}$ is the ice thickness gradient, and $\Delta h_{\mathrm{W}} / \Delta x \rightarrow \alpha_{\mathrm{W}}$ is the gradient of basal water height, giving effective basal water pressure $P_{\mathrm{W}}^{*}$ resisting gravitational ice flow, all as $\Delta x \rightarrow 0$, and $\alpha_{\mathrm{W}}=\left(\rho_{\mathrm{I}} / \rho_{\mathrm{W}}\right) \partial\left(h_{\mathrm{I}} \phi / \partial x\right) \rightarrow\left(\rho_{\mathrm{I}} / \rho_{\mathrm{W}}\right) \phi \alpha_{\mathrm{I}}$ from Eq. (10). Water buttressing produces back-stress $\sigma_{\mathrm{W}}=\left(h_{\mathrm{W}} / h_{\mathrm{I}}\right) \bar{P}_{\mathrm{W}}^{*}$ in ice due to $\bar{P}_{\mathrm{W}}^{*}$ in a longitudinal force balance. Flotation stress $\sigma_{\mathrm{F}}$ in ice is due to $\sigma_{\mathrm{W}}+\sigma_{\mathrm{T}}$ in the longitudinal force balance $\sigma_{\mathrm{F}} h_{\mathrm{I}}=\sigma_{\mathrm{W}} h_{\mathrm{I}}+\sigma_{\mathrm{T}} h_{\mathrm{I}}$. These are real stresses. They are obscured using holistic continuum mechanics in conventional ice-sheet models, but they visibly emerge from the geometrical force balance in the holistic ice-sheet model based on Fig. 5.

In Thomas (2004), compressive stress $\sigma_{\mathrm{C}}$ at $x$ results from all downstream resistance to ice flow. A longitudinal force

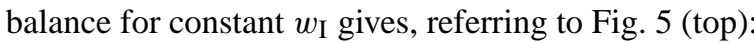

$$
\begin{aligned}
& \sigma_{\mathrm{C}} A_{x}=\sigma_{\mathrm{C}} h_{\mathrm{I}} w_{\mathrm{I}}=\bar{\tau}_{O}\left(w_{\mathrm{I}} x+A_{\mathrm{R}}\right)+\bar{\tau}_{\mathrm{S}}\left(2 \bar{h}_{\mathrm{I}} x+2 \bar{h}_{\mathrm{S}} L_{\mathrm{S}}\right. \\
& \left.+\bar{h}_{\mathrm{R}} C_{\mathrm{R}}\right)+\left(\bar{P}_{\mathrm{W}} h_{\mathrm{W}}\right)_{O} w_{\mathrm{I}},
\end{aligned}
$$

where $\bar{\tau}_{O}$ is the average basal shear stress over downslope basal area $w_{\mathrm{I}} x$ of the ice stream and basal area $A_{\mathrm{R}}$ of ice rumples on the ice shelf, $\bar{\tau}_{\mathrm{S}}$ is the average side shear stress over downslope side areas $2 \bar{h}_{\mathrm{I}} x$ of the ice stream, $2 \bar{h}_{\mathrm{S}} L_{\mathrm{S}}$ of the ice shelf, and $\bar{h}_{\mathrm{R}} C_{\mathrm{R}}$ of ice rises on the ice shelf for average ice thicknesses $\bar{h}_{\mathrm{I}}$ along length $x$ of the ice stream, $\bar{h}_{\mathrm{S}}$ along grounded side lengths $L_{\mathrm{S}}$ of the ice shelf, and $\bar{h}_{\mathrm{R}}$ around circumference $C_{\mathrm{R}}$ of ice rises, and $\left(\bar{P}_{\mathrm{W}} h_{\mathrm{W}}\right)_{O} w_{\mathrm{I}}$ is the backforce at $x=0$ due to average water pressure $\bar{P}_{\mathrm{W}}$ in water of depth $h_{\mathrm{W}}$ at the ice-shelf grounding line. Under surface ice rumples, bedrock contacts ice and allows basal sliding. Under surface ice rises, bedrock penetrates ice so ice must shear around ice rises.

As shown in Appendix B, the $\phi$ dependences of $\bar{\tau}_{O}$ and $\bar{\tau}_{\mathrm{S}}$ based on Fig. 5 are

$\bar{\tau}_{O}=\bar{P}_{\mathrm{I}} w_{\mathrm{I}} h_{\mathrm{I}}(1-\phi)^{2} /\left(w_{\mathrm{I}} x+A_{\mathrm{R}}\right)$

and

$\bar{\tau}_{\mathrm{S}}=P_{\mathrm{I}} w_{\mathrm{I}} h_{\mathrm{I}} \phi(1-\phi) /\left(2 \bar{h}_{\mathrm{I}} x+2 \bar{h}_{\mathrm{S}} L_{\mathrm{S}}+\bar{h}_{\mathrm{R}}, C_{\mathrm{R}}\right)$.

Demonstrating that $h_{\mathrm{F}}$ in Eqs. (9) and (10) is real, and therefore $\sigma_{\mathrm{W}}$ is real, has been a learning experience (Hughes, 1992, 2003, 2009, 2011, 2012, chapter 10; Reusch and Hughes, 2003; Hughes et al., 2011). Relating $h_{\mathrm{F}}$ to $h_{\mathrm{I}}$ and $h_{\mathrm{W}}$ at the calving front of an ice shelf uses the horizontal longitudinal force balance $\rho_{\mathrm{I}} h_{\mathrm{I}}=\rho_{W} h_{\mathrm{W}}$ because heavier water of height $h_{\mathrm{W}}$ buttresses lighter ice of height $h_{\mathrm{I}}$, so $h_{\mathrm{F}}=h_{\mathrm{I}}=$ $\left(\rho_{W} / \rho_{\mathrm{I}}\right) h_{\mathrm{W}}$, see Appendix A. This is also true at an ice-shelf grounding line. Ignore the ice shelf so the grounding line becomes the calving front and water buttresses both. Creep thinning of an unconfined ice shelf from the grounding line to the calving front produces a concave ice-thickness profile (Sanderson, 1979; Van der Veen, 1983), so the geometrical force balance on a column of ice must include buttressing from the wedge of water under the ice column (Hughes, 2012, chapter 9). It gives the same result as at the calving front.

This result also applies for the concave profile up an ice stream when floating fraction $\phi$ of ice is introduced. It allows water of height $h_{\mathrm{W}}$ at $x>0$ in Fig. 5 to "buttress" an ice stream at distance $x$ upstream from the ice-shelf grounding line. Height $h_{\mathrm{W}}$ acts like water impounded by a "dam" that exists because downstream resistance to water flowing under an ice stream exists. It is similar to resistance from 
a laterally confined and locally pinned ice shelf that causes $h_{\mathrm{W}}$ to be greater and gradient $\mathrm{d} h_{\mathrm{W}} / \mathrm{d} x$ to be less at the grounding line than they would be for a freely floating ice shelf. The obvious demonstration of this is the height of water in boreholes drilled by Barclay Kamb and Hermann Engelhardt along Whillans Ice Stream: the water height above the bed was well above sea level and somewhat below the height needed to float ice thickness $h_{\mathrm{I}}$, so $h_{\mathrm{F}}<h_{\mathrm{I}}$ as shown in Fig. 5, see Kamb (2001). Mean effective water pressure $\bar{P}_{\mathrm{W}}^{*}$ in Eq. (10) "buttresses" ice in the longitudinal force balance by producing a water back-stress $\sigma_{\mathrm{W}}$ in ice of height $h_{\mathrm{I}}$ above the bed in the force balance $\bar{P}_{W}^{*} h_{\mathrm{W}}=\sigma_{\mathrm{W}} h_{\mathrm{I}}$. The grounded fraction $1-\phi$ of ice allows some basal drag that "dams" basal water. MacAyeal (1989) modeled Whillans Ice Stream as a linear ice shelf with some basal drag too small to seriously affect integrating the Morland-MacAyeal equations for shelf flow. More basal drag was allowed when Hughes (1992) introduced $\phi$ and the geometrical force balance for ice streams shown in Fig. 5.

The distinction between $P_{\mathrm{W}}^{*}$ in Eq. (10) and $P_{\mathrm{W}}$ is that $P_{\mathrm{W}} \approx P_{\mathrm{I}}$ vertically when the bed is merely wet, but $P_{\mathrm{W}}^{*}<P_{\mathrm{I}}$ horizontally in proportion to $A_{\mathrm{W}}<A_{O}$ for ice floating over basal area $A_{\mathrm{F}}=A_{\mathrm{W}}$ within basal area $A_{O}$. Where Kamb and Engelhardt drilled through Whillans Ice Stream, $A_{\mathrm{W}}$ was not much less than $A_{O}$. Effective water pressure $P_{\mathrm{W}}^{*}=P_{\mathrm{I}}$ only when $\phi=1$ for fully floating ice, thereby converting the ice stream into a linear ice shelf without basal or side drag, see Eqs. (16) and (17). When $P_{\mathrm{W}}^{*}$ is multiplied by water height $h_{\mathrm{W}}$ the product is the longitudinal force of water pushing upslope at $x$, a force that is reduced from the similar force for the same $h_{\mathrm{W}}$ at the calving front by $\phi$.

The longitudinal force balance pits gravitational driving force gradient $\Delta\left(\bar{P}_{\mathrm{I}} h_{\mathrm{I}}\right) / \Delta x=P_{\mathrm{I}} \alpha$ as $\Delta x \rightarrow 0$, obtained from the difference between area $5+6+7+8$ and area $1+2+3+4$ in incremental length $\Delta x$ in Fig. 5, against resisting drag stresses $\tau_{O}$ and $\tau_{S}$ and flotation force gradient $\partial\left(\sigma_{F} h_{\mathrm{I}}\right) / \partial x$ to obtain (Hughes, 2011, 2012, Appendix G):

$P_{\mathrm{I}} \alpha=\tau_{O}+2 \tau_{\mathrm{S}}\left(h_{\mathrm{I}} / w_{\mathrm{I}}\right)+\partial\left(\sigma_{\mathrm{F}} h_{\mathrm{I}}\right) / \partial x$.

Equation (22) is satisfied using substitutions from Eqs. (16)(18). By "satisfied" we mean it includes all the components of the longitudinal gravitational force given by the area of the big triangle in the middle panel of Fig. 5, and the resisting stresses linked to floating fraction $\phi$. Gradient $\partial \phi / \partial x$ is taken as zero for each $\Delta x$ step, so changes occur between steps, as was done with bed topography.

Equation (22) is the standard equation for linear stream flow that is also obtained from linear continuum mechanics, where $\sigma_{\mathrm{F}}$ is the longitudinal deviator stress and $\partial\left(\sigma_{\mathrm{F}} h_{\mathrm{I}}\right) / \partial x$ is the longitudinal force gradient. It is identical to Eq. (3.3.12) derived by Van der Veen (1999), where $\tau_{b x}=P_{\mathrm{I}} \alpha, \tau_{\mathrm{d} x}=\tau_{O}, \partial\left(H R_{x y}\right) / \partial y=2 \tau_{\mathrm{S}}\left(h_{\mathrm{I}} / w_{\mathrm{I}}\right)$, and $\partial\left(H R_{x x}\right) / \partial x=\partial\left(\sigma_{\mathrm{F}} h_{\mathrm{I}}\right) / \partial x$.

Now approximate bed topography with an up-down staircase in which $\Delta x$ is the constant step length and $\pm \Delta h_{\mathrm{B}}$ is the variable gain or loss in step height. A normal stress $\sigma_{N}$ in the direction of ice flow pushes against $-\Delta h_{\mathrm{B}}$ and pulls away from $+\Delta h_{\mathrm{B}}$ with force $F_{N}= \pm \sigma_{N} \Delta h_{\mathrm{B}}$ compared to gravitational driving force $F_{\mathrm{G}}=\bar{P}_{\mathrm{I}} h_{\mathrm{I}}$, so that $\sigma_{N} \Delta h_{\mathrm{B}} / \Delta x$ and $P_{\mathrm{I}} \Delta h / \Delta x$ are force gradients with $\sigma_{N}$ close to viscoplastic yield stress $\sigma_{\mathrm{V}}$ in Fig. 2. Then $F_{N}$ is much less than $F_{G}$ until the bed slope exceeds \pm 30 degrees (Hughes, 2012, Appendix E), so $F_{N}$ can be ignored for lesser bed slopes. Then $\Delta h=\Delta h_{\mathrm{I}}$ can be used for each $\Delta x$ step. Substituting Eqs. (16)-(18) into Eq. (22), putting terms containing $\partial \phi / \partial x$ between $\Delta x$ steps, dividing by $P_{\mathrm{I}}$, solving for surface slope $\alpha$, and returning to the incremental form so $\partial \phi / \partial x \approx \Delta \phi / \Delta x$ and $\alpha \approx \Delta h / \Delta x$ :

$$
\begin{aligned}
& \frac{\Delta h}{\Delta x}=\frac{\Delta\left(\sigma_{\mathrm{F}} h_{\mathrm{I}}\right) / \Delta x}{P_{\mathrm{I}}}+\frac{\tau_{O}}{P_{\mathrm{I}}}+\frac{2 \tau_{\mathrm{S}}\left(h_{\mathrm{I}} / w_{\mathrm{I}}\right)}{P_{\mathrm{I}}} \\
& =\phi^{2}\left(\frac{\Delta h_{\mathrm{I}}}{\Delta x}\right)_{\mathrm{F}}+(1-\phi)^{2}\left(\frac{\Delta h_{\mathrm{I}}}{\Delta x}\right)_{\mathrm{G}}+2 \phi(1-\phi)\left(\frac{\Delta h}{\Delta x}\right) .
\end{aligned}
$$

Here $\Delta h_{\mathrm{I}}=\Delta h$ on $\Delta x$ steps, so $(\Delta h / \Delta x)_{F}$ is for the floating fraction of the ice column linked to $\sigma_{F}$ and $(\Delta h / \Delta x)_{G}$ is for the grounded fraction of the ice column linked to $\tau_{O}$ on these steps. We have ignored $\Delta h_{\mathrm{B}} / \Delta x$ and $\Delta \phi / \Delta x$ by substituting an up-down staircase that makes these changes occur instantaneously between $\Delta x$ steps. This is a major simplification that if unwarranted invalidates everything that follows, see Hughes (2012, chapter 20, Appendices E and P) for elaborations of this point. Because of the reduction in ice-bed coupling when grounded ice floats, $\left(\Delta h_{\mathrm{I}} / \Delta x\right)_{\mathrm{F}}<$ $\left(\Delta h_{\mathrm{I}} / \Delta x\right)_{\mathrm{G}}$ and a smoothed surface slope $\Delta h / \Delta x$ will lie between these values when $0<\phi<1$, as is the case with ice streams.

As shown in Appendix C, when only the geometrical force balance is used, Eqs. (19) through (21) combine with Eq. (13) to give:

$\phi=h_{0} / h_{\mathrm{I}}$,

where $h_{0}$ is at $x=0$ and $h_{\mathrm{I}}$ is at any $x$. We apply both to Jakobshavn Isbrae and Byrd Glacier. Equation (24) is obtained both for ice streams with side shear and for the central flowline of an ice stream without side shear (Hughes, 2012, chapter 11). In Eq. (24), $h_{O}$ is ice height above the bed at $x=0$ where the ice stream becomes a floating ice shelf, so $h_{O}=h_{\mathrm{I}}$ when $\phi=1$ but $\phi<1$ at horizontal distances $x$ up the ice stream where $h_{O}<h_{\mathrm{I}}$. For sheet flow, $\phi=0$ because $h_{O}=0$ at the ice margin. For shelf flow, $\phi=1$ when $h_{O}=h_{\mathrm{I}}$ everywhere. For stream flow, $1>\phi>0$ because $h_{\mathrm{I}}>h_{O}$. Fastook and Hughes (2013) obtained $\phi$ from glacial geology to compare ice-sheet reconstructions during the last glaciation cycle using Eq. (24) at specified times with reconstructions using the University Of Maine Ice Sheet Model (UMISM) in three dimensions over time.

The mass balance must be combined with the force balance to obtain solutions of $\phi$ that satisfy Eq. (9). A simple 
mass balance is shown in Fig. 7 for constant ice accumulation rate $a$ and ice thinning rate $r$ along $x$, with $h_{\mathrm{I}}=h_{L}$ where ice velocity $u_{x}=0$ at the ice divide $(x=L), h_{\mathrm{I}}=h_{S}$ where $u_{x}=u_{S}$ and stream flow begins $(x=S)$, and $h_{\mathrm{I}}=h_{O}$ where $u_{x}=u_{O}$ at the ice-shelf grounding line $(x=0)$. Appendix D shows how $(\Delta h / \Delta x)_{G}$ is obtained from the mass balance written as

$h_{\mathrm{I}} u_{x}=(a-r)(L-x)$,

where $u_{x}=\bar{u}_{x}=u_{S}$ is the basal sliding velocity where ice steams are grounded on a thawed bed in Fig. 4. Since $a$ and $r$ can vary along $x$, Eq. (25) is a simplification comparable to Eq. (23) and, if unwarranted, invalidates everything that follows. Validation requires that $\phi, h_{\mathrm{B}}, a$, and $r$ vary slowly along $\mathrm{x}$ in both equations.

In the Weertman (1957a) theory for sheet flow, $u_{x}=u_{\mathrm{S}}=$ $\left(\tau_{O} / B\right)^{m}$ with bed roughness included in sliding parameter $B$ and $m=1 / 2(n+1)$. Taking $\tau_{O}=\rho_{\mathrm{I}} g h_{\mathrm{I}} \alpha$ and $\alpha=\mathrm{d} h_{\mathrm{I}} / \mathrm{d} x$ where the ice stream is grounded in Fig. 4, Eq. (25) gives

$$
\left(\frac{\Delta h_{\mathrm{I}}}{\Delta x}\right)_{\mathrm{G}}=\frac{\tau_{O}}{\rho_{\mathrm{I}} g h_{\mathrm{I}}}=\frac{\left(B / \rho_{\mathrm{I}} g\right)[(a-r)(L-x)]^{\frac{1}{m}}}{h_{\mathrm{I}}^{\frac{m+1}{m}}} .
$$

The weak dependence $h_{\mathrm{I}} \propto(a-r)^{1 / 3}$ for $m=2$ justifies ignoring slow variations of $(a-r)$ and also of $a$ and $r$ separately along $x$ for grounded ice in mass balance Eq. (25). Following the treatment by Hughes et al. (2011) and Hughes (2012, Appendix B) for basal sliding modified to include stream flow, and using Eq. (5) by analogy, $B=\tau_{O} / u_{x}^{1 / m}=$ $\sigma_{\mathrm{T}} /\left(\dot{\varepsilon}_{x x} \Lambda_{O}\right)^{1 / m}$ with $u_{x}$ requiring longitudinal tension stress $\sigma_{\mathrm{T}}$ and strain rate $\dot{\varepsilon}_{x x}=u_{x} / \Lambda_{O}$ in ice along longitudinal diameter $\Lambda_{O}$ of bedrock bumps shaped like pyramids, where rates of melting-freezing regelation and high-stress creep are equal in distance $\Lambda_{O}$. From Fig. $2, \sigma_{\mathrm{T}}=\sigma_{\mathrm{V}}=38.6 \mathrm{kPa}$ is the viscoplastic yield stress in ice caused by basal sliding and till deformation when $n=3$ and where the ice stream is grounded in Fig. 4.

Where ice streams float above the bed in Fig. 4, Appendix $\mathrm{E}$ shows how $\left(\Delta h_{\mathrm{I}} / \Delta x\right)_{\mathrm{F}}$ is obtained from the mass balance in Fig. 7 written as follows:

$h_{\mathrm{I}} u_{x}=h_{0} u_{O}+(a-r) x$.

Differentiating Eq. (27) with respect to $x$ gives $u_{x} \alpha+h_{\mathrm{I}} \dot{\varepsilon}_{x x}=$ $(a-r)$, where $\alpha=d h_{\mathrm{I}} / \mathrm{d} x$ and $\dot{\varepsilon}_{x x}=d u_{x} / \mathrm{d} x$ is the longitudinal strain rate linked to tensile pulling stress $\sigma_{\mathrm{T}}=2 \sigma_{x x}$ in the flow law of ice $\dot{\varepsilon}_{x x}=\left(\sigma_{\mathrm{T}} / 2 A\right)^{n}$ for ice hardness parameter $A$ and viscoplastic exponent $n$ (Hughes, 2012, Appendix D). By analogy with Eq. (5), $A=\sigma_{\mathrm{T}} / 2 \dot{\varepsilon}_{x x}^{1 / n}$ and Fig. 2 gives $\sigma_{\mathrm{T}}=\sigma_{V}=66.7 \mathrm{kPa}$ for cold ice when $n=3$. Taking $\alpha=d h_{\mathrm{I}} / \mathrm{d} x$ where the ice stream is floating in Fig. 4 and using Eq. (12) for $\sigma_{\mathrm{T}}$, Eq. (27) gives the following:

$$
\left(\frac{\Delta h_{\mathrm{I}}}{\Delta x}\right)_{\mathrm{F}}=\frac{h_{\mathrm{I}}(a-r)-h_{\mathrm{I}}^{2}\left[\left(\rho_{\mathrm{I}} g h_{\mathrm{I}} / 4 A\right)\left(1-\rho_{\mathrm{I}} / \rho_{\mathrm{W}}\right) \phi^{2}\right]^{n}}{h_{0} u_{O}+(a-r) x} .
$$

\subsection{The floating fraction of ice for flowbands and flowlines}

Collecting terms in Eq. (23) and taking $h_{\mathrm{I}}=h$ for our horizontal $\Delta x$ step gives

$\left(1-2 \phi+2 \phi^{2}\right) \frac{\Delta h}{\Delta x}=\phi^{2}\left(\frac{\Delta h}{\Delta x}\right)_{\mathrm{F}}+(1-\phi)^{2}\left(\frac{\Delta h}{\Delta x}\right)_{\mathrm{G}}$.

Writing as a quadratic equation:

$$
\begin{aligned}
& {\left[2\left(\frac{\Delta h}{\Delta x}\right)-\left(\frac{\Delta h}{\Delta x}\right)_{\mathrm{F}}-\left(\frac{\Delta h}{\Delta x}\right)_{\mathrm{G}}\right] \phi^{2}-\left[2\left(\frac{\Delta h}{\Delta x}\right)-2\left(\frac{\Delta h}{\Delta x}\right)_{\mathrm{G}}\right] \phi} \\
& +\left[\left(\frac{\Delta h}{\Delta x}\right)-\left(\frac{\Delta h}{\Delta x}\right)_{\mathrm{G}}\right]=0 .
\end{aligned}
$$

Setting $\quad C_{1}=(\Delta h / \Delta x), \quad C_{2}=(\Delta h / \Delta x)_{F}, \quad$ and $C_{3}=(\Delta h / \Delta x)_{G}$ and solving for $\phi$ gives the solution for an ice stream having constant width and side shear:

$\phi=\frac{\left(C_{1}-C_{3}\right) \pm\left[\left(C_{1}-C_{3}\right)^{2}-\left(C_{1}-C_{3}\right)\left(2 C_{1}-C_{2}-C_{3}\right)\right]^{1 / 2}}{2 C_{1}-C_{2}-C_{3}}$.

In a flowline solution, width $w_{\mathrm{I}}=0$ so $\tau_{S}=0$. Yet side drag remains and contributes to the ice elevation needed to overcome resistance to ice flow, so it must be taken into account in some way, especially for narrow ice streams (Dupont and Alley, 2005, 2006). The best way is to enlarge $\tau_{O}$ to become effective basal shear stress $\tau_{O}^{*}$ linked to areas $5+6$ minus areas $1+2$ as incremental length $\Delta x \rightarrow 0$ in Fig. 5. Then $\tau_{O}^{*}$ is the following:

$\tau_{O}^{*}=\rho_{\mathrm{I}} g h_{\mathrm{I}}\left(1-\phi^{2}\right) \Delta h / \Delta x-\rho_{\mathrm{I}} g h_{\mathrm{I}}^{2} \phi \Delta \phi / \Delta x$.

The longitudinal force balance given by Eq. (23), putting the $\Delta \phi / \Delta x$ terms in Eqs. (16) through (18) as abrupt changes in $\phi$ between $\Delta x$ steps, becomes (Hughes, 2012, chapter 11) the following:

$$
\begin{aligned}
& \frac{\Delta h}{\Delta x}=\frac{\Delta\left(\sigma_{\mathrm{F}} h_{\mathrm{I}}\right) / \Delta x}{P_{\mathrm{I}}}+\frac{\tau_{O}^{*}}{P_{\mathrm{I}}} \\
& =\phi^{2}\left(\frac{\Delta h}{\Delta x}\right)_{\mathrm{F}}+\left(1-\phi^{2}\right)\left(\frac{\Delta h}{\Delta x}\right)_{\mathrm{G}} .
\end{aligned}
$$

Collecting terms containing $\phi$ gives the following:

$$
\left[\left(\frac{\Delta h}{\Delta x}\right)_{\mathrm{G}}-\left(\frac{\Delta h}{\Delta x}\right)_{\mathrm{F}}\right] \phi^{2}-\left[\left(\frac{\Delta h}{\Delta x}\right)_{\mathrm{G}}-\left(\frac{\Delta h}{\Delta x}\right)\right]=0 .
$$

Solving for $\phi$ gives the solution for an ice-stream centerline with side shear added to basal shear:

$\phi= \pm\left[\frac{C_{3}-C_{1}}{C_{3}-C_{2}}\right]^{1 / 2}$.

In Eqs. (31) and (35), the correct solution puts $\phi$ in the range $0 \leq \phi \leq 1$. 
Equation (29) includes $(\Delta h / \Delta x)_{\mathrm{F}}$ for floating fraction $\phi$ of ice in our model, linked to longitudinal strain rate $\dot{\varepsilon}_{x x}$ as incorporated into Eq. (28) using the flow law of ice when $\sigma_{\mathrm{T}}$ is given by Eq. (12). From Appendix E and Hughes (2012, chapter 12),

$$
\begin{aligned}
& \dot{\varepsilon}=\dot{\varepsilon}_{x x}=\left(\sigma_{\mathrm{T}} / 2 A\right)^{n}=\left[\left(\rho_{\mathrm{I}} g h_{\mathrm{I}} / 4 A\right)\left(1-\rho_{\mathrm{I}} / \rho_{\mathrm{W}}\right) \phi^{2}\right]^{n} \\
& =\left[\left(\rho_{\mathrm{I}} g h_{\mathrm{I}} / 4 A\right)\left(1-\rho_{\mathrm{I}} / \rho_{\mathrm{W}}\right)-\left(\sigma_{\mathrm{B}} / 2 A\right)\right]^{n} .
\end{aligned}
$$

Here $\sigma_{\mathrm{B}}$ is a back-stress due to buttressing by a confined and pinned ice shelf given by

$\sigma_{\mathrm{B}}=f_{\mathrm{B}}\left[1 / 2 \rho_{\mathrm{I}} g h_{0}\left(1-\rho_{\mathrm{I}} / \rho_{\mathrm{W}}\right)\right]$,

where $f_{\mathrm{B}}$ is a buttressing fraction with $f_{\mathrm{B}}=0$ for no buttressing and $f_{\mathrm{B}}=1$ for full buttressing.

Equations (31) and (35) allow two treatments for $\dot{\varepsilon}$ varying along $x$ for ice streams that supply ice shelves. One treatment emphasizes $\phi$ at $x>0$ :

$\dot{\varepsilon}=\left[\left(\rho_{\mathrm{I}} g h_{\mathrm{I}} / 4 A\right)\left(1-\rho_{\mathrm{I}} / \rho_{\mathrm{W}}\right) \phi^{2}\right]^{n}$,

with $\phi^{2}=\left[1-f_{\mathrm{B}}\left(h_{O} / h_{\mathrm{I}}\right)\right]$ at $x=0$ being a measure of iceshelf buttressing such that $\phi=1$ if the ice shelf has disintegrated so $f_{\mathrm{B}}=0$. If $\phi$ is replaced by ice-shelf buttressing at $x=0$, then Eq. (36) gives the other treatment with Eq. (37) substituted for $\sigma_{B}$ to emphasize $f_{\mathrm{B}}$ for buttressing at $x=0$ :

$\dot{\varepsilon}=\left[\left(\rho_{\mathrm{I}} g h_{\mathrm{I}} / 4 A\right)\left(1-\rho_{\mathrm{I}} / \rho_{\mathrm{W}}\right)\right]^{n}\left[1-f_{\mathrm{B}}\left(h_{0} / h_{\mathrm{I}}\right)\right]^{n}$.

Eq. (39) shows that ice-shelf buttressing, like $\phi$, is transmitted upstream. With either Eq. (38) or Eq. (39) substituted for $\dot{\varepsilon}$ in Eqs. (28) and (36), we see that $(\Delta h / \Delta x)_{F}$ varies with either $\phi^{6}$ or $\left[1-f_{\mathrm{B}}\left(h_{O} / h_{\mathrm{I}}\right)\right]^{3}$ for $n=3$. Both possibilities will be considered. In the case of Eq. (39), $f_{\mathrm{B}}$ in the range 0 $\leq f_{\mathrm{B}} \leq 1$ is chosen to conform with the observed $h_{O}$ at the ice-shelf grounding line because unbuttressing decreases $h_{O}$ over time due to enhanced ice-shelf thinning. When the ice shelf has disintegrated, $f_{\mathrm{B}}=0$ is expected. Eq. (39) should be compared with one used by Thomas (2004) in modeling the ongoing surge of Jakobshavn Isbrae following disintegration of its buttressing ice shelf in Jakobshavn Isfjord.

\section{Ice-bed uncoupling for shelf flow}

Our primary controlling variable for shelf flow is the unbuttressed fraction $\phi_{O}$ at the grounding line of floating ice. The ability of ice shelves to buttress ice streams was recognized early (Hughes, 1972, 1973; Thomas, 1973a, 1973b), but has only recently gained wide acceptance and spurred efforts at holistic ice sheet modeling, see Thomas (2004), Thomas et al. (2004), Dupont and Alley (2005, 2006), and Gagliardini et al. (2010) for numerical models, Schoof (2007) for a theoretical model, and Rignot et al. (2004), Scambos et al. (2004), and Pritchard et al. (2009) for field studies. One reason for the hesitation is illustrated in Fig. 5. Resistance to ice flow by basal drag is represented by the shaded part of the longitudinal gravitational driving force given by triangular area $\bar{P}_{\mathrm{I}} h_{\mathrm{I}}$ per unit flowband width $w_{\mathrm{I}}$. This shaded area vanishes when ice becomes afloat, leaving only water triangle 1 having area $\bar{P}_{\mathrm{W}} h_{\mathrm{W}}$ as the longitudinal force of water buttressing the ice. This is the case whether or not an ice shelf exists, so long as $\phi=1$ at $x=0$. However, side shear can exist for an ice shelf in a confining embayment, even if flowbands from ice streams that supply the ice shelf move with the velocity of shelf flow, so these flowbands have little or no side shear, as is generally observed for the large Antarctic ice shelves that buttress ice streams (Hughes, 1982,1983; Hulbe and Fahnestock, 2004).

\subsection{Stresses causing ice-shelf buttressing}

A freely floating ice shelf provides only water buttressing to supplying ice streams. The tensile pulling stress at the iceshelf grounding line is then given by Eq. (12) with $\phi=0$ and $h_{\mathrm{I}}=h_{0}$ so that, as shown in Appendix A:

$\sigma_{\mathrm{T}}=1 / 2 \rho_{\mathrm{I}} g h_{0}\left(1-\rho_{\mathrm{I}} / \rho_{\mathrm{W}}\right)$.

The closest approximation to keeping $h_{\mathrm{I}}=h_{O}$ everywhere on the ice shelf occurs if the ice shelf occupies a confining embayment and ice is locally pinned to the bed so ice rises (strong pinning) and ice rumples (weak pinning) develop on the ice surface. Then back-stress $\sigma_{B}$ buttresses the ice stream at the ice-shelf grounding line, where $\sigma_{B}$ is subtracted from $\sigma_{\mathrm{T}}$ given by Eq. (40):

$\sigma_{\mathrm{T}}=1 / 2 \rho_{\mathrm{I}} g h_{0}\left(1-\rho_{\mathrm{I}} / \rho_{\mathrm{W}}\right)-\sigma_{\mathrm{B}}$.

With this subtraction, solving Eq. (41) for $h_{0}$ gives the following:

$h_{0}=2\left(\sigma_{\mathrm{T}}+\sigma_{\mathrm{B}}\right) / \rho_{\mathrm{I}} g\left(1-\rho_{\mathrm{I}} / \rho_{\mathrm{W}}\right)$.

Eq. (42) shows that $h_{O}$ increases when $\sigma_{B}$ increases due to ice-shelf confinement and pinning, with $\sigma_{B}$ given by Eq. (37).

Ice-shelf buttressing of ice streams produces compressive stress $\sigma_{\mathrm{C}}$ given by Eq. (19) at the grounding line where $\phi=1, h_{\mathrm{I}}=h_{0}$, and $x=0$. Removing water-buttressing force $\left(\bar{P}_{\mathrm{W}} h_{\mathrm{W}}\right)_{O} w_{\mathrm{I}}=\bar{P}_{\mathrm{I}} h_{0}\left(\rho_{\mathrm{I}} / \rho_{\mathrm{W}}\right) w_{\mathrm{I}}$ gives the following:

$\left(\sigma_{\mathrm{B}}\right)_{O}=\left[\bar{\tau}_{O} A_{\mathrm{R}}+\bar{\tau}_{\mathrm{S}}\left(2 \bar{h}_{\mathrm{S}} L_{\mathrm{S}}+\bar{h}_{\mathrm{R}} C_{\mathrm{R}}\right)\right] / h_{0} w_{\mathrm{I}}$.

To quantify buttressing, unbuttressed fraction $\phi_{O}$ at $x=0$ is needed for ice shelves such that $\phi_{O}=1$ for freely floating ice beyond the grounding line (no buttressing) and $\phi_{O}=0$ when the entire ice shelf is fully enclosed or fully grounded (full buttressing). Ice-shelf buttressing can be quantified by 
Table 2. Quantifying the Jakobshavn Effect in a life-cycle classification for ice streams.

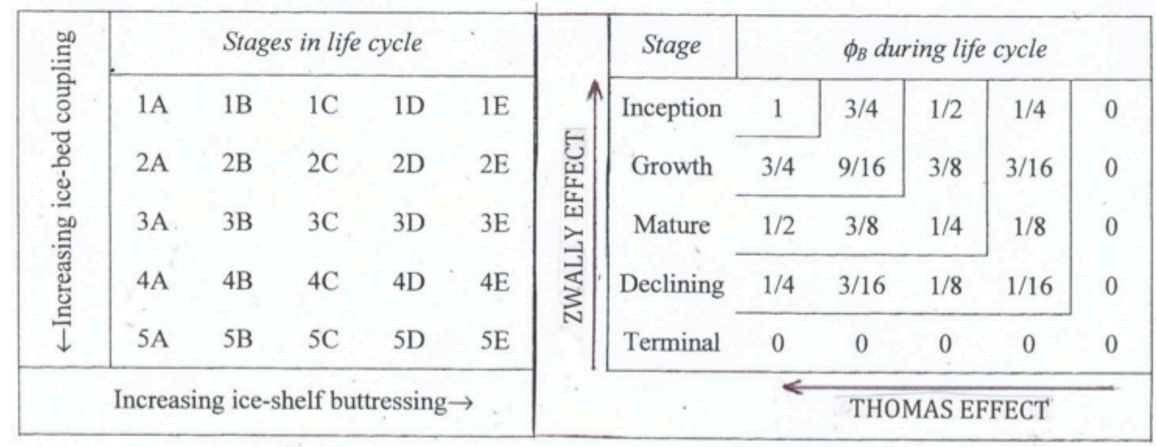

\begin{tabular}{|l|l|}
\hline $\begin{array}{l}\text { Basal buoyancy factor } \phi_{B}=\phi \phi_{O} \text { decreases from 1A to } 5 \mathrm{E} \text { defined as: } \\
\text { Increasing ice-bed coupling beneath an ice stream }\end{array}$ \\
$\begin{array}{ll}\text { ZWALLY } & \begin{array}{l}\text { 1. Full basal buoyancy along entire length }(\phi=1) . \\
\text { 2. Basal buoyancy slowly decreasing upstream. } \\
\text { 3. Basal buoyancy steadily decreasing upstream. } \\
\text { 4. Basal buoyancy rapidly decreasing upstream. } \\
\text { 5. No basal buoyancy along entire length }(\phi=0) .\end{array} \\
\text { Increasing ice-shelf buttressing beyond the ice stream } \\
\text { THOMAS }\end{array}$ & $\begin{array}{l}\text { A. No ice shelf or a freely floating ice shelf }\left(\phi_{O}=1\right) . \\
\text { B. Weak buttressing by a confined and pinned ice shelf. } \\
\text { C. Moderate buttressing by a confined and pinned ice shelf. } \\
\text { D. Strong buttressing by a confined and pinned ice shelf. } \\
\text { E. Full buttressing by a fully confined ice shelf or an ice lobe }\left(\phi_{O}=0\right) .\end{array}$ \\
\end{tabular}

applying Eq. (11) to the ice-shelf grounding line, now including $\sigma_{\mathrm{C}}$, which incorporates water buttressing:

$$
\begin{aligned}
& \left(\sigma_{\mathrm{T}}\right)_{O}=\left(\bar{P}_{\mathrm{I}}-\sigma_{\mathrm{C}}\right)_{O}=\left(\bar{P}_{\mathrm{I}}\right)_{O}- \\
& {\left[\bar{\tau}_{O} A_{\mathrm{R}}+\bar{\tau}_{\mathrm{S}}\left(2 \bar{h}_{\mathrm{S}} L_{\mathrm{S}}+\bar{h}_{\mathrm{R}} C_{\mathrm{R}}\right)+\left(\bar{P}_{\mathrm{W}} h_{\mathrm{W}}\right)_{O} w_{\mathrm{I}}\right] / h_{0} w_{\mathrm{I}}} \\
& =\left[\bar{P}_{\mathrm{I}}-\bar{P}_{\mathrm{W}}\left(\rho_{\mathrm{I}} / \rho_{\mathrm{W}}\right)\right]_{O} \\
& -\left[\bar{\tau}_{O} A_{\mathrm{R}}+\bar{\tau}_{\mathrm{S}}\left(2 \bar{h}_{\mathrm{S}} L_{\mathrm{S}}+\bar{h}_{\mathrm{R}} C_{\mathrm{R}}\right)\right] / h_{0} w_{\mathrm{I}} \\
& =\left(\bar{P}_{\mathrm{I}}\right)_{O}\left(1-\rho_{\mathrm{I}} / \rho_{\mathrm{W}}\right)-\left(\sigma_{\mathrm{B}}\right)_{O},
\end{aligned}
$$

where $\left(\sigma_{\mathrm{B}}\right)_{O}=0$ in the absence of a confining embayment and basal pinning points that impede pure shelf flow. Comparing Eq. (44) with Eq. (12) for $\phi=1$ at $x=0$ shows that compressive stress $\left(\sigma_{\mathrm{B}}\right)_{O}$ is a result of ice-shelf buttressing, as formulated by Thomas (1973a, b).

\subsection{The unbuttressed ice fraction at the grounding line}

Define an ice-shelf unbuttressed fraction $\phi_{O}$ at $x=0$ as follows:

$$
\begin{aligned}
& \left(\sigma_{\mathrm{T}}\right)_{O}=\left(\bar{P}_{\mathrm{I}}\right)_{O}\left(1-\rho_{\mathrm{I}} / \rho_{\mathrm{W}}\right)-\left(\sigma_{\mathrm{B}}\right)_{O} \\
& =\left(\bar{P}_{\mathrm{I}}\right)_{O}\left(1-\rho_{\mathrm{I}} / \rho_{\mathrm{W}}\right) \phi_{O}=\left(\sigma_{U}\right)_{O} \phi_{O},
\end{aligned}
$$

where $\left(\sigma_{U}\right)_{O}=\left(\bar{P}_{\mathrm{I}}\right)_{O}\left(1-\rho_{\mathrm{I}} / \rho_{\mathrm{W}}\right)$ is $\sigma_{\mathrm{T}}$ at $h_{\mathrm{I}}=h_{0}$ in Eq. (44) for an unconfined ice shelf that provides no buttressing from partial grounding. Solving Eq. (45) for $\phi_{O}$ :

$$
\begin{aligned}
& \phi_{O}=\frac{\left(\bar{P}_{\mathrm{I}}\right)_{O}\left(1-\rho_{\mathrm{I}} / \rho_{\mathrm{W}}\right)-\left(\sigma_{\mathrm{B}}\right)_{O}}{\left(\bar{P}_{\mathrm{I}}\right)_{O}\left(1-\rho_{\mathrm{I}} / \rho_{\mathrm{W}}\right)}=\frac{\left(\sigma_{U}\right)_{O}-\left(\sigma_{\mathrm{B}}\right)_{O}}{\left(\sigma_{U}\right)_{O}} \\
& =1-\left(\frac{\sigma_{\mathrm{B}}}{\sigma_{U}}\right)_{O} \cdot
\end{aligned}
$$

Equation (46) preserves in $\phi_{O}$ the definition of $\phi$ as a floating fraction. An ice shelf can be grounded along its sides in an embayment and locally where ice rises and ice rumples appear on the surface. The more of these grounded regions, the less "floating" is the ice shelf. Eq. (46) also suggests a basal buoyancy factor $\phi_{B}$ defined as:

$\phi_{B}=\phi \phi_{O}$, 
where $\phi$ represents the loss of ice-bed coupling under an ice stream as $\phi$ increases, and $\phi_{O}$ represents the loss of ice-shelf buttressing beyond the ice stream as $\phi_{O}$ increases (Hughes, 1992, 2011, 2012, chapter 25).

Table 2 links Eq. (47) to the life cycle of an ice stream, beginning with $\phi_{B}=\phi=\phi_{O}=1$ and ending with $\phi_{B}=\phi=$ $\phi_{O}=0$. Note that an ice stream shuts down when either $\phi$ or $\phi_{O}$ is zero, leaving only slow sheet flow. The point here is that ice-bed coupling is quantified by floating fraction $\phi$ at $x>0$ linked to longitudinal and shear stresses that resist stream flow, whereas ice-shelf buttressing is quantified by $\phi_{O}$ at $x=0$ linked to grounding ranging from a freely floating ice tongue to a fully confined ice shelf or a fully grounded ice lobe. Their product $\phi_{B}$ then quantifies coupling for sheet, stream, and shelf flow. Any path can be taken between $\phi_{B}=1$ and $\phi_{B}=0$, as well as paths that remain between these limits so no life cycle is completed. Two independent paths can complete a life cycle. One moves along the $\phi$ axis and represents increasing ice-bed coupling, called here the Zwally Effect (Zwally et al., 2002). The other moves along the $\phi_{O}$ axis and represents increasing ice-shelf buttressing, called here the Thomas Effect (Thomas, 2004). Their studies were made near and on Jakobshavn Isbrae, respectively, and contribute to the Jakobshavn Effect (Hughes, 1986). Movement along both axes quantifies the Jakobshavn Effect by $\phi_{B}=\phi \phi_{O}$.

Table 2 replaces a similar table in Hughes (1992). Both the Thomas and Zwally effects allow $\phi_{B}=0$ independently, as seen in Table 2. A proxy for the Zwally Effect occurred under Byrd Glacier in 2006-2007 when two large subglacial lakes upstream suddenly drained and temporarily reduced ice-bed coupling under Byrd Glacier by increasing $\phi$. The Thomas Effect occurred beyond Jakobshavn Isbrae in 2002 when its buttressing ice shelf suddenly disintegrated, thereby increasing $\phi_{O}$. Disintegration triggered the Zwally Effect under Jakobshavn Isbrae, which continues today. These events initiated life cycles that would end with $\phi_{B}=\phi \phi_{O}=0$ if they went to completion.

In Eqs. (31) and (35), from Appendix E, where $\dot{\varepsilon}=\dot{\varepsilon}_{x x}$ and ratio $R \approx 1$ when $\dot{\varepsilon}_{x x}$ exceeds other strain rates in an ice stream,

$$
\begin{aligned}
& C_{2}=\left(\frac{\Delta h}{\Delta x}\right)_{\mathrm{F}}=\frac{h_{\mathrm{I}}(a-r)-h_{\mathrm{I}}^{2} \dot{\varepsilon}}{h_{0} u_{O}+(a-r) x}=\frac{h_{\mathrm{I}}(a-r)-h_{\mathrm{I}}^{2} R\left(\sigma_{\mathrm{T}} / 2 A\right)^{n}}{h_{0} u_{O}+(a-r) x} \\
& =\frac{h_{\mathrm{I}}(a-r)}{h_{0} u_{O}+(a-r) x}-\frac{h_{\mathrm{I}}^{2} R}{h_{0} u_{O}+(a-r) x} \\
& \cdot\left[\frac{\rho_{\mathrm{I}} g h_{\mathrm{I}}\left(1-\rho_{\mathrm{I}} / \rho_{\mathrm{W}}\right) \phi^{2}}{4 A}\right]^{n} .
\end{aligned}
$$

For ice-shelf buttressing at $x=0$ where $h_{\mathrm{I}}=h_{O}$ and $\phi=$ $\phi_{O}$, Eq. (46) gives $\phi_{O}=\left(1-\sigma_{B} / \sigma_{U}\right)_{O}=1-f_{\mathrm{B}}\left(h_{O} / h_{\mathrm{I}}\right)$ from Eqs. (38) and (39). With these changes,

$$
\begin{aligned}
& C_{2}=\frac{h_{\mathrm{I}}(a-r)}{h_{0} u_{O}+(a-r) x}-\frac{h_{\mathrm{I}}^{2} R}{h_{0} u_{O}+(a-r) x} \\
& {\left[\frac{\rho_{\mathrm{I}} g h_{\mathrm{I}}\left(1-\rho_{\mathrm{I}} / \rho_{\mathrm{W}}\right)}{4 A}\left(1-\frac{\sigma_{\mathrm{B}}}{\sigma_{U}}\right)_{O}^{2}\right]^{n}=\frac{h_{\mathrm{I}}(a-r)}{h_{0} u_{O}+(a-r) x}} \\
& -\frac{h_{\mathrm{I}}^{2} R}{h_{0} u_{O}+(a-r) x}\left[\frac{\rho_{\mathrm{I}} g h_{\mathrm{I}}\left(1-\rho_{\mathrm{I}} / \rho_{\mathrm{W}}\right)}{4 A}\right]^{n}\left[1-f_{\mathrm{B}}\left(\frac{h_{0}}{h_{\mathrm{I}}}\right)\right]^{2 n} .
\end{aligned}
$$

For full ice-shelf buttressing, $f_{\mathrm{B}}=1$ and,

$$
\begin{aligned}
& C_{2}=\frac{h_{\mathrm{I}}(a-r)}{h_{0} u_{O}+(a-r) x} \\
& -\frac{h_{\mathrm{I}}^{2} R}{h_{0} u_{O}+(a-r) x}\left[\frac{\rho_{\mathrm{I}} g h_{\mathrm{I}}\left(1-\rho_{\mathrm{I}} / \rho_{\mathrm{W}}\right)}{4 A}\right]^{n}\left[1-\frac{h_{0}}{h_{\mathrm{I}}}\right]^{2 n} .
\end{aligned}
$$

For no ice-shelf buttressing, $f_{\mathrm{B}}=0$ and,

$$
\begin{aligned}
& C_{2}=\frac{h_{\mathrm{I}}(a-r)}{h_{0} u_{O}+(a-r) x} \\
& -\frac{h_{\mathrm{I}}^{2} R}{h_{0} u_{O}+(a-r) x}\left[\frac{\rho_{\mathrm{I}} g h_{\mathrm{I}}\left(1-\rho_{\mathrm{I}} / \rho_{\mathrm{W}}\right)}{4 A}\right]^{n} .
\end{aligned}
$$

Appendix E shows that $R=1$ is a good approximation. Appendix $\mathrm{C}$ shows that $h_{O} / h_{\mathrm{I}}=\phi$ when using only the force balance.

\section{Comparison with ice-sheet models based on standard continuum mechanics}

To emphasize the simplicity of our geometrical approach to holistic ice-sheet modeling, we now examine the complexity of standard models using continuum mechanics, one by Schoof and Hindmarsh (2010) and one by Pattyn (2003), showing how they treat ice-bed coupling.

A major problem with applying standard continuum mechanics to model ice-sheet dynamics is the aspect ratio, defined as the ratio of the thickness to the diameter of an ice sheet, which is typically in the range of $10^{-3}$. This is the case in our study, taking $\bar{h}_{\mathrm{I}} / 2 L$ for distance $L$ from the iceshelf grounding line to the interior ice divide, see Fig. 7, and $\bar{h}_{\mathrm{S}} / L_{\mathrm{S}}$ for the ice shelf, see Fig. 5 . The other major problem is treating slip vs. no slip at the bed. Slip is defined as a combination of localized yielding of soft temperate ice just above the bed, sliding of this ice over the bed, and shear deformation of till dilated by water between the bed and bedrock. No slip is defined as deformation confined to overlying ice because cold basal ice is frozen to the bed and any underlying till is immobilized because it is a rigid composite of rock fragments cemented by cold ice. We compare our holistic model for continuous transitions from sheet to stream to shelf flow shown in Fig. 5, using the geometrical force balance between gravitational and resisting forces for ice streams, with the approach taken by Schoof and Hindmarsh (2010) for treating the aspect ratio and basal slip in ice-sheet models based on continuum mechanics. 


\subsection{Ice-bed uncoupling treated by Schoof and Hindmarsh}

Schoof and Hindmarsh (2010) recognize including the aspect ratio and boundary slip are two problems common in deforming systems, citing flow of ice in ice sheets, flow of lava over the land, and flow of mucus in our lungs as examples. They call these "thin films" having "wall slip" at the slip/no-slip interface. The thin film thins and spreads rapidly when slip replaces no-slip at the wall, the wall being the bed for an ice sheet, with frictionless slip for spreading of a floating ice shelf and no slip for spreading of an interior ice dome frozen to its bed. Since ice streams are the major dynamic link between ice domes and ice shelves of an ice sheet, an adequate slip/no-slip criterion should describe the dynamics of holistic transitions from sheet to stream to shelf flow in ice-sheet models based on continuum mechanics.

Schoof and Hindmarsh (2010) employ the same Cartesian coordinate system we use, with $x$ horizontal and $z$ vertical. They use actual bed topography, not the up-down staircase we use to approximate bed topography, so their basal sliding velocity $u_{t}=\boldsymbol{u} \cdot \boldsymbol{t}$ parallels the bed, which has unit normal and tangent vectors $\boldsymbol{n}$ and $\boldsymbol{t}$, respectively. Their velocity vector $\boldsymbol{u}=(u, v)$ has component $u$ along $x$ and component $v$ along $z$. Boundary conditions are $z=h(x, t)$ at the top surface and $z=b(x)$ at the bed, where $u_{x}+v_{z}=0$ for mass conversation when no flow is allowed in the transverse $y$ direction. For two-dimensional flow confined to the $x, z$ plane, the deviatoric stress tensor $\tau$ is the following:

$\boldsymbol{\tau}=\left(\begin{array}{cc}\tau_{1} & \tau_{2} \\ \tau_{2} & -\tau_{1}\end{array}\right)=\left(\begin{array}{cc}\left(\sigma_{x x}-p\right) & \sigma_{x z} \\ \sigma_{z x} & \left(\sigma_{z z}-p\right)\end{array}\right)$

Taking $i=1,2$ and $j=x, z$, the force balance for stresses $\tau_{i, j}=\partial \tau_{i} / \partial j$ and pressure gradients $p_{j}=\partial p / \partial j$ is given by the Stokes equations:

$\tau_{1, x}+\tau_{2, z}-p_{x}=0$

$-\tau_{1, z}+\tau_{2, x}-p_{z}-\rho_{\mathrm{I}} g=0$.

The constitutive equations based on a power-law rheology for creep in ice are the following:

$u_{x}=A\left(\tau_{1}^{2}+\tau_{2}^{2}\right)^{(n-1) / 2} \tau_{1}$

$u_{z}+v_{x}=2 A\left(\tau_{1}^{2}+\tau_{2}^{2}\right)^{(n-1) / 2} \tau_{2}$,

where $u_{x}=\partial u / \partial x, u_{z}=\partial u / \partial z$, and $v_{z}=\partial v / \partial z$ are strain rates, and $A$ and $n$ are positive constants in the flow law defined by Paterson (1994).

Schoof and Hindmarsh (2010) then use a length scale $[x]$ and a thickness scale $[h]$ to define scales for time $[t]$, velocities $[u]$ and $[v]$, and stresses $\left[\tau_{1}\right]$ and $\left[\tau_{2}\right]$ through the scale relations:

$$
\begin{aligned}
& {\left[\tau_{2}\right]=\rho_{\mathrm{I}} g[h]^{2} /[x]} \\
& C[u]^{m}=\left[\tau_{2}\right] \\
& {[u] /[x]=A\left[\tau_{1}\right]^{n}} \\
& {[v] /[h]=[u] /[x]} \\
& {[t]=[x] /[u] .}
\end{aligned}
$$

They then define an aspect ratio $\varepsilon$ and a stress ratio $\lambda$ as follows:

$\varepsilon=[g] /[x]$

$\lambda=\left[\tau_{2}\right] /\left[\tau_{1}\right]$.

The power-law rheology using $\left[u_{d}\right]$ as a scale for vertical shear in ice is then:

$\left[u_{d}\right]=A\left[\tau_{2}\right]^{n}[h]$.

Now $\lambda$ can be related to slip ratio $\left[u_{d}\right] /[u]$ as follows, which includes both $\lambda$ and $\varepsilon$ :

$\left[u_{d}\right] /[u]=\lambda^{n} \varepsilon$.

Schoof and Hindmarsh (2010) then proceed to show how $\lambda$ allows smooth transitions between slip and no slip at the bed that provide holistic transitions from sheet flow to stream flow to shelf flow, where $\lambda$ varies from $\lambda \ll 1$ for slip and $\lambda \gg 1$ for no slip. Vertical shear distributed through the ice thickness accompanies basal sliding when $\lambda \sim 1$.

Our variables are thawed bed fraction $f$ given by Eq. (3) for sheet flow, floating ice fraction $\phi$ given by Eq. (10) for stream flow, and unbuttressed ice fraction $\phi_{O}$ given by Eq. (46) for shelf flow. Since $\lambda$ is a ratio of stresses, with $\lambda \gg 1$ for sheet flow, $\lambda \sim 1$ for stream flow, and $\lambda \ll 1$ for shelf flow, comparisons with results from Schoof and Hindmarsh (2010) should also relate $f, \phi$, and $\phi_{O}$ to stress or pressure ratios. For sheet flow,

$\lambda_{\mathrm{f}}=\frac{1}{f}$,

where $\lambda_{\mathrm{f}} \gg 1$ when $f \ll 1$ for no slip on a frozen bed and $\lambda_{\mathrm{f}}=1$ when $f=1$ when a thawed bed allows slip. For stream flow,

$\lambda_{\phi}=1-\phi$,

where $\lambda_{\phi} \ll 1$ when $\phi \rightarrow 1$ and, and $\lambda_{\phi}=1$ when $\phi=0$. For shelf flow,

$\lambda_{O}=1-\phi_{O}$,

where $\lambda_{O}=0$ when $\phi_{O}=1$ for a freely floating ice shelf and $\lambda_{O} \rightarrow 1$ when $\phi_{O} \rightarrow 0$ for a strongly buttressing ice shelf. It is beyond the scope of our study to make these comparisons for Byrd Glacier and Jakobshavn Isbrae. 


\subsection{Ice-bed uncoupling treated by Pattyn}

We can also compare our approach with the model based on continuum mechanics by Pattyn (2003). He presents a threedimensional thermomechanical ice sheet model for the following experiments: (A) solving the momentum and mass balance equations for an isothermal ice sheet on a flat horizontal bed, (B) computing ice temperature variations by also solving the energy balance equations for this ice sheet, (C) applying the model when the ice sheet spreads over sinusoidal undulating bed topography, (D) including an ice stream that develops halfway toward the ice-sheet margin, and (E) allowing the ice sheet to cross an elongated subglacial lake.

Pattyn (2003) presents a clear description of how conservation of momentum, mass, and energy are incorporated into his model using continuum mechanics. When reduced to two dimensions in the $x, z$ plane, his results can be compared directly with results from our holistic approach. For sheet flow in his experiment $\mathrm{A}$, he includes the longitudinal stress at the ice divide which we ignore, so his ice divide is slightly lower. Our approach allows any distribution of frozen and thawed patches on the bed, quantified as thawed fraction $f$, with a lower yield stress for ice and basal till where the bed is thawed. His thawed fraction is output, ours is input based on ice elevations above the bed as the primary measured expression of ice-bed coupling.

For sheet flow in his experiment B, Pattyn (2003) allows surface lowering when a frozen bed becomes thawed, but he allows only basal melting, not basal freezing when the bed is a mosaic of thawed and frozen patches. We also allow basal melting, which is progressive because ice-stream tributaries in Fig. 1 converge on ice streams so an initially frozen bed at the ice divide is wholly thawed at the heads of ice streams. Pattyn (2003) reduces basal drag as a frozen bed thaws, but he does not invoke "laws" for basal sliding and/or deformation of basal till. We also reduce basal drag without invoking such "laws" since they are poorly known. Instead, we invoke two yield criteria. Our critical strain rate criterion specifies a higher yield stress when a critical strain rate is reached in cold ice. Our critical yield stress criterion specifies a lower yield stress in temperate ice and wet till when the change in effective stress $\sigma$ with effective strain rate $\dot{\varepsilon}$ is most rapid. Both criteria apply for $n=3$ in our Eq. (4), see our Fig. 2. Our higher yield stress is attained using the critical yield stress criterion when $n=8$ in temperate ice and wet till.

Sheet flow over a uniformly undulating bed is treated by Pattyn (2003) in his experiment C, allowing frozen patches over hills and thawed patches over hollows. This becomes sheet flow over a sinusoidal bed in the $x$ direction with flow confined to the $x, z$ plane. A Fourier series can convert his bed to our up-down staircase for a direct comparison. Pattyn's treatment includes stress gradients we avoid by ignoring $\partial \phi / \partial x$. His results show how stress gradients contribute to the force balance. Our approach fails when bed slopes ex- ceed 30 degrees. Pattyn shows the actual bed should be used. That would add considerable mathematics to our simple approach.

Stream flow treated by Pattyn (2003) in his experiment D does not include basal drag. When ignoring transverse flow, his model allows only longitudinal stresses and side drag to provide resistance to gravitational flow. He shows how the longitudinal stress "pulls" upstream ice and "pushes" downstream ice, just as we show in our holistic approach. We also allow basal drag, and link all these stresses to our "floating fraction" $\phi$ of ice, see our Figs. 4 and 6. As a result, our ice streams are less flat and have smoother transitions with sheet flow and shelf flow.

Pattyn (2003) does not treat shelf flow as such, but his experiment $\mathrm{E}$ for sheet flow over an elongated subglacial lake allows a comparison with liner shelf flow in our approach. He allows no basal drag over his lake, which is elongated in the $x$ direction when flow is confined to the $x, z$ plane. His subglacial lake would be equivalent to our linear ice shelf when it is grounded around its entire perimeter. This occurs when side drag exists along the entire length of our ice shelf in Fig. 5, and basal drag at the calving front produces ice rumples. In this case, our pulling stress $\sigma_{U}$ is close to our buttressing stress $\sigma_{\mathrm{B}}$ at the ice-shelf grounding line in Eq. (46), see our Fig. 5 , so $\phi_{O} \simeq 0$. Our ice streams attain a maximum velocity when they enter an ice shelf because both basal and side drag vanish. But then buttressing due to basal and side drag on the ice shelf slows flow before flow increases with reduced buttressing as ice nears the calving front. This behavior is observed for both Byrd Glacier and Jakobshavn Isbrae.

\section{Ice-bed uncoupling for Byrd Glacier}

Some ice-bed uncoupling took place under Byrd Glacier when two subglacial lakes in the zone of strongly converging flow just above Byrd Glacier drained rapidly in 20062007, causing the velocity of Byrd Glacier to increase by $10 \%$, as reported by Stearns et al. (2008). We applied our holistic steady-state model before and after this event, using a flowband the width of Byrd Glacier and a flowline along the center of the flowband.

Figure 8 is a satellite image of Byrd Glacier showing the centerline along which the surface and bed topography and ice thickness were mapped using airborne radio-echo sounding, which also located the probable (un)grounding line, see Fig. 9. The array of all radar flight lines and the two subglacial lakes are shown in Fig. 10. From these flight lines, the Center for Remote Sensing of Ice Sheets (CReSIS) at the University of Kansas mapped surface and bed topography in the map plane (Gogineni et al., 2014). We calculated floating fraction $\phi$ along the centerline. Byrd Glacier occupies Barne Inlet, a fjord through the Transantarctic Mountains. The largest ice catchment area of any Antarctic ice 


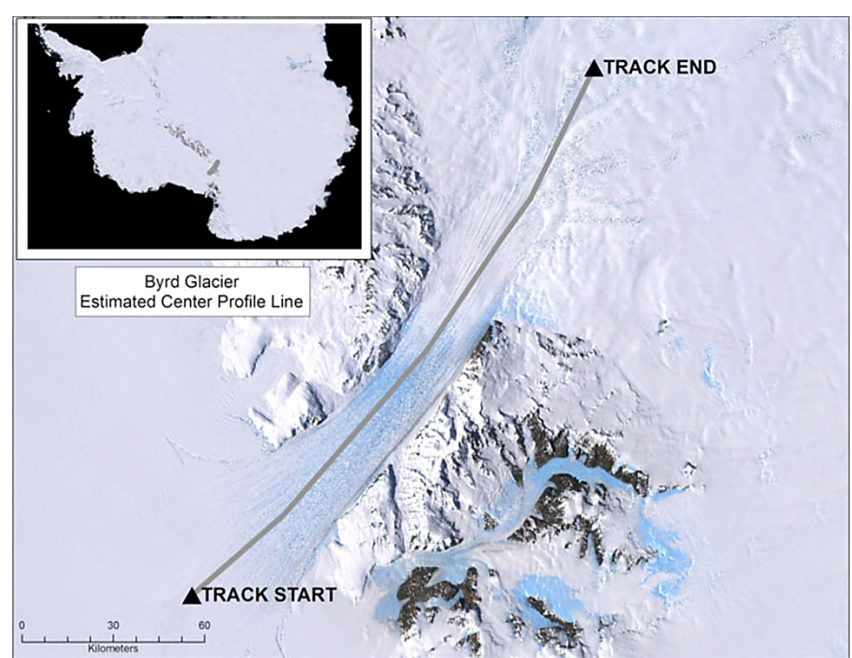

Figure 8. A satellite image of Byrd Glacier showing the centerline along which the ice surface, base, and thickness were determined by radar sounding. The inset locates Byrd Glacier supplying the Ross Ice Shelf in Antarctica.
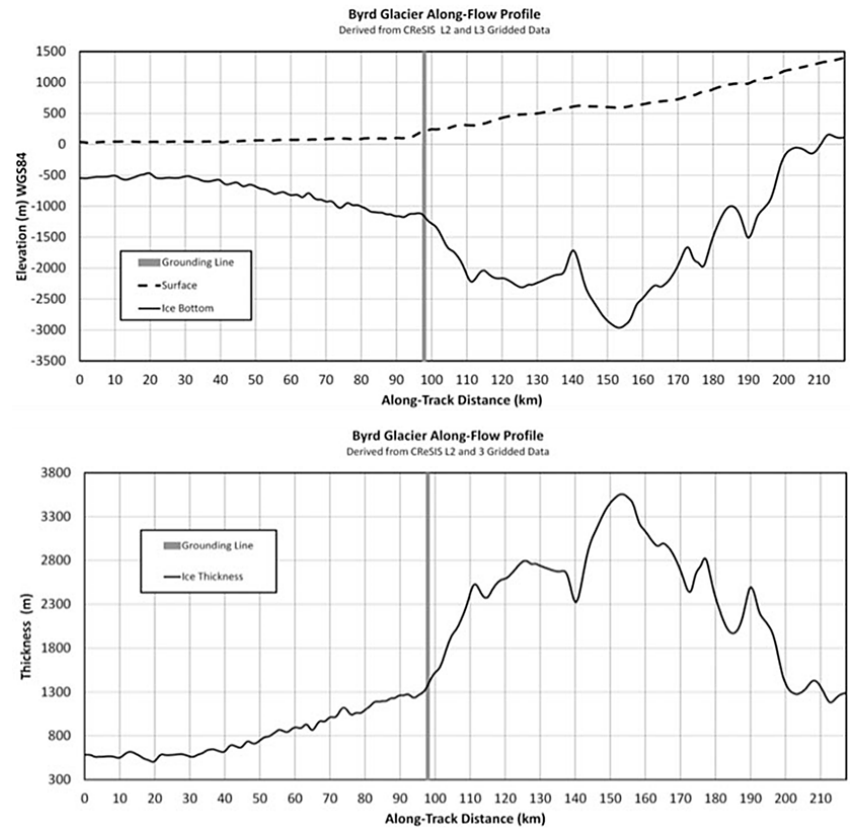

Figure 9. Surface, base, and thickness radar profiles down the centerline of Byrd Glacier shown in Fig. 8. The vertical line separates grounded ice (right) from floating ice (left) where the flotation criterion is still approximately satisfied nearly $100 \mathrm{~km}$ from the track start in Fig. 8. Top: Ice surface (dashed line) and ice base (solid line). Bottom: Ice thickness.

stream is drained by Byrd Glacier, and it supplies the Ross Ice Shelf with more ice than any other ice stream. It becomes ungrounded in the fjord and moves much faster than the adjacent ice shelf, so giant rifts separate it from the ice shelf for some $40 \mathrm{~km}$ beyond the fjord until the rifts close.

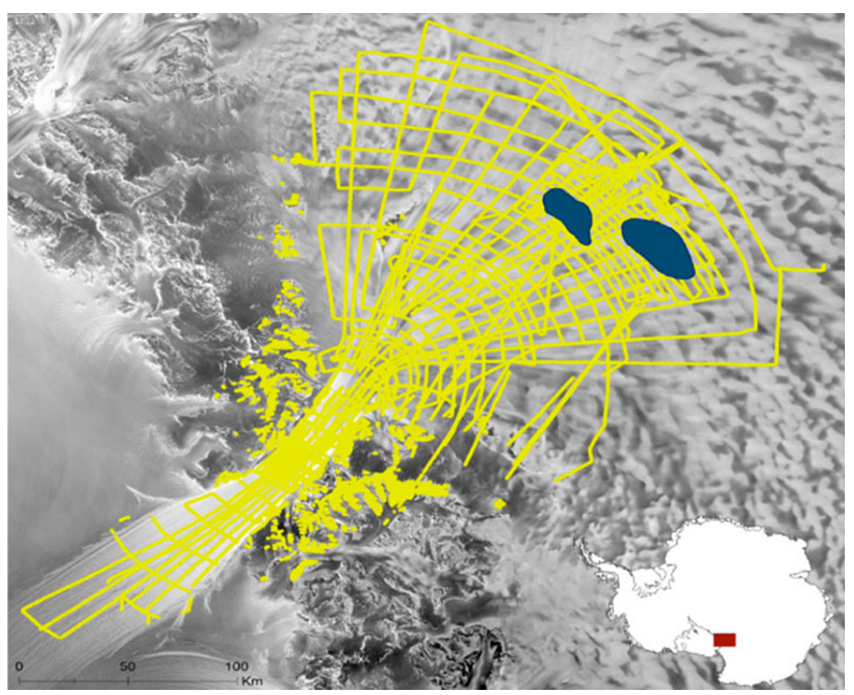

Figure 10. A map showing Byrd Glacier in relation to the two subglacial lakes that drained suddenly in 2006-2007. The lakes are green. Radar flight lines are in yellow, with the fan of flight lines flown along ice flowlines. The inset map locates this region of Antarctica as the red rectangle. Map provided by Leigh Stearns.

Then, the Byrd Glacier flowband moves with the same velocity as the ice shelf. Surface velocities on Byrd Glacier were first measured by Swithinbank (1963) across the floating portion in the fjord. Surface velocities and elevations were measured photogrammetrically over the whole surface by Brecher (1982).

The first attempt to model Byrd Glacier employed plasticity theory, with sheet flow converging on the fjord treated as extrusion through a rigid die, stream flow in the fjord treated as compression between rigid parallel plates, and diverging flow leaving the fjord treated as indentation by a rigid flat die (Hughes, 1977). The stress field as lateral rifts open when Byrd Glacier punches into the Ross Ice Shelf was analyzed using a finite-element model in the map plane controlled by plane stress modeling and surface velocity measurements (Zhao, 1990). In 1979, Charles Swithinbank provided radar surface-and-bed profiles near the centerline of Byrd Glacier that allowed attempts to model basal conditions. Whillans et al. (1989) and Scofield et al. (1991) obtained a bed having frozen and thawed patches. Reusch and Hughes (2003) and Hughes et al. (2011) obtained a bed having grounded and floating patches. Van der Veen et al. (2014) modeled Byrd Glacier using CReSIS bed topography in the map plane to obtain a largely thawed bed. Using the same force budget approach to calculate stresses resisting gravitational flow for Swithinbank's profiles, Van der Veen (1999, chapter 3) concluded the bed was frozen everywhere.

In recent years, subglacial lakes were found to be ubiquitous under the Antarctic Ice Sheet (Smith et al., 2009), and were often interconnected, allowing ice tributaries to form and supply major ice streams that discharge about $90 \%$ of 
Antarctic ice (Rignot et al., 2011). Two such lakes, shown in Fig. 10, were located about $200 \mathrm{~km}$ inland from Barne Inlet. The peak water discharge from late 2006 to early 2007 was measured by lowered ICESat surface elevations, and coincided with a $10 \%$ increase in velocity of Byrd Glacier along its whole length, jumping to $900 \mathrm{~m} \mathrm{a}^{-1}$ where Byrd Glacier became afloat in Barne Inlet (Stearns et al., 2008). Since then the lakes have been refilling.

Lake-drainage coincident with velocity increases can be linked to reductions in ice-bed coupling under Byrd Glacier caused by an increase in floating fraction $\phi$ of ice when lake water flooded through Barne Inlet to the Ross Sea under the Ross Ice Shelf. Increases in $\phi$ can be calculated from Eq. (31) using width $w_{\text {I }}$ of Byrd Glacier when side shear along the fjord walls is included, and from Eq. (35) along the centerline of Byrd Glacier where side shear is incorporated into basal shear. Data used to evaluate $\mathrm{C}_{1}$ are measured ice surface slopes $\Delta h / \Delta x$ in incremental distances $\Delta x$ along $x$, with $x=0$ where Byrd Glacier becomes afloat about $25 \mathrm{~km}$ from the entrance to Barne Inlet. Evaluations of $C_{2}$ for $(\Delta h / \Delta x)_{\mathrm{F}}$ use estimated values of $(a-r)=23 \times 10^{-3} \mathrm{~m} \mathrm{a}^{-1}$ averaged along $x$ (Hughes et al., 2011), and measured values of $h_{0}$ where ice becomes afloat, $x=0$ in Eqs. (31) and (35), and $\dot{\varepsilon}_{x x}$ along $x$ in 1978-1979 (Whillans et al., 1989). Here $\dot{\varepsilon}_{x x}$ can be calculated using either the $\phi$ or the $f_{\mathrm{B}}$ dependence of $\dot{\varepsilon}_{x x}$ in Eq. (36). We used the $f_{\mathrm{B}}$ dependence with $f_{\mathrm{B}}$ related to $\sigma_{\mathrm{B}}$ by Eq. (37). We took $\rho_{\mathrm{I}}=917 \mathrm{~kg} \mathrm{~m}^{-3}, \rho_{W}=1000 \mathrm{~kg} \mathrm{~m}^{-3}$, $g=9.81 \mathrm{~m} \mathrm{~s}^{-1}, A=250 \mathrm{MPa} \mathrm{s}^{1 / 3}=7.9$ bar a $^{1 / 3} \approx 8$ bar a $^{1 / 3}$, $n=3$, and measured values of $h_{\mathrm{I}}$ along $x$ in Fig. 9 (Hughes et al., 2011), with $\sigma_{\mathrm{B}}=1 / 2 \rho_{\mathrm{I}} g h_{0}\left(1-\rho_{\mathrm{I}} / \rho_{\mathrm{W}}\right)$ for $\phi=1$ at $x=0$ for full buttressing by the Ross Ice Shelf. Then $\dot{\varepsilon}_{x x}=0$ at $x=0$ as observed (Brecher, 1982; Whillans et al., 1989). Evaluations of $C_{3}$ for $(\Delta h / \Delta x)_{\mathrm{G}}$ use $B=1.123 \times 10^{4} \mathrm{kPa} \mathrm{s}^{1 / 2} \mathrm{~m}^{-1 / 2}=0.02$ bara $^{1 / 2} \mathrm{~m}^{-1 / 2}, m=$ $2, L=1250 \mathrm{~km}, h_{0}=1.3 \mathrm{~km}$ at $x=0$, and measured values of $h_{\mathrm{I}}$ along $x$ (Hughes et al., 2011), see Eq. (26) with $h_{\mathrm{I}}$ measured by radar sounding along $x$ for Byrd Glacier (Gogineni et al., 2014).

Figure 11 plots $\phi$ along $x$ using Eq. (31) for width $w_{\mathrm{I}}=25 \mathrm{~km}$ across Byrd Glacier with side shear along the fjord walls, using Eq. (35) for the centerline of Byrd Glacier with side shear incorporated into basal shear, both equations combining the force balance with the mass balance, and also using Eq. (24) obtained from the force balance only. Values of $\phi$ using $A=8.0$ bar a $^{1 / 3}$ drop rapidly to 0.10 from hovering around 0.80 with side shear and around 0.95 with side shear incorporated into basal shear (from Eqs. (31) and (35), respectively) both at about $50 \mathrm{~km}$ from $x=0$ at the beginning of the radar profile in Figs. 8 and 9. This is the shortest distance where floating ice may have become grounded. From there on, $\phi=0.10 \pm 0.05$ for mostly grounded ice.

A floating-ice requirement at the beginning of the radar profile can be enforced by setting $\phi=1.0$ at $x=0$ and solving for ice hardness parameter $A$ in Equations (31) and (35).

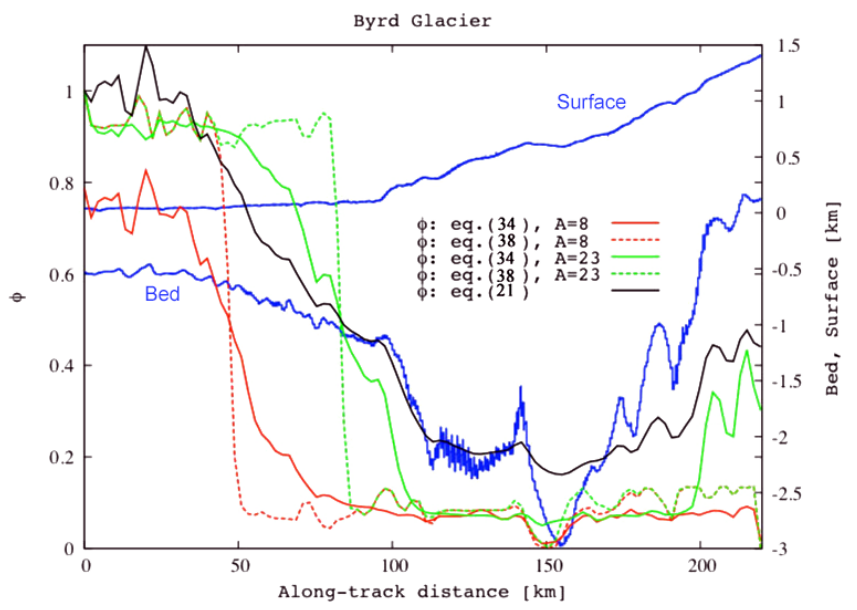

Figure 11. Plots of floating fraction $\phi$ of ice along Byrd Glacier obtained from Equations (31), (35), and (24), originally 34, 38, and 21 . Blue lines are the top and bottom surfaces of Byrd Glacier for both grounded and floating ice. Variations of $\phi$ along $x$ are from Eq. (31) for a flowband the width of Byrd Glacier with side shear and from Eq. (35) for the central flowline with side shear incorporated into basal shear. The two plots cross for values of hardness parameter $A$ that locate grounding lines at about 50 and $80 \mathrm{~km}$ from the beginning of the radar profile. Both locations satisfy the flotation criterion for locating the ungrounding line of Byrd Glacier. The higher value of $A$ puts $\phi$ closer to $\phi=1$ required for fully floating ice. Equations (31) and (35) use both the force balance and the mass balance. The $\phi$ plot for Eq. (24) uses only the force balance. All $\phi$ plots are compatible with an ungrounding line 40 to $80 \mathrm{~km}$ from the beginning of the radar flight line in Fig. 8.

Then $A=23$ bar a $^{1 / 3}$ and floating ice grounds about $90 \mathrm{~km}$ from $x=0$, see Fig. 9. Ice elevation then increases all the way up Byrd Glacier, as is expected for increasing ice-bed coupling. This is reflected in $\phi=0.15 \pm 0.5$ under most of Byrd Glacier. In all cases, $\phi \rightarrow 0$ at a bedrock low point about halfway up the fjord $(x \approx 150 \mathrm{~km})$, where surface slope is negative (ice does not flow uphill; we flattened this section to make $\phi \rightarrow 0$ ). Variations in $\phi$ have no obvious correlation with bed topography, but peaks in $\phi$ have some correlation with more gentle surface slopes, which is compatible with reduced ice-bed coupling. Values of $\phi$ were smoothed using the Bezier method because $\phi$ is sensitive to variations in surface slopes not directly related to ice-bed coupling, such as ablation rates related to variations in the solar angle with the ice surface (Hughes, 1975) and variable katabatic winds that cause variable ablation rates. Alternatively, we could have smoothed the ice surface using a running mean for surface slopes.

Variations of $\phi$ in Fig. 11 suggest two locations for the grounding line of floating ice in Byrd Glacier fjord. One is where ice is $1100 \mathrm{~m}$ thick about $90 \mathrm{~km}$ from the start of the radar profiles and near where the $\phi$ plots cross. We calculated $\phi$ variations using $A=23$ bar a ${ }^{1 / 3}$. The other one is where ice is $750 \mathrm{~m}$ thick about $50 \mathrm{~km}$ from the start of 
the profiles. We calculated $\phi$ variations using $A=8 \mathrm{bara}^{1 / 3}$. Both locations satisfy the buoyancy requirement for floating ice. Nearly tripling $A$ makes ice too stiff, but apparently stiffer ice would also be produced by strong buttressing from the Ross Ice Shelf, which is the case since $\dot{\varepsilon}_{x x} \approx 0$ over the $40 \mathrm{~km}$ between these two possible grounding lines. In 19781979, daily tidal elevation changes at the ice surface obtained by surveying vertical angles from the north fjord sidewall showed the grounding line was actually a zone between the 80 and $90 \mathrm{~km}$ locations at that time (Hughes and Fastook, 1981). There are no other data to document migrations of the ice-shelf grounding line for Byrd Glacier from 19781979 to 2006-2007 when the subglacial lakes drained and the grounding line was close to the $50 \mathrm{~km}$ location (Stearns et al., 2008).

The threefold increase in $A$ causes a very sharp reduction of $\dot{\varepsilon}_{x x}$ in Eq. (36). Indeed, Brecher (1982) found that $\dot{\varepsilon}_{x x} \approx 0$ at $x \approx 80 \mathrm{~km}$, which is close to the grounding line for floating ice in both Eqs. (31) and (35) with and without side shear, respectively. This is possible if extending stress $\sigma_{\mathrm{T}}$ for unbuttressed ice is 5.5 bars for ice $1100 \mathrm{~m}$ thick and 3.8 bars for ice $750 \mathrm{~m}$ thick in Eq. (48), so keeping $\dot{\varepsilon}_{x x} \approx 0$ in this region requires that $\sigma_{\mathrm{T}}$ in Eq. (40) is nearly balanced by buttressing back-stress $\sigma_{\mathrm{B}}$ in Eq. (41). Then $A$ can remain at 8 bar a $^{1 / 3}$ if some grounding between $1100 \mathrm{~m}$ at $x=90 \mathrm{~km}$ and $750 \mathrm{~m}$ at $x=50 \mathrm{~km}$ keeps $\phi$ around 0.8 instead of 1.0 or if buttressing by the Ross Ice Shelf is nearly total.

Thomas and MacAyeal (1982) calculated buttressing back-forces on the Ross Ice Shelf using data from the Ross Ice Shelf Geophysical and Glaciological Survey (RIGGS). Although their data did not include the floating part of Byrd Glacier, R. H. Thomas (personal communication, 16 March 2013) calculated that $\sigma_{\mathrm{B}} \approx 4.7$ bars if $h_{0}=1100 \mathrm{~m}$ at the grounding line and $\sigma_{B} \approx 3.0$ bars if $h_{0}=750 \mathrm{~m}$ at the grounding line. His results are close enough to ours for us to conclude Byrd Glacier is almost fully buttressed by the Ross Ice Shelf because we find $\phi_{O}$ to be very small. Putting $\phi_{O}=$ 0 in Eq. (46) delivers $\sigma_{U} \simeq \sigma_{\mathrm{B}}$, so $\sigma_{\mathrm{T}}+\sigma_{\mathrm{B}} \simeq 2 \sigma_{\mathrm{B}}$ in Eq. (42) for $h_{0}$ either $1100 \mathrm{~m}$ or $750 \mathrm{~m}$ at the ice-shelf grounding line, making $\phi_{B}=\phi \phi_{O}=0$ in Eq. (47). These conditions on the Ross Ice Shelf are largely satisfied in the vicinity of Byrd Glacier, since the grounded length between outlet glaciers consists of many inlets along the Transantarctic Mountains that make the grounded coastline look like fitted pieces of a jigsaw puzzle. The ice shelf is therefore firmly locked to the coastline. Some outlet glaciers assist Byrd Glacier in pushing the ice shelf forward. But the flowbands from six large ice streams draining West Antarctica curve sharply northward toward the calving front. This introduces bending stresses that resist shelf flow, as analyzed by Hughes (1982, 1983). These features require modeling dynamics of the Ross Ice Shelf in the map plane, with discharge from all ice streams and outlet glaciers included, as was done in the pioneering finite-element analysis by Thomas and MacAyeal (1982), and subsequently by Hulbe and Fahnstock (2004). We used

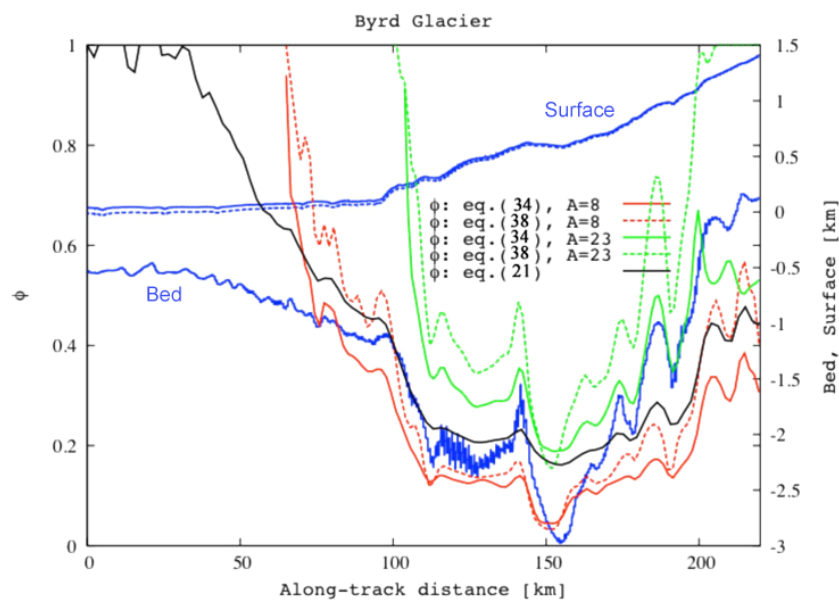

Figure 12. Plots of floating fraction $\phi$ along Byrd Glacier if the discharge of lake water had been sustained. Equations (31), (35), and (24), originally 34,38 , and 21 , are solved for $\phi$ when ice thickness is reduced linearly from 0 to $10 \%$ along Byrd Glacier to accommodate the $10 \%$ increase in ice velocity at the ungrounding line while the two subglacial lakes in Fig. 10 were draining. This thinning did not take place in real time, but it would have if the faster ice discharge rate of ice were sustained over time, with a corresponding reduction in ice-bed coupling. Note how the choice of $A$ affects the position of the ungrounding line. Blue lines are the top and bottom surfaces of Byrd Glacier. The "bed" includes floating basal ice. Including side shear, Eq. (31), reduces $\phi$.

their study to obtain a buttressing back stress after Byrd Glacier leaves Barne Inlet and merges fully with the Ross Ice Shelf, before the lateral rifts (40 km long) close (Zhao, 1990).

Drainage of the two subglacial lakes reported by Stearns et al. (2008) was accompanied by a $10 \%$ increase in the discharge velocity of ice across the ungrounding line of Byrd Glacier. For mass-balance continuity, this would require a $10 \%$ reduction in ice thickness over time and a corresponding retreat of the ice-shelf grounding line up Barne Inlet. Initially, the grounding line should advance because ice having the present thickness would be moving $10 \%$ faster. Stearns et al. (2008) reported the grounding line in 2006-2007 was about $40 \mathrm{~km}$ beyond the grounding line in 1977-1978 reported by Hughes and Fastook (1911). No data were obtained to measure ice-thickness changes. If eventual ice thinning increases linearly along Byrd Glacier to $10 \%$ at the ungrounding line, the variation of $\phi$ along $x$ is doubled or tripled, as shown in Fig. 12 using Eq. (29), which includes side shear against the fjord walls, and Eq. (34) for the centerline with side shear incorporated into basal shear, leading to Equations (31) and (35), respectively, with $\mathrm{C}_{2}$ given by Eq. (50) for full ice-shelf buttressing. Thinning did not happen, of course, because the discharged subglacial water crossed the ungrounding line before the ice surface could lower to accommodate the temporary reduction in ice-bed coupling. 
Figures 11 and 12 also plots $\phi$ variations along $x$ using Eq. (24) obtained only from the force balance. For the first $35 \mathrm{~km}, \phi=1.0 \pm 0.1$ before it decreases sharply along $x$, with $\phi$ increasing slightly along $x$ due to surface lowering by $10 \%$. This increase is within the $10 \%$ uncertainty in $\phi$, but the trend of the increase is the same before and after thinning, so it may be real. This is consistent with a grounding line close to $40 \mathrm{~km}$. By excluding the mass balance, $\phi$ does not reach the low values in Fig. 11 obtained by including the mass balance, and generally lies between these values in Fig. 12 given by Eqs. (31) and (35).

\section{Ice-shelf unbuttressing for Jakobshavn Isbrae}

Jakobshavn Isbrae drains 5 to $7 \%$ of the Greenland Ice Sheet (Bindschadler, 1984; Pelto et al., 1989) and ended in Jakobshavn Isfjord as a floating ice shelf $6-8 \mathrm{~km}$ long and $6 \mathrm{~km}$ wide until the ice shelf disintegrated suddenly in 2002 (Joughin et al., 2008). Summer velocities are still increasing (Joughin et al., 2014). Jakobshavn Isbrae had retreated $27 \mathrm{~km}$ since 1850, the end of the Little Ice Age in Greenland, and its calving front had been relatively stable since 1964 (Weidick and Bennike, 2007). Since velocity measurements began in 1964, it has been the fastest-known ice stream on Earth (Carbonnell and Bauer, 1968). Surface elevations and velocities were mapped by aerial photogrammetry over a $100 \mathrm{~km}$ by $100 \mathrm{~km}$ area of ice converging on Jakobsavn Isfjord and on the ice shelf in 1985 and 1986 (Fastook et al., 1995; Prescott et al., 2003). The surface morphology and mass balance were studied extensively by Echelmeyer et al. $(1991,1992)$ from 1985 to 1988. Temperatures were measured through Jakobshavn Isbrae by hot-water drilling in 1988 and 1989 (Iken et al., 1993; Funk et al., 1994; Luthi et al., 2002). CReSIS mapped surface and bed topography by radar for Jakobshavn Isbrae and its ice catchment/drainage basin from 2004 to 2008 (Gogineni et al., 2014). Jakobshavn Isbrae occupies a subglacial trench we informally call "Gogineni Gorge" that is fairly straight, $100 \mathrm{~km}$ long, $4 \mathrm{~km}$ wide, and up to $1500 \mathrm{~m}$ deep.

Figure 13 is a satellite image of Jakobshavn Isbrae showing the centerline along which floating fraction $\phi$ is calculated. Figure 14 is the CReSIS map of bed topography where ice converges on Jakobshavn Isfjord. Gogineni Gorge is clearly seen. Ice thickness approximately doubles in the gorge. The flowline shown in Fig. 13 follows the centerline of the gorge. Figure 15 shows profiles of the ice surface, base, and thickness along the centerline, and locates the (un)grounding line. Two surface and thickness profiles are shown, one in 1985 before the buttressing ice shelf in Jakobshavn Isfjord disintegrated in 2002 and one in 2012 after the ice shelf disintegrated. Other profiles in 1993, 2003, and 2006 lie between these profiles and reflect transient events preceding and following disintegration (Hofstede and Hughes, 2014).

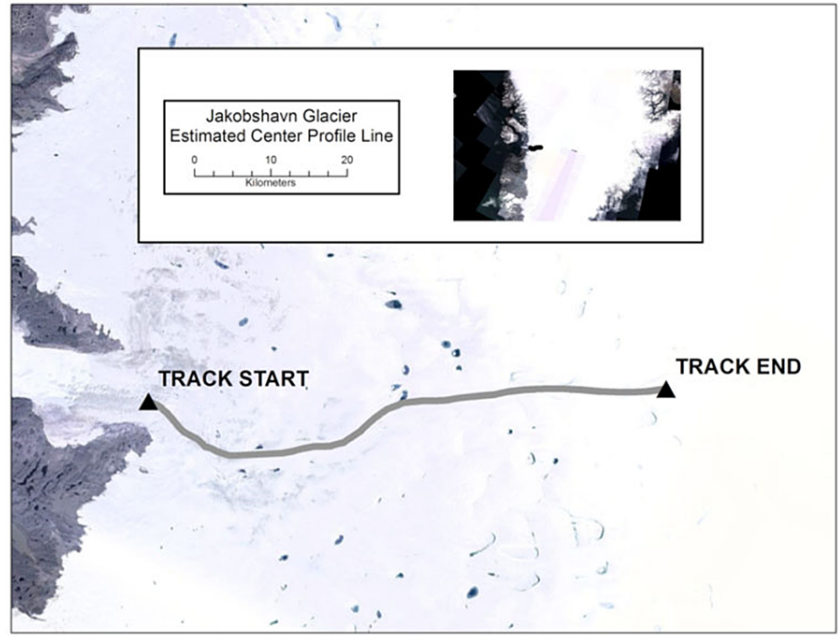

Figure 13. A satellite image of Jakobshavn Isbrae showing the centerline along which the ice surface, base, and thickness were determined by radar sounding. The inset map locates Jakobshavn Isbrae in the Greenland Ice Sheet (black rectangle).

\section{Jakobshavn Channel Bed Topography}

$$
\text { CReSIS L3 Gridded Topography }
$$

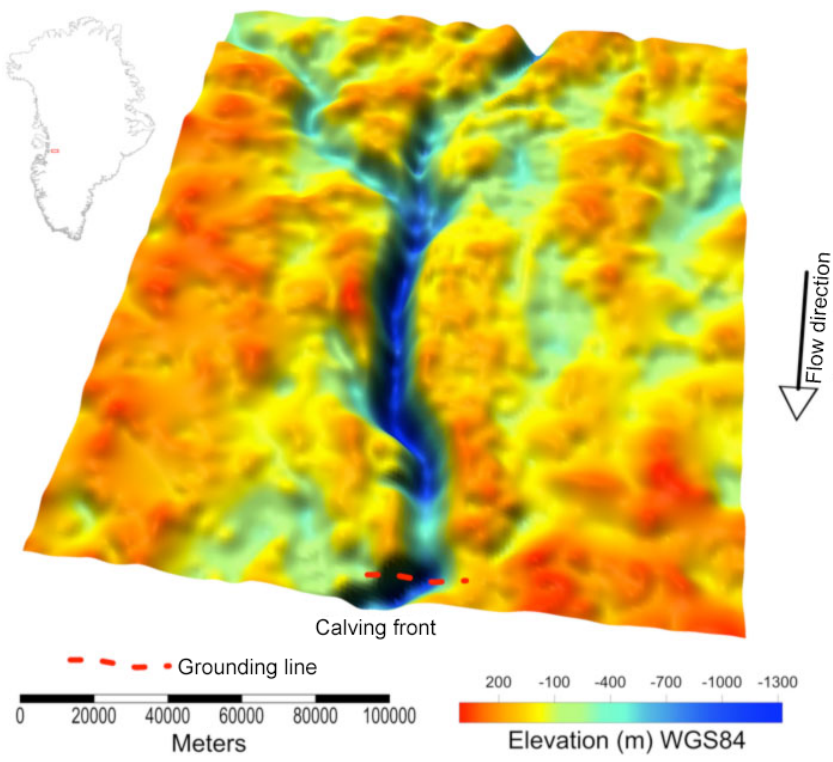

Figure 14. Gogineni Gorge and surrounding bed topography beneath ice entering Jakobshavn Isbrae. The radar track in Fig. 13 is along the centerline of Gogineni Gorge. This map was produced from radar sounding by the Center for Remote Sensing of Ice Sheets (CReSIS) at the University of Kansas.

The first attempt to model Jakobshavn Isbrae was a force perturbation approach by Thomas (2004). Treating Jakobshavn Isbrae as a linear ice shelf with side drag and some basal drag, removing the final $6 \mathrm{~km}$ that is actually afloat eliminated ice-shelf buttressing, allowing Jakobshavn Isbrae to move faster and lower. Using a version of the model we use 

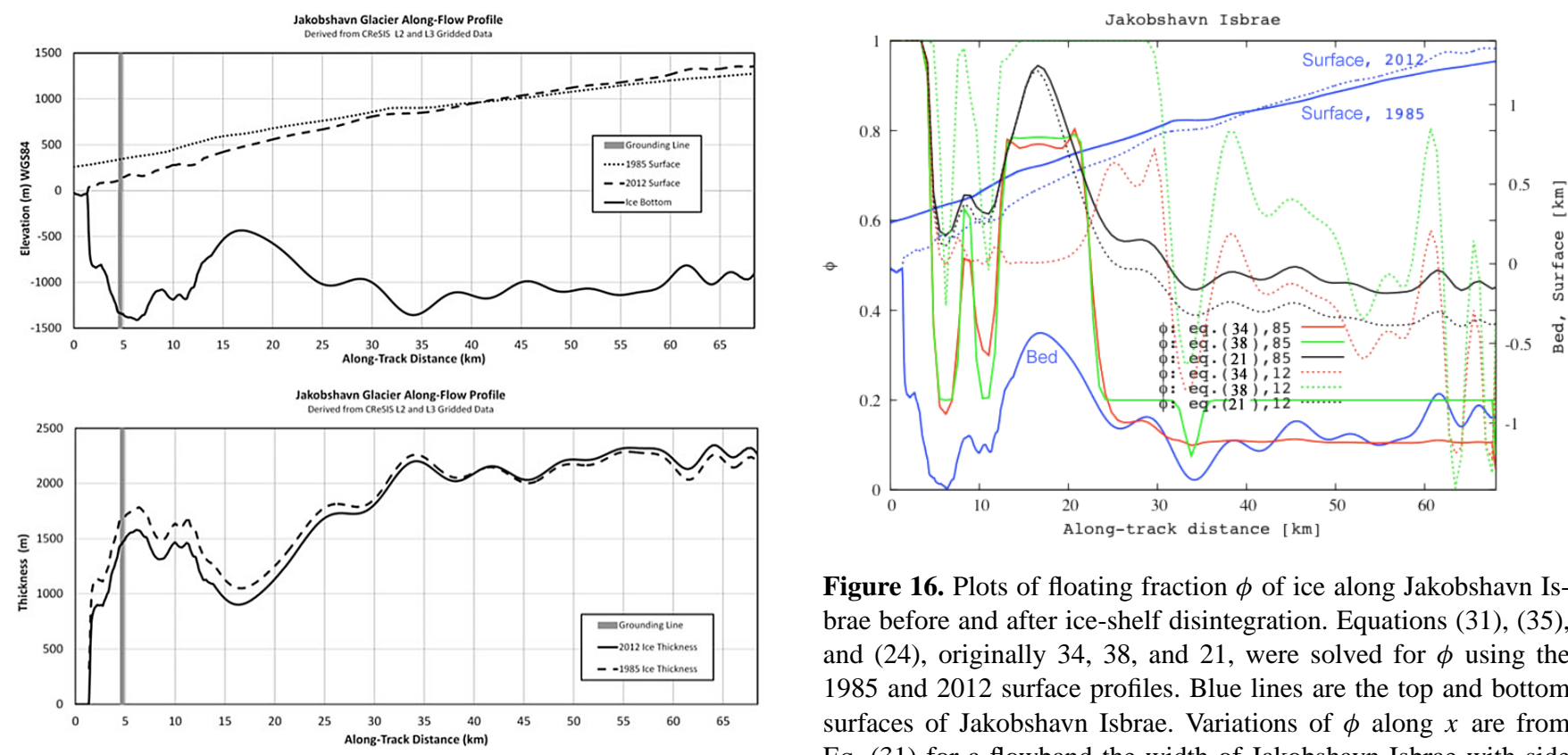

Figure 15. Surface, base, and thickness profiles down the centerline of Jakobshavn Isbrae shown in Fig. 13. The vertical line separates grounded ice (right) from floating ice (left). Top: Ice surfaces in 1985 (dotted line) and 2012 (dashed line) and ice base (solid line). Bottom: Ice thickness in 1985 (dashed line) and 2012 (solid line).

here, Hofstede and Hughes (2014) modeled Jakobshvns Isbrae before and after the ice shelf disintegrated over a timespan of 21 years from 1985 to 2006 . The main differences are bed topography and the numerical solution one of us (Aitbala Sargent) used in our study to enforce the requirement that $0 \leq \phi \leq 1$.

Ice rumples behind the ice-shelf calving front and side shear against the fjord walls allowed the ice shelf to buttress Jakobshavn Isbrae. Buttressing was nearly total because longitudinal strain rate $\dot{\varepsilon}_{x x}$ was nearly zero from the grounding line to the calving front (Prescott et al., 2003). The velocity increase and surface lowering that accompanied disintegration of the buttressing ice shelf in 2002 can be linked to a reduction in ice-shelf buttressing using $u_{x}$ in a sliding "law" to get $(\Delta h / \Delta x)_{\mathrm{G}}$ in Eq. (26) and $\dot{\varepsilon}_{x x}$ in the flow in the flow law to get $(\Delta h / \Delta x)_{F}$ in Eq. (28). We used $h_{O}=1000 \mathrm{~m}$ and $u_{O}=7.0 \mathrm{~km} \mathrm{a}^{-1}$ at $x=0$ before disintegration (Prescott et al., 2003) and $h_{O}=850 \mathrm{~m}$ and $u_{O}=12.6 \mathrm{~km} \mathrm{a}^{-1}$ at $x=0$ after disintegration (Joughin et al., 2008). For $(\Delta h / \Delta x)_{G}$, we took $B=1.123 \times 10^{4} \mathrm{kPa} \mathrm{s}^{1 / 2} \mathrm{~m}^{-1 / 2}=0.02$ bar a $^{1 / 2} \mathrm{~m}^{-1 / 2}$ (Hofstede and Hughes, 2014), $L=500 \mathrm{~km}$, and used $h_{\mathrm{I}}$ in Fig. 15 with $m=2$ because ice thickness is measured directly. For $(\Delta h / \Delta x)_{\mathrm{F}}$ Fastook et al. (1995) measured velocities $u$ before disintegration, for comparison with $u_{x}$ and we obtained $h_{\mathrm{I}}$ from Figs. 14 and 15 for Gogineni Gorge, to obtain $A=1.4 \times 10^{5} \mathrm{kPa} \mathrm{s}^{1 / 3}=4.43$ bar a $^{1 / 3}$, corresponding to an

Figure 16. Plots of floating fraction $\phi$ of ice along Jakobshavn Isbrae before and after ice-shelf disintegration. Equations (31), (35), and (24), originally 34,38, and 21, were solved for $\phi$ using the 1985 and 2012 surface profiles. Blue lines are the top and bottom surfaces of Jakobshavn Isbrae. Variations of $\phi$ along $x$ are from Eq. (31) for a flowband the width of Jakobshavn Isbrae with side shear and from Eq. (35) for the central flowline of Jakobshavn Isbrae with side shear incorporated into basal shear. Reasonable variations of hardness parameter $A$ produce essentially the same variations of $\phi$ along $x$. The sharp drop of $\phi$ from $\phi=1$ for floating ice occurs where the first-order surface profile of Jakobshavn Isbrae is concave, with $\phi \rightarrow 0$ when the first-order surface profile is convex. Equations (31) and (35) use both the force balance and the mass balance. The $\phi$ plots for Eq. (24) uses only the force balance.

ice temperature averaging $-15^{\circ} \mathrm{C}$, which lies within measured temperatures ranging from -2 to $-22^{\circ} \mathrm{C}$ (Iken et al., 1993; Luthi et al., 2002). Robert Thomas (personal communication, 22 April 2013) recommends $A=2.5$ bar a $^{1 / 3}$ as a better fit with measured temperatures, so we prefer his value. For $(a-r)$, we set $a=0.59 \mathrm{~m} \mathrm{a}^{-1}$, following Bindschadler (1984), Pelto et al. (1989), and Echelmeyer et al. (1992), with $r$ to be calculated from ice-surface lowering rates during and following disintegration of the buttressing ice shelf. Then $\phi$ variations along $x$ can be calculated from measured values of $\mathrm{C}_{1}=\Delta h / \Delta x$ and calculated values of $\mathrm{C}_{2}=(\Delta h / \Delta x)_{F}$ and $\mathrm{C}_{3}=(\Delta h / \Delta x)_{G}$ in Eqs. (31) and (35), respectively, with side shear in Gogineni Gorge and with side shear absorbed into basal shear along the ice-stream centerline.

Measured surface slopes $(\Delta h / \Delta x)$ in Eqs. (29) and (33) can now be used to calculate variations of $\phi$ along $x$ from Eqs. (31) and (35). These results are shown in Fig. 16, which also shows $\phi$ variations calculated from Eq. (24) using only the force balance. Reasonable limits to ice hardness parameter $A$ have little effect on $\phi$ variations. Values of $\mathrm{C}_{2}$ used to calculate $\phi$ obtained from Eqs. (31) and (35) are obtained from Eq. (49), with $f_{\mathrm{B}}=1$ for full buttressing, giving Eq. (50) before ice-shelf disintegration, and $f_{\mathrm{B}}=0$ for no buttressing, giving Eq. (51) after disintegration. Full buttressing is assumed, given the observation in 1985 that lon- 
gitudinal strain rate $\dot{\varepsilon}_{x x} \approx 0$ from the grounding line to the calving front of the ice shelf (Prescott et al., 2003).

In 1985, variations of $\phi$ along $x$ from Eqs. (31) and (35) remain high all along $x$, mostly in the range $0.4<\phi<0.8$, after falling from $\phi=1$ at the ungrounding line. Eq. (31) for side shear again gives the expected lower $\phi$ values, but gives a high value of $\phi=0.7$ for $24 \mathrm{~km}<x<30 \mathrm{~km}$ just before ice encounters a high sill or riegel. Equation (35) without side shear gives $\phi=1$ over the range $14 \mathrm{~km}<x<30 \mathrm{~km}$, which includes the sill or riegel. Disintegration of the buttressing ice shelf in 2002 has reduced the floating fraction of Jakobshavn Isbrae.

In 2012, variations of $\phi$ along $x$ from Eqs. (31) and (35) are low after falling sharply from $\phi=1$ at the ungrounding line over the $5 \mathrm{~km}$ where Jakobshavn Isbrae has a concave surface profile, mostly in the range $0.1<\phi<0.2$, with Eq. (31) for side shear giving the lower values as expected, but both rising to $\phi=0.8$ where the bed rises halfway to the ice surface at $14 \mathrm{~km}<x<22 \mathrm{~km}$. We do not know if this is a bedrock sill that "dams" water on the stoss side (so $\phi \rightarrow 1$ ), or if it is a riegel (a high bedrock hill) that allows lateral extrusion flow (Hooke et al., 1987), or if it is an overlying shear plane that becomes the effective bed (Rowden-Rich and Wilson, 1996). The low $\phi$ values identify regions where stream flow is dominated by basal sliding of mostly grounded ice. Jakobshavn Isbrae is narrow, so side shear is important (Dupont and Alley, 2005, 2006).

Equation (24) from the force balance alone has $\phi=1$ at the ungrounding line, then decreasing rapidly to $\phi=0.6$ in both 1985 and 2012, before rising to $\phi=0.9$ above the sill or riegel before falling to between 0.4 and 0.5 , with the lower values in 2012. This is because $h_{O}=1000 \mathrm{~m}$ in 1985 became $h_{O}=850 \mathrm{~m}$ in 2012 at $x=0$. This surface lowering at the (un)grounding line exceeds lowering at locations $x>0$. Disintegration of the buttressing ice shelf in 2002 has enhanced stream flow. Variations of $\phi$ along $x$ in Fig. 16 obtained from Equs. (31) and (35) using both the force balance and the mass balance show a sharp drop from $\phi=1$ to $0.1<\phi<0.2$ over distance $x \approx 5 \mathrm{~km}$ behind the ungrounding line in 2012, but falling to only $\phi \approx 0.6$ in 1985 , with large fluctuations. This is the same drop produced by Eq. (24) using only the force balance. The decrease in $\phi$ has been accompanied by a four fold summer velocity increase since 2009 and retreat of the grounding line into a subglacial depression after 2012, see Figs. 14 and 15 (Joughin et al., 2014; Weertman, 1974).

The overall drop in $\phi$ from 1985 to 2012, accompanied by an increasingly convex surface profile, show the increased velocity is causing sheet flow to replace stream flow. This is consistent with Jakobshavn Isbrae accelerating through a life cycle in Table 2, even though $\phi_{O}$ rose from nearly zero to one when the buttressing ice shelf disintegrated in 2002. So today, $\phi_{B} \rightarrow 0$ in Eq. (47) even though $\phi_{O}=1$. We conclude that Jakobshavn Isbrae will eventually shut down unless reductions in $\phi$ are reversed.

\section{Discussion}

Our ice-sheet modeling approach is based on the first-order dependence of ice-sheet thickness on the strength of ice-bed coupling, such that ice $3000 \mathrm{~m}$ high and $4000 \mathrm{~m}$ thick at an interior ice divide can lower to $100 \mathrm{~m}$ high and $1000 \mathrm{~m}$ thick when ice margins become afloat, and lower further to $30 \mathrm{~m}$ high and $300 \mathrm{~m}$ thick at the front of calving ice shelves, a $99 \%$ reduction of ice elevations, all due to reduced ice-bed coupling. We began by quantifying ice-bed uncoupling as an increase in thawed fraction $f$ of the bed for sheet flow, of floating fraction $\phi$ of ice for stream flow, and of unbuttressed fraction $\phi_{O}$ of ice for shelf flow. Our treatment is holistic in the sense it provides smooth transitions from sheet flow to stream flow to shelf flow for steady-state conditions along surface flowlines.

We compared our treatment for ice sheets with two treatments based on continuum mechanics, one by Schoof and Hindmarsh (2010) and one by Pattyn (2003). All three treatments avoided flow "laws" and sliding "laws" of dubious reliability for sheet flow. We substituted respective upper and lower yield stresses applied to cold ice over a frozen bed and to temperate ice sliding over bedrock and/or deforming till for sheet flow, with cold ice above temperate basal ice in ice streams and ice shelves. Schoof and Hindmarsh (2010) introduced "slip" and "no-slip" interfaces at the bed linked to separate deviator stress tensors that can be applied to sheet, stream, and shelf flow. Pattyn (2003) reduced basal drag as a frozen bed thaws. His approach can also be applied to sheet, stream, and shelf flow.

We applied our treatment to Byrd Glacier, Antarctica, which has the largest ice drainage system and is buttressed by the largest ice shelf, and to Jakobshavn Isbrae, Greenland, which is the fastest ice stream and was buttressed by a much smaller ice shelf that disintegrated completely in 2002. Both ice streams continue as initially linear ice shelves. We related standard flow and sliding "laws" to our upper yield stress for a standard flow law in cold ice and our lower yield stress in a standard sliding law modified to allow temperate ice to slide over deforming till. Cold ice exists in ice overlying a frozen bed and in ice floating above a thawed bed, so the upper yield stress applies to sheet, stream, and shelf flow. Temperate ice exists where basal ice contacts a thawed bed in sheet flow and floats above basal water in sheet and stream flow.

A concern exists on how to treat floating fraction $\phi$ along ice streams and unbuttressed fraction $\phi_{O}$ for a confined and pinned ice shelf supplied by ice streams. Equations (31) and (35) are used to calculate $\phi$, with term $\mathrm{C}_{2}$ obtained from Eqs. (E3) and (E4) in Appendix E, yet $\sigma_{\mathrm{T}}$ in Eq. (30) does not contain $\phi^{2}$, unlike $\sigma_{\mathrm{T}}$ in Eq. (12) for ice streams. The reason for omitting $\phi^{2}$ in Eq. (E4) is it applies only to the floating fraction of ice in an ice stream, for which $\phi=1$. However, if $\phi^{2}$ is included, then $\mathrm{C}_{2}$ includes $\phi$ raised to the $2 n+2$ power, giving $\phi^{8}$ for $n=3$. Then $\phi$ has eight solutions, among which only those with $0 \leq \phi \leq 1$ can be used. This alternative was 
employed by Hofstede and Hughes (2014) for Jakobshavn Isbrae. It led to $\phi$ values that decrease irregularly from $\phi=1$ at the ungrounding line, $x=0$, to $\phi \approx 0.5 \pm 0.1$ at $x=70$ $\mathrm{km}$ upstream. Their values generally exceed our $\phi$ values obtained from the $\phi^{2}$ link to $C_{2}$ in Eqs. (29) and (33) for 1985, but compare with our $\phi$ values for 2012. The big difference is $\phi$ values over the riegel, a feature absent from bed topography used by Hofstede and Hughes (2014).

If the $\phi^{2}$ dependence of $(\Delta h / \Delta x)_{F}=\mathrm{C}_{2}$ is retained, as in Eq. (29), the opportunity is opened for converting $\phi$ in Eq. (12) into $\phi_{O}$ for ice-shelf buttressing. This leads to Eq. (49), with $f_{\mathrm{B}}=1$ for full ice-shelf buttressing and $f_{\mathrm{B}}=0$ for no ice-shelf buttressing, the two conditions we have for Jakobshavn Isbrae before and after the ice shelf disintegrated in 2002. Is this justified? We cannot be sure. However, if a confined and pinned ice shelf is not so different from an ice stream, as Thomas (2004) maintains, then the $\phi^{2}$ term in Eq. (12) can be related to ice-shelf buttressing expressed by buttressing fraction $f_{\mathrm{B}}$. This may account for values of $0.8<\phi<0.9$ as Byrd Glacier becomes afloat when $A=8 \mathrm{bara}^{1 / 3}$ is the ice hardness parameter. Making $\phi=1$ at the ungrounding line requires tripling $A$. The seemingly stiffer ice is equivalent to partial grounding of floating ice over the $40 \mathrm{~km}$ where $\dot{\varepsilon}_{x x} \approx 0$ between possible ungrounding lines at $x=50 \mathrm{k}$ where $h_{O}=750 \mathrm{~m}$ and at $x=90 \mathrm{~km}$ where $h_{O}=1100 \mathrm{~m}$ or, more likely, by nearly full buttressing by the Ross Ice Shelf.

We postulate that an ice shelf differs from an ice stream mainly in that water flows freely beneath an ice shelf, even when the ice shelf is confined in an embayment and has basal pinning points that produce ice rises and ice rumples on the ice surface, whereas water flowing under an ice stream encounters resistance from grounded regions beneath ice streams, as seen in Fig. 5. This resistance reduces a water buttressing stress $\sigma_{\mathrm{W}}$ along $x$ for a given $h_{\mathrm{I}}$ because water under an ice stream cannot flow freely to the sea. At the ice-shelf calving front the longitudinal force balance is $\sigma_{\mathrm{W}} h_{\mathrm{I}}=\bar{P}_{W} h_{\mathrm{W}}$. This "water" stress $\sigma_{\mathrm{W}}$ along an ice stream is not readily recovered from solving the standard NavierStokes equilibrium equations used in continuum mechanics, so its existence is questioned. Evidence supporting the existence of $\sigma_{\mathrm{W}}$ is the observation by Kamb (2001) that basal water under West Antarctic ice streams rises in boreholes to heights far above sea level, heights at the drilling sites that would "float" ice if site elevations were reduced to about $90 \%$ of the observed ice height above the bed.

Another difference between stream flow and shelf flow is flow in ice shelves generally diverges and converges in the map plane, whereas flow in ice streams is primarily linear. Our holistic treatment required linear ice shelves of nearly constant width, with resisting stresses along the sides and at local pinning points, see Fig. 5. Hughes (2012, chapter 13) presents a similar treatment for a broad ice shelf in the map plane that links unbuttressed fraction $\phi_{O}$ to ice-shelf geometry: its shape, the location, size, and shape of its ice rises and ice rumples, and the grounded and floating lengths of its perimeter.

Where extreme surface roughness is not sufficiently smoothed by a running mean of ice elevations, $\phi$ may not be confined to the range $0 \leq \phi \leq 1$. If solutions of Eqs. (29) and (33) are real numbers between 0 and 1, we calculated them using Eqs. (31) and (35). If the solutions are complex numbers, or real numbers not in the $0-1$ range, we find approximate solutions of Equations (29) and (33) using a variation of a dissection method. The method consists of dividing the segment 0,1 into 1000 points and calculating absolute values of the quadratic functions, Eqs. (29) and (33), at each of these points. The point on the segment 0,1 which generates the smallest value of the corresponding function is accepted as the solution of this function. The method always generates an answer between 0 and 1, but does not satisfy the equation exactly. This method is illustrated in Fig. 16 for Eq. (35), where $\phi=1$ above the sill or riegel in 1985 .

Our results for both Byrd Glacier and Jakobshavn Isbrae are compatible with basal buoyancy fraction $\phi_{B}=\phi \phi_{O}$ in Table 2 used to quantify a hypothetical "life cycle" of ice streams. The product of fraction $\phi$ linked to ice-bed uncoupling and fraction $\phi_{O}$ linked to ice-shelf unbuttressing is maximized when surface meltwater floods the bed under an ice stream, and when its buttressing ice shelf shelf disintegrates. Hughes (1986) postulated these two processes, augmented by other processes, are sufficient to collapse marine portions of an ice sheet, and to that extent contribute to Termination of glaciation cycles lasting approximately 90000 years during the Quaternary Ice Age in which we now live. He called this the Jakobshavn Effect because all the processes were active for Jakobshavn Isbrae. Contributing processes include additional surface melting when crevasses are ubiquitous, analyzed by Pfeffer and Bretherton (1987), warm ocean water entering Jakobshavn Isfjord, reported by Holland et al. (2008) and restricted flow of outlet glaciers in curving and branching fjords like Jakobsahvn Isfjord (Pfeffer et al., 2008).

We conclude the Jakobshavn Effect may have a long-term impact in Greenland if global warming allows these processes to migrate northward, causing successive ice streams to surge, thereby completing their life cycles. Some processes are already appearing in ice streams draining the east, west, and northwest parts of the Greenland Ice Sheet (Rignot and Kanagaratnam, 2006). Schoof (2010) shows how ongoing acceleration and thinning of Jakobshavn Isbrae reported by Joughin et al. (2014) could continue for a century. Various paths can be taken by $\phi$ and $\phi_{O}$ in Table 2 during a life cycle, including reversals, as documented by Engelhardt and Kamb (2013) for Kamb Ice Stream. Hughes (2011) used Table 2 to determine where major Antarctic ice streams are in their life cycles today. When the Jakobshavn Effect is nearly simultaneous for many ice streams, Table 2 can be used to identify stadials and interstadials within Quaternary glaciation cycles, and to account for Terminations of cycles, all 
linked to global sea level (Denton et al., 1986) and the Jakobshavn Effect.

\section{Conclusions}

A holistic approach for steady-state transitions from slow sheet flow to fast stream flow to buttressing shelf flow along flowlines of an ice sheet was applied to the ice drainage systems of Byrd Glacier in Antarctica and Jakobshavn Isbrae in Greenland. These ice streams bracket ice-bed uncoupling ranging from no surface meltwater lubricating the bed and a massive buttressing ice shelf for Byrd Glacier to massive surface meltwater lubricating the bed and an ice shelf that has recently disintegrated for Jakobshavn Isbrae. Ice elevations are controlled primarily by the strength of ice-bed coupling, with maximum coupling to a frozen bed vanishing completely when ice becomes afloat. Surface and basal ice profiles were obtained by radar sounding along these two ice streams, with ice-bed coupling deduced from these profiles. Sudden drainage of subglacial lakes in ice converging on Byrd Glacier in 2006-2007 has had no lasting effect on Byrd Glacier, but sudden disintegration of an ice shelf buttressing Jakobshavn Isbrae in 2002 seems to have accelerated its progression through a life cycle from stream flow to sheet flow.

For sheet flow, only basal drag resisted gravitational forcing. We avoided using problematic "laws" for creep in ice frozen to the bed, ice sliding over a thawed bed, and shear of any underlying till that is mobilized by water. Instead we linked ice motion to two yield stresses, a higher stress when the bed is frozen and a lower stress when the bed is thawed, with thawed bed fraction $f$ linking the two. In stream flow, gravitational forcing was resisted by basal drag, side drag, upstream pulling, and downstream pushing of ice. We used floating ice fraction $\phi$ to quantify ice-bed uncoupling along an ice stream. For shelf flow, unbuttressed ice fraction $\phi_{O}$ increases as the length of side grounding and local grounding at ice rises and ice rumples decreases. A comparison is made between our approach and two approaches based on continuum mechanics which also avoid flow and sliding "laws" for sheet, stream, and shelf flow.

Buoyancy fraction $\phi_{B}=\phi \phi_{O}$ locates ice streams in a life cycle from inception to growth to mature to declining to terminal stages as $\phi_{B}$ decreases from 1 to 0 over time. This product can increase and decrease in many ways over time to lend structure to a given life cycle, and can lead to Termination of a glaciation cycle. Today, Byrd Glacier has low values of $\phi$ and $\phi_{O}$, but both values are substantially higher for Jakobshavn Isbrae. For Byrd Glacier we temporarily increased $\phi$ when two subglacial lakes at its head drained rapidly in 2006-2007 (Stearns and others, 2008). For Jakobshavn Isbrae, we set $\phi_{O}=1$ when its buttressing ice shelf suddenly disintegrated in 2002 (Thomas, 2004).
Warming in high polar latitudes can, in principle, trigger a succession of positive feedback mechanisms called the Jakobshavn Effect (Hughes, 1986). Buoyancy fraction $\phi_{B}$ combines the two dominant mechanisms: reduced icebed coupling when surface meltwater floods the bed under an ice stream and reduced ice-shelf buttressing when an ice shelf disintegrates beyond the ice stream. For Greenland, the Jakobshavn Effect would move northward along the east and west coasts, affecting all calving ice streams. For Antarctica, it would affect the northernmost ice streams, which are primarily in East Antarctica, but also ice streams entering the Pine Island Bay polynya in West Antarctica (Hughes, 1987, 2011; Pingree et al., 2011).

Equation (24), based only on the force balance is especially useful here, because of its robust simplicity that applies to all flowlines and flowbands (ice streams) that end at a specified ice thickness $h_{O}$. It gives $\phi$ variations along $x$ that are usually somewhat higher than when the mass balance is also included, but with the same general trend. Pingree et al. (2011) showed how Eq. (24) produced ice elevations before and after a former surge lifecycle of Lambert Glacier in East Antarctica, and for impending surge lifecycles of Thwaites Glacier and Pine Island Glacier entering the Pine Island Bay polynya in West Antarctica that continue into East Antarctica. Hughes (2011) has tentatively assigned inception, growth, mature, declining, and terminal lifecycle stages shown in Table 2 to all major Antarctic ice streams at the present time. Fastook and Hughes (2013) reconstructed Northern Hemisphere ice sheets during stages of a Quaternary glaciation cycle, including stadials and interstadials, using Eq. (24) with $\phi$ variations deduced from glacial geology, and compared those ice elevations with ice elevations calculated using J. L. Fastook's time-dependent UMISM ice-sheet reconstructions based on continuum mechanics. 


\section{Appendix A: Simple demonstrations of the geometrical force balance}

The simplest demonstrations of the geometrical force balance are for ideal sheet flow and ideal shelf flow, see the figure below. Ideal sheet flow is for ice grounded on a horizontal bed (left) and ideal shelf flow is for ice floating at the calving front (right).

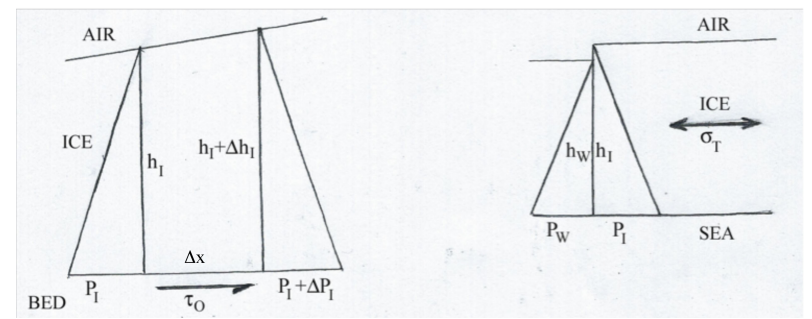

For ideal sheet flow, the net horizontal gravitational driving force $\Delta F_{G}$ is the difference between triangular area $F_{G}+\Delta F_{G}=1 / 2\left(P_{\mathrm{I}}+\Delta P_{\mathrm{I}}\right)\left(h_{\mathrm{I}}+\Delta h_{\mathrm{I}}\right)$ on the upslope side of the ice column above basal length $\Delta \mathrm{x}$ and triangular area $F_{G}=1 / 2\left(P_{\mathrm{I}} h_{\mathrm{I}}\right)$ on the downslope side:

$$
\begin{aligned}
& \Delta F_{\mathrm{G}}=1 / 2\left(P_{\mathrm{I}}+\Delta P_{\mathrm{I}}\right)\left(h_{\mathrm{I}}+\Delta h_{\mathrm{I}}\right)-1 / 2\left(P_{\mathrm{I}} h_{\mathrm{I}}\right) \\
& =1 / 2 \rho_{\mathrm{I}} g\left(h_{\mathrm{I}}+\Delta h_{\mathrm{I}}\right)^{2}-1 / 2 \rho_{\mathrm{I}} g h_{\mathrm{I}}^{2}=\rho_{\mathrm{I}} g h_{\mathrm{I}} \Delta h_{\mathrm{I}},
\end{aligned}
$$

where basal ice pressure is $P_{\mathrm{I}}=\rho_{\mathrm{I}} g h_{\mathrm{I}}$ for ice density $\rho_{\mathrm{I}}$ and gravity acceleration $g$. The net horizontal gravitational force is balanced by basal drag force $F_{O}=\tau_{O} \Delta x$, where $\tau_{O}$ is the basal shear stress. Equating $F_{O}$ with $\Delta F_{G}$ gives the following:
$\tau_{O}=\rho_{\mathrm{I}} g h_{\mathrm{I}} \Delta h_{\mathrm{I}} / \Delta x=\rho_{\mathrm{I}} g h_{\mathrm{I}} \alpha$,

where $\alpha=\Delta h_{\mathrm{I}} / \Delta x$ is the ice surface slope.

For ideal shelf flow, $\Delta F_{G}$ at the calving front is the difference between triangular area $1 / 2 P_{I} h_{\mathrm{I}}$ for ice and triangular area $1 / 2 P_{W} h_{\mathrm{W}}$ for water:

$$
\begin{aligned}
& \Delta F_{\mathrm{G}}=1 / 2\left(P_{\mathrm{I}} h_{\mathrm{I}}-P_{\mathrm{W}} h_{\mathrm{W}}\right)=1 / 2\left(\rho_{\mathrm{I}} g h_{\mathrm{I}}^{2}-\rho_{\mathrm{W}} g h_{\mathrm{W}}^{2}\right) \\
& =1 / 2 \rho_{\mathrm{I}} g\left[h_{\mathrm{I}}^{2}-h_{\mathrm{I}}^{2}\left(\rho_{\mathrm{I}} / \rho_{\mathrm{W}}\right)\right],
\end{aligned}
$$

where basal water pressure $P_{\mathrm{W}}=\rho_{W} g h_{\mathrm{W}}$ for water density $\rho_{W}$ and basal buoyancy requires $P_{\mathrm{I}}=P_{\mathrm{W}}$ in a vertical gravitational force balance, so $h_{\mathrm{W}}=\left(\rho_{\mathrm{I}} / \rho_{W}\right) h_{\mathrm{I}}$. The net horizontal gravitational force produces a horizontal pulling force $F_{P}=\sigma_{\mathrm{T}} h_{\mathrm{I}}$ in ice, where $\sigma_{\mathrm{T}}$ is a longitudinal tensile stress. Equating $F_{P}$ with $\Delta F_{G}$ gives the following:

$\sigma_{\mathrm{T}}=1 / 2 \rho_{\mathrm{I}} g h_{\mathrm{I}}\left(1-\rho_{\mathrm{I}} / \rho_{\mathrm{W}}\right)$.

Hughes (2012, Appendix D) derives identical analytical solutions of Eqs. (A3) and (A5) obtained by integrating the Navier-Stokes equilibrium/momentum equations. 
Table A1. Variables used in quantifying ice bed uncoupling for sheet, stream, and shelf flow.

\begin{tabular}{|c|c|}
\hline \multicolumn{2}{|r|}{ Sheet flow } \\
\hline$f$ & basal thawed fraction of the bed at a given location \\
\hline$\tau_{O}=P_{\mathrm{I}} \alpha$ & gravitational driving stress for sheet flow \\
\hline$P_{\mathrm{I}}$ & ice overburden pressure at the bed \\
\hline$\alpha$ & ice surface slope in the direction of ice flow \\
\hline$\tau_{T}$ & viscoplastic yield stress for temperate ice and wet till on a thawed bed \\
\hline$\tau_{\mathrm{F}}$ & viscoplastic yield stress for cold ice above a frozen bed \\
\hline$\dot{\varepsilon}$ & strain rate caused by gravitational driving stress $\sigma$ \\
\hline$\dot{\varepsilon}_{O}$ & strain rate when $\sigma$ is the plastic yield stress $\sigma_{O}$ \\
\hline$n$ & viscoplastic exponent in flow law $\dot{\varepsilon}=\dot{\varepsilon}_{O}\left(\sigma / \sigma_{O}\right)^{n}$ \\
\hline$A=\left(\sigma_{O} / \dot{\varepsilon}_{O}^{1 / n}\right)$ & ice hardness parameter given by Eq. (8) \\
\hline \multicolumn{2}{|r|}{ Stream flow } \\
\hline$\phi_{\mathrm{B}}=P_{\mathrm{W}}^{*} / P_{\mathrm{I}}=h_{\mathrm{F}} / h_{\mathrm{I}}$ & floating fraction of ice at a given location \\
\hline$P_{\mathrm{W}}^{*}$ & basal water pressure in a horizontal force balance along ice flow \\
\hline$P_{\mathrm{W}}^{*}$ & basal water pressure in a vertical force balance \\
\hline$P_{\mathrm{I}}$ & basal ice pressure in a vertical force balance \\
\hline$h_{\mathrm{I}}$ & ice height above the bed. \\
\hline$h_{\mathrm{W}}$ & water height above the bed caused by $P_{W}^{*}$ \\
\hline$h_{\mathrm{F}}$ & ice height above the bed that would float in water of height $h_{\mathrm{W}}$ \\
\hline$h$ & ice height above sea level \\
\hline$h_{\mathrm{L}}$ & ice height above the bed at the ice divide \\
\hline$h_{\mathrm{S}}$ & ice height above the bed where stream flow begins \\
\hline$h_{O}$ & ice height above the bed where stream flow ends \\
\hline$\phi=h_{O} / h_{\mathrm{I}}$ & floating fraction of ice based on the force balance only \\
\hline$\sigma_{\mathrm{T}}$ & tensile stress that pulls upstream ice \\
\hline$\sigma_{\mathrm{C}}$ & compressive stress that pushes downstream ice \\
\hline$\tau_{O}$ & basal shear stress \\
\hline$\tau_{\mathrm{S}}$ & side shear stress \\
\hline$\sigma_{\mathrm{W}}$ & longitudinal back-stress caused by average water pressure \\
\hline$\sigma_{F}=\sigma_{\mathrm{T}}+\sigma_{\mathrm{W}}$ & longitudinal flotation stress that resists ice flow \\
\hline$\phi_{\mathrm{B}}=\phi \phi_{O}$ & basal buoyancy factor in the life cycle of ice streams \\
\hline$f_{\mathrm{B}}=1-\phi_{O}$ & buttressed fraction of ice at $h_{O}$ \\
\hline \multicolumn{2}{|r|}{ Shelf flow } \\
\hline$\phi_{O}=1-\left(\sigma_{\mathrm{B}} / \sigma_{\mathrm{U}}\right)_{O}$ & unbuttressed fraction of an ice shelf at its grounding line \\
\hline$\sigma_{\mathrm{B}}$ & buttressing back-stress caused by side and local ice-shelf grounding \\
\hline$\sigma_{U}$ & pulling stress of an unbuttressed freely-floating ice shelf \\
\hline$A_{\mathrm{R}}$ & grounded area under ice rumples on the surface \\
\hline$C_{\mathrm{R}}$ & grounded circumference around ice rises on the surface \\
\hline$L_{\mathrm{S}}$ & grounded length on each side of an ice shelf \\
\hline $\bar{h}_{\mathrm{R}}$ & mean ice thickness around ice rises \\
\hline $\bar{h}_{\mathrm{S}}$ & mean ice thickness along side grounding lines \\
\hline$h_{O}$ & ice thickness at the ice-shelf grounding line with an ice stream \\
\hline
\end{tabular}




\section{Appendix B: The dependence on $\phi$ of $\bar{\tau} O$ and $\bar{\tau}_{\mathrm{S}}$ using} Fig. 5

Gravitational force $\left(F_{\mathrm{G}}\right)_{1}$ at $x$ is $w_{\mathrm{I}}$ times the area of triangle 1 in Fig. 5 (bottom). It is resisted by a downslope basal shear force $\left(F_{O}\right)_{1}$ given by mean downslope basal shear stress $\bar{\tau}_{O}$ times basal area $w_{\mathrm{I}} x$ beneath the ice stream and total area $A_{\mathrm{R}}$ beneath ice rumples on the ice shelf. Since triangle 1 occupies the shaded area in Fig. 5 (top), its basal ice pressure $\left(P_{\mathrm{I}}\right)_{1}=\rho_{\mathrm{I}} g\left(h_{\mathrm{I}}-h_{\mathrm{F}}\right)$ is supported by the bed and its mean downstream ice pressure $\left(\bar{P}_{\mathrm{I}}\right)_{1}=1 / 2\left(P_{\mathrm{I}}\right)_{1}$ is exerted over an area of width $w_{\text {I }}$ times triangle height $h_{\mathrm{I}}-h_{\mathrm{F}}$. Equating this negative gravitational force $\left(F_{\mathrm{G}}\right)_{1}=$ $\left(\bar{P}_{\mathrm{I}}\right)_{1}\left(h_{\mathrm{I}}-h_{\mathrm{F}}\right) w_{\mathrm{I}}=1 / 2 \rho_{\mathrm{I}} g\left(h_{\mathrm{I}}-h_{\mathrm{F}}\right)^{2} w_{\mathrm{I}}$ with positive downstream resisting force $\left(F_{O}\right)_{1}=\bar{\tau}_{O}\left(w_{\mathrm{I}} x+A_{\mathrm{R}}\right)$, and solving for $\bar{\tau}_{O}$ using $h_{\mathrm{F}}=h_{\mathrm{I}} \phi$ gives Eq. (20):

$$
\begin{aligned}
& \bar{\tau}_{O}=\frac{1 / 2 \rho_{\mathrm{I}} g\left(h_{\mathrm{I}}-h_{\mathrm{F}}\right)^{2} w_{\mathrm{I}}}{w_{\mathrm{I}} x+A_{\mathrm{R}}}=\frac{1 / 2 \rho_{\mathrm{I}} g h_{\mathrm{I}}(1-\phi)^{2} h_{\mathrm{I}} w_{\mathrm{I}}}{w_{\mathrm{I}} x+A_{\mathrm{R}}} \\
& =\frac{\bar{P}_{\mathrm{I}}(1-\phi)^{2} h_{\mathrm{I}} w_{\mathrm{I}}}{w_{\mathrm{I}} x+A_{\mathrm{R}}} .
\end{aligned}
$$

Triangular areas 1, 3, and 4 in Fig. 5 (bottom) have now been linked to $\bar{P}_{\mathrm{I}}$ and $\phi$ through stresses $\bar{\tau}_{O}, \sigma_{\mathrm{W}}$, and $\sigma_{\mathrm{T}}$, respectively. All that remains is the area of rectangle 2 in Fig. 5 (bottom) and $\bar{\tau}_{\mathrm{S}}$ for side shear averaged over downslope side areas $2 \bar{h}_{\mathrm{I}} x$ of the ice stream and side areas $2 \bar{h}_{\mathrm{S}} L_{\mathrm{S}}$ and $\bar{h}_{\mathrm{R}} C_{\mathrm{R}}$ of the ice shelf and ice rises having total grounded side lengths $2 L_{\mathrm{S}}$ and circumference $C_{\mathrm{R}}$, respectively, as shown in Fig. 5 (top). The negative downstream gravitational force given by $w_{\mathrm{I}}$ times the area of rectangle 2 for $\left(P_{\mathrm{I}}\right)_{1}=\left(P_{\mathrm{I}}\right)_{2}$ is $\left(F_{\mathrm{G}}\right)_{2}=\left(P_{\mathrm{I}}\right)_{2} h_{\mathrm{F}} w_{\mathrm{I}}=\rho_{\mathrm{I}} g\left(h_{\mathrm{I}}-h_{\mathrm{F}}\right) h_{\mathrm{F}} w_{\mathrm{I}}$. It is resisted by positive downstream side shear force $\left(F_{\mathrm{S}}\right)_{2}=$ $\bar{\tau}_{\mathrm{S}}\left(2 \bar{h}_{\mathrm{I}} x+2 \bar{h}_{\mathrm{S}} L_{\mathrm{S}}+\bar{h}_{\mathrm{R}} C_{\mathrm{R}}\right)$. Equating these forces and solving for $\bar{\tau}_{\mathrm{S}}$ using $h_{\mathrm{F}}=h_{\mathrm{I}} \phi$ gives Eq. (21):

$$
\begin{aligned}
& \bar{\tau}_{\mathrm{S}}=\frac{\rho_{\mathrm{I}} g\left(h_{\mathrm{I}}-h_{\mathrm{F}}\right) h_{\mathrm{F}} w_{\mathrm{I}}}{2 \bar{h}_{\mathrm{I}} x+2 \bar{h}_{\mathrm{S}} L_{\mathrm{S}}+\bar{h}_{\mathrm{R}} C_{\mathrm{R}}}=\frac{\rho_{\mathrm{I}} g h_{\mathrm{I}}(1-\phi) \phi h_{\mathrm{I}} w_{\mathrm{I}}}{2 \bar{h}_{\mathrm{I}} x+2 \bar{h}_{\mathrm{S}} L_{\mathrm{S}}+\bar{h}_{\mathrm{R}} C_{\mathrm{R}}} \\
& =\frac{P_{\mathrm{I}}(1-\phi) \phi h_{\mathrm{I}} w_{\mathrm{I}}}{2 \bar{h}_{\mathrm{I}} x+2 \bar{h}_{\mathrm{S}} L_{\mathrm{S}}+\bar{h}_{\mathrm{R}} C_{\mathrm{R}}} .
\end{aligned}
$$

\section{Appendix C: Derivation of floating ice fraction using only the force balance}

For ice rumples and ice rises with mean ice thickness $\bar{h}_{D}$ in transverse diameter $D_{\mathrm{R}}$, the local respective compressive stresses on the stoss side are $\sigma_{D}=\left(A_{\mathrm{R}} / D_{\mathrm{R}} \bar{h}_{D}\right) \tau_{O}$ for ice rumples and $\sigma_{D}=\left(C_{\mathrm{R}} \bar{h}_{\mathrm{R}} / D_{\mathrm{R}} \bar{h}_{D}\right) \tau_{\mathrm{S}}$ for ice rises, where $\sigma_{D}$ adds to $\sigma_{\mathrm{C}}$. In Eq. (19), therefore, compressive force $\sigma_{\mathrm{C}} A_{x}$ at $x$ on the left side is the result of average downslope basal and side shear forces and a water-pressure buttressing force at $x=0$, all on the right side. Solving for $\sigma_{\mathrm{C}}$,

$\sigma_{\mathrm{C}}=\frac{\bar{\tau}_{O}\left(w_{\mathrm{I}} x+A_{\mathrm{R}}\right)+\bar{\tau}_{\mathrm{S}}\left(2 \bar{h}_{\mathrm{I}} x+2 \bar{h}_{\mathrm{S}} L_{\mathrm{S}}+\bar{h}_{\mathrm{R}} C_{\mathrm{R}}\right)+\left(\bar{P}_{\mathrm{W}} h_{\mathrm{W}}\right)_{O} w_{\mathrm{I}}}{h_{\mathrm{I}} w_{\mathrm{I}}}$.

Equation (C1) can now be solved for $\phi$ using Eqs. (11) and (12) for $\sigma_{\mathrm{T}}$ and $\sigma_{\mathrm{C}}$, respectively. First, substitute Eqs. (20) and (21) for $\bar{\tau}_{O}$ and $\bar{\tau}_{\mathrm{S}}$ in Eq. (C1) as such:

$$
\begin{aligned}
& \sigma_{\mathrm{C}}=\frac{\left(\bar{P}_{\mathrm{W}} h_{\mathrm{W}}\right)_{O}}{h_{\mathrm{I}}}+\left[\frac{\bar{P}_{\mathrm{I}}(1-\phi)^{2}}{w_{\mathrm{I}} x+A_{\mathrm{R}}}\right]\left(w_{\mathrm{I}} x+A_{\mathrm{R}}\right) \\
& +\left[\frac{\bar{P}_{\mathrm{I}}(1-\phi) \phi}{2 \bar{h}_{\mathrm{I}} x+2 \bar{h}_{\mathrm{S}} L_{\mathrm{S}}+\bar{h}_{\mathrm{R}} C_{\mathrm{R}}}\right]\left(2 \bar{h}_{\mathrm{I}} x+2 \bar{h}_{\mathrm{S}} L_{\mathrm{S}}+\bar{h}_{\mathrm{R}} C_{\mathrm{R}}\right) \\
& =\frac{1}{2} \rho_{\mathrm{I}} g\left(h_{0}^{2} / h_{\mathrm{I}}\right)\left(\rho_{\mathrm{I}} / \rho_{\mathrm{W}}\right)+\frac{1}{2} \rho_{\mathrm{I}} g h_{\mathrm{I}}(1-\phi)^{2}+\rho_{\mathrm{I}} g h_{\mathrm{I}}(1-\phi) \phi \\
& =\frac{1}{2} \rho_{\mathrm{I}} g h_{0}\left(\rho_{\mathrm{I}} / \rho_{\mathrm{W}}\right)\left(h_{0} / h_{\mathrm{I}}\right)+\frac{1}{2} \rho_{\mathrm{I}} g h_{\mathrm{I}}\left(1-2 \phi+\phi^{2}+2 \phi-2 \phi^{2}\right) \\
& =\frac{1}{2} \rho_{\mathrm{I}} g h_{0}\left(\rho_{\mathrm{I}} / \rho_{\mathrm{W}}\right)\left(h_{0} / h_{\mathrm{I}}\right)+\frac{1}{2} \rho_{\mathrm{I}} g h_{\mathrm{I}}\left(1-\phi^{2}\right) .
\end{aligned}
$$

Equations (11) and (12) give another expression for $\sigma_{\mathrm{C}}$ :

$\sigma_{\mathrm{C}}=\bar{P}_{\mathrm{I}}-\sigma_{\mathrm{T}}=\bar{P}_{\mathrm{I}}-\bar{P}_{\mathrm{I}}\left(1-\rho_{\mathrm{I}} / \rho_{\mathrm{W}}\right) \phi^{2}$.

Combining Eqs. (C2) and (C3) for $\bar{P}_{\mathrm{I}}=\frac{1}{2} \rho_{\mathrm{I}} g h_{\mathrm{I}}$ leads to the following:

$\phi=h_{0} / h_{\mathrm{I}}$.

Compare Eq. (C4) with Eq. (9) to see that $h_{0}$ is at $x=0$ and $h_{\mathrm{F}}$ is at any $x$. Equation (9) is therefore the more rigorous definition of $\phi$. 


\section{Appendix D: Deriving $\left(\Delta h_{\mathrm{I}} / \Delta x\right)_{\mathrm{G}}$ in Eq. (26)}

From Fig. 7, the mass balance equation of mean surface accumulation rate $a$ and ice thinning rate $r$ over distance $L-x$ from the ice divide gives ice flux $h_{\mathrm{I}} u_{x}$ at $x$ :

$h_{\mathrm{I}} u_{x}=(a-r)(L-x)$.

Assume the bed is thawed in grounded areas $A_{\mathrm{G}}=A_{O}-A_{\mathrm{F}}$ so grounded ice slides over the bed at velocity $u_{\mathrm{S}}$. Using a conventional sliding law for ice (Weertman, 1957a), where $B$ includes bed roughness and physical properties of temperate ice at the bed, $m=2$ for sliding ice, and $u=u_{x}=u_{\mathrm{S}}$ :

$u=u_{\mathrm{S}}=\left(\tau_{O} / B\right)^{m}$.

Equate ice elevation $h$ with ice thickness $h_{\text {I }}$ for a horizontal bed at sea level. Combine Eqs. (D1) and (D2), with $\tau_{O}=$ $\rho_{\mathrm{I}} g h_{\mathrm{I}} \mathrm{d} h_{\mathrm{I}} / \mathrm{d} x$ now depending only on the strength of ice-bed coupling linked to grounded thawed fraction $f=1$ under ice streams:

$(a-r)(L-x)=h_{\mathrm{I}} u=h_{\mathrm{I}}\left(\tau_{O} / B\right)^{m}=h_{\mathrm{I}}\left[\left(\rho_{\mathrm{I}} g h_{\mathrm{I}} / B\right) \mathrm{d} h_{\mathrm{I}} / \mathrm{d} x\right]^{m}$.

Here the assumption is made that the shallow ice approximation holds for grounded ice in an ice stream. Floating ice would have a lesser ice thickness, but the combination of grounded and floating parts results in the radar-measured ice thickness we use in Eq. (D3).

Now let $h_{\mathrm{I}}$ vary with bed topography, using measured values of $h_{\mathrm{I}}$ in Eq. (D3). Solve for surface slope $\alpha=\mathrm{d} h / \mathrm{d} x$ :

$\alpha=\frac{\mathrm{d} h}{\mathrm{~d} x}=\frac{B}{\rho_{\mathrm{I}} g h_{\mathrm{I}}}\left[\frac{(a-r)(L-x)}{h_{\mathrm{I}}}\right]^{\frac{1}{m}}$.

Taking $\tau_{O}=\rho_{\mathrm{I}} g h_{\mathrm{I}} \alpha$ and setting $\alpha=(\Delta h / \Delta x)_{\mathrm{G}}$ for ice grounded in incremental length $\Delta x$, Eq. (D4) gives the following:

$$
\left(\frac{\Delta h_{\mathrm{I}}}{\Delta x}\right)_{\mathrm{G}}=\frac{\tau_{O}}{\rho_{\mathrm{I}} g h_{\mathrm{I}}}=\frac{\left(B / \rho_{\mathrm{I}} g\right)[(a-r)(L-x)]^{\frac{1}{m}}}{h_{\mathrm{I}}^{\frac{m+1}{m}}} .
$$

Appendix E: Deriving $\left(\Delta h_{\mathrm{I}} / \Delta x\right)_{\mathrm{F}}$ in Eq. (28)

From Fig. 7, the mass balance is written as follows:

$h_{\mathrm{I}} u_{x}=h_{0} u_{O}+(a-r) x$.

Note that velocities $u_{x}$ and $u_{O}$ are negative with $x$ positive upslope. Differentiating at point $x$,

$$
\begin{gathered}
\partial\left(h_{\mathrm{I}} u_{x}\right) / \partial x=\partial\left[h_{0} u_{O}+(a-r) x\right] / \partial x=(a-r) \\
=u_{x} \partial h_{\mathrm{I}} / \partial x+h_{\mathrm{I}} \partial u_{x} / \partial x=u_{x} \partial h_{\mathrm{I}} / \partial x+h_{\mathrm{I}} \dot{\varepsilon}_{x x},
\end{gathered}
$$

where $\dot{\varepsilon}_{x x}=\partial u_{x} / \partial x$ is the longitudinal strain rate along $x$. Solve for incremental slope $(\Delta h / \Delta x)_{\mathrm{F}}$ by setting $u_{x}=u$ and $\dot{\varepsilon}_{x x}=\dot{\varepsilon}$ with $u_{x}$ obtained from Eq. (E2):

$$
\left(\frac{\Delta h}{\Delta x}\right)_{\mathrm{F}}=\frac{(a-r)-h_{\mathrm{I}} \dot{\varepsilon}}{u_{x}}=\frac{h_{\mathrm{I}}(a-r)-h_{\mathrm{I}}^{2} \dot{\varepsilon}}{h_{0}+u_{O}(a-r) x} .
$$

Using the flow law of ice (Glen, 1958), where $A$ is an icehardness parameter dependant on temperature and $n=3$ for ice, $\dot{\varepsilon}_{x x}=\Delta u / \Delta x$ is the extending strain rate for stress $\sigma_{\mathrm{T}}$ given by Eq. (12) with $\phi=1$ for floating ice, and $R$ is a dimensionless scalar that takes account of other strain rates in addition to $\dot{\varepsilon}_{x x}$ :

$\dot{\varepsilon}=\dot{\varepsilon}_{x x}=\frac{\Delta u}{\Delta x}=R\left(\frac{\sigma_{x x}^{\prime}}{A}\right)^{n}=R\left(\frac{\sigma_{\mathrm{T}}}{2 A}\right)^{n}$,

where deviator stress $\sigma_{x x}^{\prime}=1 / 2 \sigma_{\mathrm{T}}$ for ice streams (Hughes, 2012, chapter 10). From Hughes (2012, Appendix A, see Eq. (33) when $i j=x x$ ): 
$R=\left[1+\left(\frac{\dot{\varepsilon}_{y y}}{\dot{\varepsilon}_{x x}}\right)+\left(\frac{\dot{\varepsilon}_{y y}}{\dot{\varepsilon}_{x x}}\right)^{2}+\left(\frac{\dot{\varepsilon}_{x y}}{\dot{\varepsilon}_{x x}}\right)^{2}+\left(\frac{\dot{\varepsilon}_{x z}}{\dot{\varepsilon}_{x x}}\right)^{2}\right]^{\frac{n-1}{2}}$

Here $\dot{\varepsilon}_{x x}, \dot{\varepsilon}_{y y}, \dot{\varepsilon}_{x y}$, and $\dot{\varepsilon}_{x z}$ are strain rates associated with longitudinal extension, lateral compression, side drag, and basal drag, respectively. Lateral compression occurs when slow sheet flow converges on fast stream flow, but ice streams have relatively constant widths. There is no lateral shear down the centerline of ice streams, and there is little basal shear if the bed is wet and $\phi$ is high. So $\dot{\varepsilon}_{x x}$ is the dominant strain rate and $R \approx 1$ for $n=3$ is a useful approximation. However, $\dot{\varepsilon}_{x y}$ cannot be ignored for narrow ice streams (Dupont and Alley, 2005, 2006). For the central flowline of a narrow ice stream, the contribution from $\dot{\varepsilon}_{x y}$ can be added to $\dot{\varepsilon}_{x z}$, which is zero for floating ice.

Using Eq. (12) for $\sigma_{\mathrm{T}}=\left(\rho_{\mathrm{I}} g h_{\mathrm{I}} / 2\right)\left(1-\rho_{\mathrm{I}} / \rho_{\mathrm{W}}\right) \phi^{2}$, Eq. (E3) becomes

$\left(\frac{\Delta h_{\mathrm{I}}}{\Delta x}\right)_{\mathrm{F}}=\frac{h_{\mathrm{I}}(a-r)-h_{\mathrm{I}}^{2}\left[\left(\rho_{\mathrm{I}} g h_{\mathrm{I}} / 4 A\right)\left(1-\rho_{\mathrm{I}} / \rho_{\mathrm{W}}\right) \phi^{2}\right]^{n}}{h_{0} u_{O}+(a-r) x}$. 
Acknowledgements. Funding for this work was provided by the Center for Remote Sensing of Ice Sheets (CReSIS) at the University of Kansas, under contracts with the US National Science Foundation (NSF) and the U.S. National Aeronautical and Space Administration (NASA). Robert Thomas of NASA provided valuable input to our work. Martin Truffer and Jeremy Bassis provided thorough reviews. We also thank the editor, Frank Pattyn, and three anonymous referees for many more important criticisms and recommendations. This work was supported by National Science Foundation Grant Number NSF ANT-0424589.

Edited by: F. Pattyn

\section{References}

Anandakrishnan, A. and Alley, R. B.: Tidal forcing of basal seismicity of ice stream C, West Antarctica, observed far inland, J. Geophys. Res., 102, 15183-15196, 1997.

Benn, D., Gulley, J., Luckman, A., Adamek, A., and Glowacki, P.: Englacial drainage system formed by hydrologically driven crevasse propagation, J. Glaciol., 55, 513-523, 2009.

Bindschadler, R. A.: Jakobshavns Glacier drainage basin: a balance assessment, J. Geophys. Res., 89, 2066-2072, 1984.

Blatter, H.: Velocity and stress fields in grounded glaciers: a simple algorithm for including deviatoric stress gradients, J. Glaciol., 41, 333-344, 1995.

Blatter, H., Greve, R., and Abe-Ouchi, A.: Present State and Prospects of Ice Sheet and Glacier Modelling, Surv. Geophys., Springer, New York, 2011.

Bougamont, M., Price, S., Christoffersen, P., and Payne, A. J.: Dynamic patterns of ice stream flow in a 3-D higher-order ice sheet model with plastic bed and simplified hydrology, J. Geophys. Res., 116, F04018, doi:10.1029/2011JF002025, 2011.

Brecher, H. H.: Photogrammetric determination of surface velocities and elevations on Byrd Glacier, Antarct. J. US, 17, 79-81, 1982.

Budd, W. F., Jensen, D., and Radok, U.: Derived Physical Characteristics of the Antarctic Ice Sheet, Meteorology Department Australian National Antarctic Research Expeditions (ANARE) Interim Reports, Series A (IV), Glaciology 120, University of Melbourne, Melbourne, 1971.

Bueler, E. and Brown, J.: Shallow shelf approximation as a "sliding law" in a thermomechanically coupled ice sheet model, J. Geophys. Res., 114, F03008, doi:10.1029/2008JF001179, 2009.

Carbonnell, M. and Bauer, A.: Exploitation des couvertures photographiques aériennes répétées du front des glaciers vêlant dans Diske Bugt en Umanak Fjord, Juin-Juillet, 1964, Meddelelser om Groenland, 173, 1-78, 1968.

Carlson, A. E., Jenson, J. W., and Clark, P. U.: Modeling the subglacial hydrology of the James Lobe of the Laurentide Ice Sheet, Quaternary Sci. Rev., 26, 1384-1397, 2007.

Clark, P. U.: Surface form of the southern Laurentide Ice Sheet and its implications to ice-sheet dynamics, Geol. Soc. Am. Bull., 104, 595-605, 1992.

Cook, A. C., Vel, S. S., Gerbi, C., and Johnson, S. E.: Computational analysis of nonlinear creep of polyphase aggregates: influence of phase morphology, J. Geophys. Res., 119, 29 pp., doi:10.1002/2014JB011197, 2014.
Denton, G. H. and Hughes, T. J. (Eds.): The Last Great Ice Sheets, Wiley-Interscience, New York, 1981.

Denton, G. H., Hughes, T. J., and Karlen, W.: Global ice-sheet system interlocked by sea level, Quat. Res., 26, 3-26, 1986.

Drewry, D. J. (Ed.): Antarctica: Glaciological and Geophysical Folio, Scott Polar Research Institute, University of Cambridge, Cambridge, 1983.

Dupont, T. and Alley, R. B.: Assessment of the importance of ice-shelf buttressing to ice-sheet flow, Geophys. Res. Lett., 32, L04503, doi:10.1029/2004GL022024, 2005.

Dupont, T. and Alley, R. B.: Role of small ice shelves in sea-level rise, Geophys. Res. Lett., 33, L09503, doi:10.1029/2005GL025665, 2006.

Echelmeyer, K., Clarke, T. S., and Harrison, W. D.: Surficial glaciology of Jakobshavns Isbræ, West Greenland: Part I. Surface morphology, J. Glaciol., 37, 368-382, 1991.

Echelmeyer, K., Harrison, W. D., Clarke, T. S., and Benson, C.: Surficial glaciology of Jakobshavns Isbræ, West Greenland: Part II. Ablation, accumulation and temperature, J. Glaciol., 38, 169-181, 1992.

Engelhardt, H. and Kamb, B.: Ice stream flow history and surge potential, Ann. Glaciol., 54, 287-298, 2013.

Fastook, J. L. and Hughes, T. J.: New perspectives on paleoglaciology, Quaternary Sci. Rev., 80, 169-194, 2013.

Fastook, J. L. and Prentice, M.: A finite-element model of Antarctica; sensitivity test for meteorological mass-balance relationship, J. Glaciol., 40, 167-175, 1994.

Fastook, J. L., Brecher, H. H., and Hughes, T. J.: Derived bedrock elevations, strain rates, and stresses from measured surface elevations and velocities: Jakobshavn Glacier, Greenland, J. Glaciol., 41, 161-173, 1995.

Fricker, H. A. and Scambos, T.: Connected subglacial lake activity on lower Mercer and Whillans Ice Streams, 2003-2008, J. Glaciol., 55, 303-315, 2009.

Funk, M., Echelmeyer, K., and Iken, A.: Mechanisms of fast flow in Jakobshavns Isbrae, West Greenland: Part II - Modeling of englacial temperatures, J. Glaciol., 40, 569-585, 1994.

Gagliardini, O., Durand, G., Zwinger, T., Hindmarsh, R. C. A., and Le Meur, E.: Coupling of ice-sheet melting and buttressing is a key process in ice-sheet dynamics, Geophys. Res. Lett., 37, L14501 doi:10.1029/2010GL043334, 2010.

Gerbi, C., Johnson, S. E., Cook, A., and Senthil, S. V.: Effect of phase morphology on bulk strength for power-law materials, Geophys. J. Int., 200, 374-389, 2015.

Glen, J. W.: The Flow Law of Ice, Int. Assoc. Scient. Hydrol., 47, 171-183, 1858.

Gogineni, S., Yan, J.-B., Paden, J., Leuschen, C., Li, J., RodriguesMorales, F., Braaten, D., Purdon, K., Wang, Z., Liu, W., and Gauch, J.: Bed topography of Jakobshavn Isbrae, Greenland, and Byrd Glacier, Antarctica, J. Glaciol., 60, 813-833, doi:10.3189/2014JoG14J129, 2014.

Gow, A. J., Meese, D. A., Alley, R. B., Fitzpatrick, J. J., Anandakrishnan, S., Woods, G. A., and Elder, B. C.: Physical and structural properties of the Greenland Ice Sheet Project 2 ice cores: a review, J. Geophys. Res., 102, 26559-26575, 1997.

Greve, R.: A continuum-mechanical formulation for shallow polythermal ice sheets, Philos. T. Roy. Soc. A, 355, 921-974, doi:10.1098/rsta.1997.0050, 1997. 
Hofstede, C. and Hughes, T.: Can ice sheets self-destruct and cause rapid climate change? A case study: Jakobshavn Isbrae, Greenland, in: Horizons in Earth Sciences, Vol. 11, chapter 4, edited by: Veress, B. and Szigethy, J., Nova Science Publishers, Inc., Hauppauge, NY, 2014.

Holland, D. R., Thomas, R., Young, B. de, Ribergaard, M., and Lyberth, B.: Acceleration of Jakobshavn Isbrae triggered by warm subsurface ocean waters, Nat. Geosci., 1, 659-664, doi:10.1038/ngeo316, 2008.

Hooke, R. LeB., Holmlund, P., and Iverson, N. R.: Extrusion flow demonstrated by bore-hole deformation measurements over a riegel, Shorglaciaren, Sweden, J. Glaciol., 33), 72-78, 1987.

Hughes, T.: Ice Streamline Cooperative Antarctic Project, ISCAP Bulletin No. 1: Scientific Justification, Institute of Polar Studies, The Ohio State University, Columbus, Ohio, 1972.

Hughes, T.: Is the West Antarctic Ice Sheet disintegrating?, J. Geophys. Res., 78, 7884-7910, 1973.

Hughes, T.: A differential ablation-longitudinal compression mechanism for generating wave trains on cold alpine glaciers, in: IASH - AISH Publication Number 104, Snow and Ice Symposium - Neiges et Glaces, Proceedings of the Moscow Symposium, August 1971, Actes du Colloque de Moscou, aout 1971 Moscou, 1975.

Hughes, T.: West Antarctic ice streams, Rev. Geophys. Space Ge., 15, 1-46, doi:10.1029/RG015i001p00001, 1977.

Hughes, T.: Numerical Reconstruction of Paleo-Ice Sheets, in: The Last Great Ice Sheets, edited by: Denton, G. H. and Hughes, T. J., Wiley-Interscience, New York, 221-261, 1981.

Hughes, T.: On the disintegration of ice shelves: the role of thinning, Ann. Glaciol., 3, 146-151, 1982.

Hughes, T.: On the disintegration of ice shelves: the role of fracture, J. Glaciol., 29, 98-117, 1983.

Hughes, T.: The Jakobshavns effect, Geophys. Res. Lett., 13, 46-48, 1986.

Hughes, T.: Deluge II and the continent of doom: rising sea level and collapsing Antarctic ice, Boreas, 16, 89-100, 1987.

Hughes, T.: On the pulling power of ice streams, J. Glaciol., 38, 125-151, 1992.

Hughes, T.: Ice Sheets, Oxford University Press, New York, 1998.

Hughes, T.: The geometrical force balance in glaciology, J. Geophys. Res., 108, 2526, doi:10.1029/2003JB002557, 2003.

Hughes, T., Greenland Ice Sheet and rising sea level in a worst-case climate change scenario, Polar Meteorol. Climatol., 18, 54-71, 2007.

Hughes, T.: Variations of ice-bed coupling, beneath and beyond ice streams: the force balance, J. Geophys. Res., 114, B01410, doi:10.1029/2008JB005714, 2009a.

Hughes, T.: Correction to "Variations of ice-bed coupling beneath and beyond ice streams: the force balance", J. Geophys. Res., 114, B04499, doi:10.1029/2009JB006426, 2009b.

Hughes, T.: A simple holistic hypothesis for the self-destruction of ice sheets, Quaternary Sci. Rev., 30, 1829-1845, 2011.

Hughes, T.: Holistic Ice Sheet Modeling: a First-Order Approach, Nova Science Publishers, Inc., Hauppauge, New York, 2012.

Hughes, T. J. and Fastook, J. L.: Byrd Glacier: 1978-1979 field results, Antarct. J. US, 16, 86-89, 1981.

Hughes, T., Sargent, A., and Fastook, J.: Ice-bed coupling beneath and beyond ice streams: Byrd Glacier, Antarctica, J. Geophys. Res., 116, 1-17, 2011.
Hulbe, C. L. and Fahnestock, M. A.: West Antarctic ice stream discharge variability: mechanism, controls, and pattern of grounding line retreat, J. Glaciol., 50, 471-484, 2004.

Iken, A.: The effect of subglacial water pressure on the sliding velocity of a glacier in an idealized numerical model, J. Glaciol., 27, 407-422, 1981.

Iken, A. and Bindschadler, R. A.: Combined measurements of subglacial water pressure and surface velocity of Findelengletscher, Switzerland: conclusions about drainage system and sliding mechanism, J. Glaciol., 32, 101-119, 1986.

Iken, A., Echelmeyer, K., Harrison, W., and Funk, M.: Mechanics of fast flow in Jakobshavns Isbrae, West Greenland: Part I. Measurements of temperature and water level in deep boreholes, J. Glaciol., 39, 15-25, 1993.

Jenson, J. W., Clark, P. U., MacAyeal, D. R., Ho, C. L., and Vela, J. C.: Numerical modeling of advective transport of saturated deforming sediment beneath the Lake Michigan Lobe, Laurentide Ice Sheet, Geomorphology, 14, 157-166, 1995.

Jenson, J. W., MacAyeal, D. R., Clark, P. U., Ho, C. L., and Vela, J. C.: Numerical modeling of subglacial sediment deformation: implications for the behavior of the Lake Michigan Lobe, Laurentide Ice Sheet, J. Geophys. Res., 101, 8717-8728, 1996.

Joughin, I., Smith, B. E., Shean, D. E., and Floricioiu, D.: Brief Communication: Further summer speedup of Jakobshavn Isbræ, The Cryosphere, 8, 209-214, doi:10.5194/tc-8-209-2014, 2014.

Joughin, I. R., Howat, I. M., Fahnestock, M. A., Smith, B., Krabill, W. B., Alley, R. B., Stern, H., and Truffer, M.: Continued evolution of Jakobshavn Isbrae following its rapid speedup, J. Geophys. Res., 113, F04006, doi:10.1029/2008JF001023, 2008.

Kamb, B.: Basal zone of the West Antarctic ice streams and its role in lubrication of their rapid motion, in: The West Antarctic Ice Sheet: Behavior and Environment, edited by: Alley, R. B. and Bindschadler, R. A., Antarctic Research Series, American Geophysical Union, Washington, D.C., 157-200, 2001.

Kenneally, J. P. and Hughes, T.: Calving giant icebergs: old principles, new applications, Antarct. Sci., 18, 409-419, 2006.

Larour, E., Setousi, H., Morlighem, M., and Rignot, E.: Continental scale, high order, high spatial resolution, ice sheet modeling using the Ice Sheet System Model (ISSM), J. Geophys. Res., 117, F01022, doi:10.1029/2011JF002140, 2012.

Lliboutry, L.: General theory of subglacial cavitation and sliding of temperate glaciers, J. Glaciol., 7, 21-58, 1968.

Lüthi, M., Funk, M., Iken, A., Gogineni, S. P., and Truffer, M.: Mechanism of fast flow in Jakobshavns Isbrae, West Greenland. Part III. Measurements of ice deformationm, temperpature and cross-borehole conductivity in boreholes to the bedrock, J. Glaciol., 48, 369-385, 2002.

MacAyeal, D. R.: Large-scale ice flow over a viscous basal sediment: Theory and application to Ice Stream B, Antarctica, J. Geophys. Res., 94, 4071-4087, 1989.

Nye, J. F.: The mechanics of glacier flow, J. Glaciol., 2, 82-93, 1952.

Paterson, W. S. B.: The Physics of Glaciers, 3rd Edn., ButterworthHeineman, Oxford, 481 pp., 1994.

Pattyn, F.: A new three-dimensional higher-order thermomechanical ice sheet model: basic sensitivity, ice stream development, and ice flow across subglacial lakes, J. Geophys. Res., 108, 2382, doi:10.1029/2002JB002329, 2003. 
Pelto, M. S., Hughes, T. J., and Brecher, H. H.: Equilibrium state of Jakobshavns Isbrae, West Greenland, Ann. Glaciol., 12, 127131, 1989.

Pfeffer, W. T. and Bretherton, C. S.: The effect of crevasses on the solar heating of a glacier surface, in: IASH Publiction No. 170, The Physical Basis of Ice Sheet Modeling, Proceeedings of the Vancouver Symposium, August 1987, Vancouver, 191-205, 1987.

Pfeffer, W. T., Harper, J. T., and O'Neel, S.: Kinematic constraints on glacier contributions to 21 st Century sea-level rise, Science, 321, 1340-1343, 2008.

Pingree, K., Lurie, M., and Hughes, T.: Is the East Antarctic Ice Sheet stable?, Quaternary Res., 75, 417-429, 2011.

Pollard, D. and DeConto, R. M.: Description of a hybrid ice sheetshelf model, and application to Antarctica, Geosci. Model Dev., 5, 1273-1295, doi:10.5194/gmd-5-1273-2012, 2012.

Prescott, P. R., Kenneally, J. P., and Hughes, T. J.: Relating crevassing to nonlinear strain in the floating part of Jakobshavns Isbrae, West Greenland, Ann. Glaciol., 36, 149-156, 2003.

Pritchard, H. D., Arthern, D. G., Vaughan, D. G., and Edwards, L. A.: Extensie dynamic thinning on the margins of the Greenland and Antarctic ice sheets, Nature, 461, 803-806, doi:10.1038/Nature08471, 2009.

Rathbun, A. P., Marone, C., Alley, R. B., and Anandakrishnan, S.: Laboratory study of the frictional rheology of sheared till, J. Geophys. Res., 113, F02020, doi:10.1029/2007JF000815, 2008.

Reeh, N.: A plasticity approach to the steady-state shape of a threedimensional ice sheet, J. Glaciol., 7, 215-232, 1982.

Reeh, N.: Reconstruction of the glacial ice covers of Greenland and the Canadian Arctic islands by three-dimensional, perfectly plastic ice-sheet modeling, Ann. Glaciol., 5, 115-121, 1984.

Reusch, D. and Hughes, T. J.: Surfaxe "waves" on Byrd Glacier, Antarct. Sci., 15, 547-555, doi:10.1017/S0954102003001664, 2003.

Rignot, E. and Kanagaratnam, P.: Changes in the velocity structure of the Greenland Ice Sheet, Science, 311, 986-990, 2006.

Rignot, E., Casassa, G., Gogineni, P., Krabill, W., Rivera, A., and Thomas, R.: Accelerated ice discharge from the Antarctic Peninsula following the collapse of Larsen B ice shelf, Geophys. Res. Lett., 31, L18401, doi:10.1029/2004GL020697, 2004.

Rignot, E., Mouginet, J., and Scheuchl, B.: NASA research yields field map of Antarctic ice flow, NASA News, available at: www. jpl.nasa.gov/news/news.php?release $=2011-256$ (last access: August 2015), 2011a.

Rignot, E., Mouginot, J., and Scheuchl, B.: Ice flow of the Antarctic Ice Sheet, Science, 333, 1427-1430, 2011b.

Rowden-Rich, R. J. M. and Wilson, C. J. L.: Models for strain localization in Law Dome, East Antarctica, Ann. Glaciol., 23, 396401, 1996.

Saito, F. and Abe-Ouchi, A.: Sensitivity of Greenland ice sheet simulation to the numerical procedure employed for ice-sheet dynamics, Ann. Glaciol., 42, 331-336, doi:10.3189/172756405781813069, 2005.

Sanderson, T. J. O.: Equilibrium profile of ice shelves, J. Glaciol., 22, 435-460, 1979.

Sane, S. M., Desai, C. S., Jenson, J. W., Contractor, D. N., Carlson, A. E., and Clark, P. U.: Disturbed state constitutive modeling of two Pleistocene tills, Quaternary Sci. Rev., 27, 267-283, 2008.
Sargent, A.: Modeling Ice Streams, $\mathrm{PhD}$ thesis, University of Maine, Orono, 106 pp., 2009.

Sargent, A. and Fastook, J. L.: Manufactured analytical solutions for isothermal full-Stokes ice sheet models, The Cryosphere, 4, 285-311, doi:10.5194/tc-4-285-2010, 2010.

Scambos, T. A., Bohlander, J. A., Shuman, A., and Skvarca. P.: Glacier acceleration and thinning after ice shelf collapse in the Larsen B embayment, Antarctica, Geophys. Res. Lett., 31, L184021, doi:10.1029/2004GL020670, 2004.

Schoof, C.: Marine ice-sheet dynamics. Part 1. The case of rapid sliding, J. Fluid Mech., 573, 27-55, 2007.

Schoof, C.: Ice-sheet acceleration driven by melt supply variability, Nature, 468, 803-806, 2010.

Schoof, C. and Hindmarsh, R. C. A.: Thin-film flows with wall slip: an asymptotic analsis of higher order glacier flow models, Q. J. Mech. Appl. Math., 63, 73-114, doi:10.1093/qjmam/hbp025, 2010.

Schulson, E. M. and Duval, P.: Creep and Fracture of Ice, Cambridge University Press, Cambridge, UK, 401 pp., 2009.

Scofield, J. P., Fastook, J. L., and Hughes, T. J.: Evidence for a frozen bed, Byrd Glacier, Antarctica, J. Geophys. Res., 96, 11649-11655, doi:10.1029/91JB00839, 1991.

Seddik, H., Greve, R., Zwinger, T., Gillet-Chaulet, F., and Gagliardini, O.: Simulations of the Greenland Ice Sheet 100 years into the future with the full Stokes model Elmer/Ice, J. Glaciol., 58, 427-440, doi:10.3189/2012JoG11J177, 2012.

Siegert, M. J.: Comments on "Calculating basal thermal zones beneath the Antarctic Ice Sheet" by Wilch and Hughes, J. Glaciol., 46, 159-160, 2001.

Smith, B. E., Fricker, H. A., Joughin, I. R., and Tulaczyk, S.: An inventory of active subglacial lakes in Antarctica detected by ICESat (2003-2008), J. Glaciol., 55, 573-595, 2009.

Stearns, L. A., Smith, B. E., and Hamilton, G. S.: Increased flow speed on a large East Antarctic outlet glacier due to subglacial floods, Nat. Geosci., 1, 827-831, 2008.

Swithinbank, C. W.: Ice movement of valley glaciers flowing into the Ross Ice Shelf, Antarctica, Science, 141, 523-524, 1963.

Thomas, R. H.: The creep of ice shelves: theory, J. Glaciol., 12, 45-53, 1973a.

Thomas, R. H.: The creep of ice shelves: interpretation of observed behaviour, J. Glaciol., 12, 55-70, 1973b.

Thomas, R. H.: Force-perturbation analysis of recent thinning and acceleration of Jakobshavns Isbrae, Greenland, J. Glaciol., 50, 57-66, 2004.

Thomas, R. H. and MacAyeal, D. R.: Derived characteristics of the Ross Ice Shelf, J. Glaciol., 28, 397-412, 1982.

Thomas, R. H., Rignot, E. J., Kanagaratnam, P., Krabill, W. B., and Casassa, G.: Force-perturbation analysis of Pine Island Glacier, Antarctica, suggests cause for recent acceleration, Ann. Glaciol., 39, 133-138, 2004.

Van der Veen, C. J.: A note on the equilibrium profile of a free floating ice shelf, The Netherlands, Institut voor Meteorologie en Oceanografie, Rijksuniversiteit-Utrecht, Utrecht, 1-15, 1983.

Van der Veen, C. J.: Fracture mechanics approach to penetration of surface crevasses on glaciers, Cold Reg. Sci. Technol., 27, 31-47, 1998a.

Van der Veen, C. J.: Fracture mechanics approach to penetration of bottom crevasses on glaciers, Cold Reg. Sci. Technol., 27 213$223,1998 b$. 
Van der Veen, C. J.: Fundamentals of Glacier Dynamics, A. A. Balkema, Rotterdam, 462 pp., 1999.

Van der Veen, C. J., Stearns, L. A., Johnson, J., and Csatho, B.: Flow dynamics of Byrd Glacier, East Antarctica, J. Glaciol., 60, doi:10.3189/2014JoG14J052, 2014.

Weertman, J.: On the sliding of glaciers, J. Glaciol., 3, 33-38, $1957 \mathrm{a}$.

Weertman, J.: Deformation of floating ice shelves, J. Glaciol., 3, 38-42, 1957b.

Weertman, J.: Stability of the junction of an ice sheet and an ice shelf, J. Glaciol., 13, 3-11, 1974.

Weideck, A. and Bennike, O.: Quaternary Glaciation History and Glaciology of Jakobshavn Isbrae and the Disko Bugt Region, West Greenland: a Review, Ministry of Climate and Energy, Copenhagen, Denmark, 2007.
Whillans, I. M., Chen, Y. H., Van der Veen, C. J., and Hughes, T.: Force Budget III: application to three-dimensional flow of Byrd Glacier, Antarctica, J. Glaciol., 35, 68-80, 1989.

Wilch, E. and Hughes, T.: Mapping basal thermal zones beneath the Antarctic ice sheet, J. Glaciol., 46, 297-310, 2000.

Zhao, Z.: Measurement, analysis, and modeling deformation of the shelf-flow, Byrd Glacier, PhD thesis, University of Maine, Orono, 108 pp., 1990.

Zwally, H. J., Abdalati, W., Herring, T., Larson, K., Savba, J., and Steffen, K.: Surface melt-induced acceleration of Greenland IceSheet flow, Science, 297, 218-222, 2002. 